Danilo Hernane Spatti

\title{
Sistema Inteligente Para Controle de Relés Reguladores de Tensão
}

Dissertação apresentada à Escola de Engenharia de São Carlos da Universidade de São Paulo, sendo parte dos requisitos para obtenção do título de Mestre em Engenharia Elétrica.

Orientador: Prof. Dr. Ivan Nunes da Silva

São Carlos 

"Porque dele e por meio dele, e para ele, são todas as coisas. Glória, pois a ele eternamente. Amém."

Romanos 11, 36 



\section{Agradecimentos}

Gostaria de agradecer a todos os meus tutores e professores que me permitiram chegar até aqui, em especial ao Prof. Ivan Nunes da Silva pelo total apoio e ensinamentos nessa nova etapa de minha carreira.

À minha família pelo especial apoio que sempre me concederam.

À minha namorada Maria Fernanda pelo companheirismo e compreensão.

Aos colegas de outros laboratórios, em especial ao Eng. ${ }^{\circ}$ MSc Wesley Fernando Usida por todo o suporte que tem me fornecido.

Ao Prof. MSc. Alessandro Goedtel pelo apoio e conselhos acadêmicos que sempre está prontamente disposto a dar.

À CAPES - Coordenação de Aperfeiçoamento de Pessoal de Nível Superior, pelo auxílio financeiro concedido no período de realização deste trabalho, sem o qual o mesmo não seria possível. 



\section{Resumo}

SPATTI, D. H. (2007). Sistema Inteligente Para Controle de Relés Reguladores de Tensão. Dissertação (Mestrado) - Escola de Engenharia de São Carlos, Universidade de São Paulo, 2007.

Este trabalho apresenta uma estratégia para realizar o controle de tensão em um sistema de distribuição de energia elétrica dotado de comutadores de tap sob carga. Será investigada a aplicação de Sistemas Inteligentes para tornar os relés reguladores de tensão mais flexíveis. A inserção de módulos inteligentes em relés reguladores de tensão convencionais irá permitir um melhor aproveitamento das funcionalidades já existentes destes dispositivos. Ainda como foco do estudo, pretende-se atuar apenas na subestação de distribuição, realizando medições no barramento secundário e tomando medidas de controle também neste barramento. A capacidade dos sistemas fuzzy em tratar informações incertas, bem como sua potencial aplicabilidade em problemas tendo comportamentos não previsíveis, permitiram a criação de uma estratégia de controle de tensão que atende todas as regulamentações dos órgãos fiscalizadores e, também, os anseios das concessionárias de distribuição de energia elétrica devido aos resultados promissores obtidos em simulação com dados reais das subestações.

Palavras chave: Sistemas de distribuição, comutador de tap, sistemas fuzzy, relé regulador de tensão. 



\section{Abstract}

SPATTI, D. H. (2007). Intelligent System to Control Voltage Regulator Relays. Dissertation (Masters Degree) - Escola de Engenharia de São Carlos, Universidade de São Paulo, 2007.

This work presents an approach to voltage control in power distribution systems with load tap changers. Intelligent approaches are studied and applied in voltage regulator relay in order to improve the voltage profiles of the system. The proposal of this work is the addition of fuzzy modules in the conventional voltage regulator relays, which allows the exploration of the main functionalities already implemented in such devices. The adaptive fuzzy voltage regulator relay controls the voltage in the distribution substation, monitoring electrical variables and performing the regulation on secondary bus based on the results provided by the fuzzy modules, which are capable to take into account the voltage profile standards for distribution systems as well as operational interests defined by electrical distribution companies. Simulation results using real data from substations are presented to validate the proposed approach.

Keywords: Distribution Systems, tap changers, fuzzy systems, voltage regulator relay. 



\section{Lista de Siglas e Abreviaturas}

$\begin{array}{ll}\text { ANEEL } & \text { Agência Nacional de Energia Elétrica } \\ \text { LTC } & \text { Load tap Changer } \\ \text { ULTC } & \text { Under Load tap Changer } \\ \text { AVR } & \text { Automatic Voltage Regulator } \\ \text { SEP } & \text { Sistema Elétrico de Potência } \\ \text { LDC } & \text { Line-Drop Compensation } \\ \text { TP } & \text { Transformador de Potencial } \\ \text { TC } & \text { Transformador de Corrente }\end{array}$





\section{Lista de Figuras}

FIGURA 1.1 - Níveis de tensão de distribuição superiores a $1 \mathrm{kV}$ e inferiores a $69 \mathrm{kV}$.

FIGURA 1.2 - Representação dos tempos de transgressão para tensões de distribuição superiores a $1 \mathrm{kV}$ e inferiores a $69 \mathrm{kV}$............................. 5

FIGURA 1.3 - Subestação de distribuição do estudo. ........................................... 6

FIGURA 1.4 - Relé regulador de tensão com módulo inteligente............................ 8

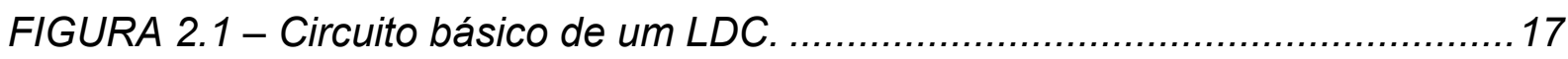

FIGURA 2.2 - Perfis de tensão com e sem atuação do LDC................................ 19

FIGURA 2.3 - Centro de carga para uma condição de carga pesada. .....................21

FIGURA 2.4 - Centro de carga para uma condição de carga leve. ..........................22

FIGURA 2.5 - Capacitores instalados ao longo do alimentador e na barra

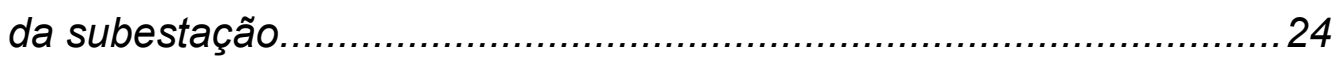

FIGURA 2.6 - Alimentador de distribuição com e sem regulador de tensão. ........... 25

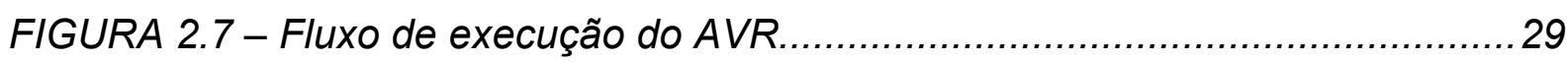

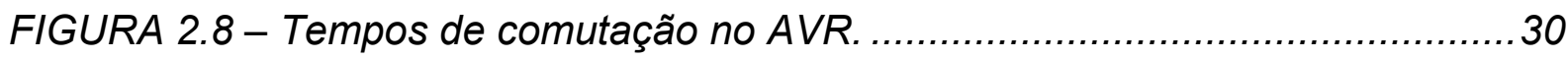

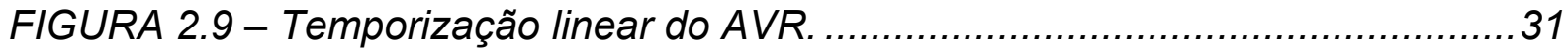

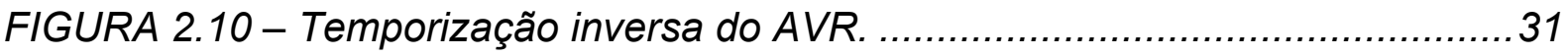

FIGURA 4.1 - Classes de conjuntos na lógica clássica......................................... 43

FIGURA 4.2 - Função de pertinência da lógica fuzzy..............................................4

FIGURA 4.3 - Conjuntos de funções de pertinência da lógica fuzzy. ....................... 45

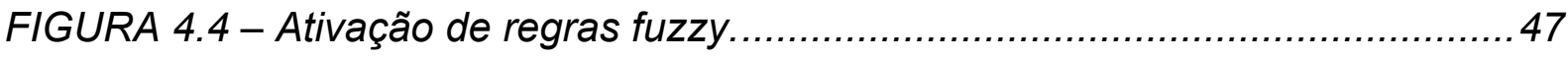

FIGURA 4.5 - Entrada do sistema fuzzy de exemplo. .......................................... 48

FIGURA 4.6 - Saída do sistema fuzzy de exemplo. ………………………........ 48

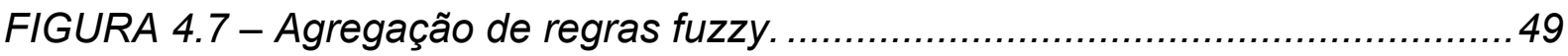

FIGURA 4.8 - Método de defuzzificação através do centro de área.........................50

FIGURA 4.9 - Módulo inteligente agregado ao relé regulador de tensão..................51

FIGURA 4.10 - Topologia do sistema fuzzy desenvolvido....................................54

FIGURA 4.11 - Entrada 1 do sistema fuzzy desenvolvido.....................................55

FIGURA 4.12 - Entrada 2 do sistema fuzzy desenvolvido.....................................56

FIGURA 4.13 - Saída do sistema fuzzy desenvolvido. .......................................57 
FIGURA 4.14 - Superfície de relacionamento entre entradas e saída do

sistema fuzzy desenvolvido.

FIGURA 4.15 - Bloco de software que verifica se a tensão está acima da faixa

para o AVR convencional.

FIGURA 4.16 - Bloco de software que verifica se a tensão está acima da faixa

para o AVR com módulo fuzzy.

FIGURA 5.1 - Histórico de comutações de tap para Votuporanga 1

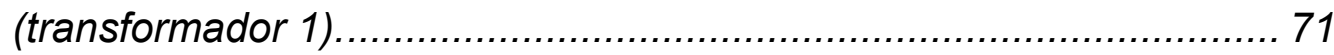

FIGURA 5.2 - Perfis de tensão para Votuporanga 1 (transformador 1). ................. 72

FIGURA 5.3 - Referência fuzzy para Votuporanga 1 (transformador 1). ............... 73

FIGURA 5.4 - Perfil de tensão em carga pesada para Votuporanga 1

(transformador 1)......................................................... 74

FIGURA 5.5 - Tempo de permanência nas faixas para Votuporanga 1

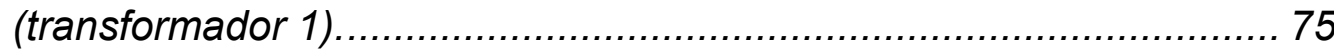

FIGURA 5.6 - Tensão média em carga pesada para Votuporanga 1

(transformador 1).......................................................... 76

FIGURA 5.7 - Histórico de comutações de tap para Votuporanga 1

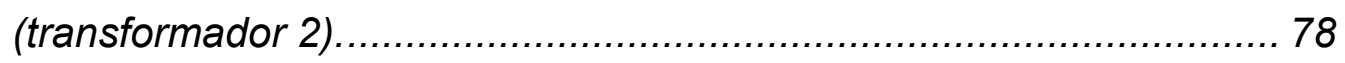

FIGURA 5.8 - Perfis de tensão para Votuporanga 1 (transformador 2). ................. 79

FIGURA 5.9 - Referência fuzzy para Votuporanga 1 (transformador 2). ................ 80

FIGURA 5.10 - Perfil de tensão em carga pesada para Votuporanga 1

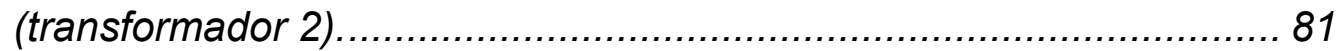

FIGURA 5.11 - Tempo de permanência nas faixas para Votuporanga 1

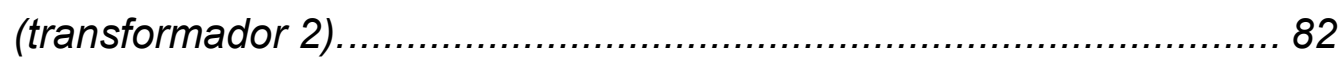

FIGURA 5.12 - Tensão média em carga pesada para Votuporanga 1

(transformador 2)........................................................... 83

FIGURA 5.13 - Histórico de comutações de tap para Ubatuba 2

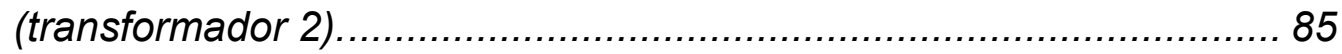

FIGURA 5.14 - Perfis de tensão para Ubatuba 2 (transformador 2). ...................... 86

FIGURA 5.15 - Referência fuzzy para Ubatuba 2 (transformador 2). ..................... 87

FIGURA 5.16 - Perfil de tensão em carga pesada para Ubatuba 2

(transformador 2)...................................................... 88

FIGURA 5.17 - Tempo de permanência nas faixas para Ubatuba 2

(transformador 2)......................................................... 89 
FIGURA 5.18 - Tensão média em carga pesada para Ubatuba 2

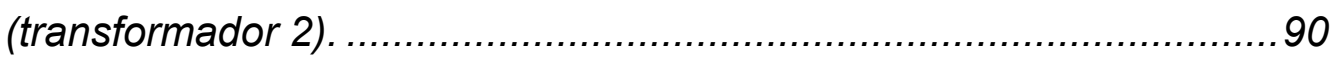





\section{Lista de Tabelas}

TABELA 2.1 - Aproximações recomendadas para modelagem de cargas. 16

TABELA 4.1 - Regras do sistema fuzzy desenvolvido. .59

TABELA 4.2 - Resumo das principais características do sistema fuzzy desenvolvido. 60

TABELA 5.1 - Informações do transformador de cada subestação simulada. 69

TABELA 5.2 - Resumo dos resultados computacionais obtidos para Votuporanga 1 (transformador 1)... 76

TABELA 5.3 - Resumo dos resultados computacionais obtidos para Votuporanga 1 (transformador 2).... .83

TABELA 5.4 - Resumo dos resultados computacionais obtidos para Ubatuba 2 (transformador 2)...... 90 



\section{SUMÁRIO}

Resumo .iii
Abstract. $\mathbf{V}$
Lista de Siglas e Abreviaturas .................................................................... vii
Lista de Figuras .............................................................................................
Lista de Tabelas .............................................................................................

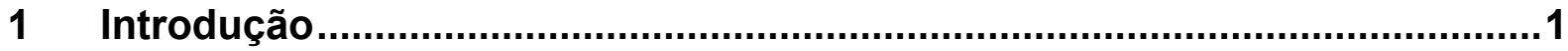

1.1 Estrutura atual do setor elétrico brasileiro .............................................2

1.2 Aspectos relativos à conformidade dos níveis de tensão em regime permanente 3

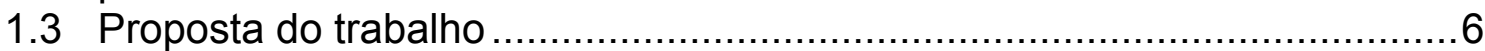

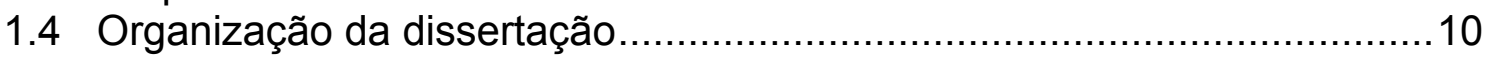

2 Aspectos relacionados ao melhoramento do perfil de tensão em sistemas de distribuição de energia elétrica ..............................................11

2.1 Queda de tensão ao longo do alimentador de distribuição .....................11

2.2 Principais estratégias utilizadas na regulação de tensão ........................14

2.2.1 Modelagem por fluxo de carga ................................................. 14

2.2.2 Compensação por queda de linha (LDC) ................................. 16

2.2.3 Compensação por queda de linha utilizando o centro de carga.....18

2.3 Dispositivos utilizados em sistemas de distribuição para controle da tensão .................................................................................... 23

2.3.1 Bancos de capacitores ...................................................... 23

2.3.2 Reguladores de tensão de linha ............................................... 24

2.3.3 Transformadores com comutador de tap................................26

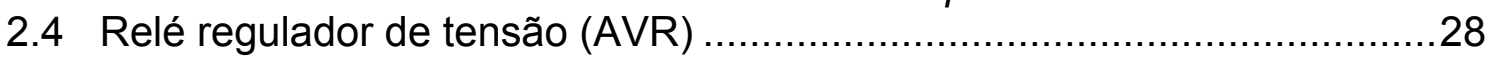

3 Estado da arte referente à aplicação de sistemas inteligentes no

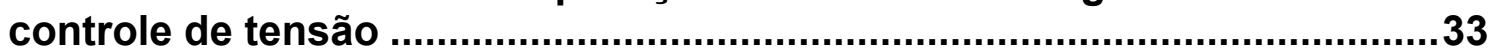

4 Modelagem das funções inteligentes para relés reguladores de tensão ...41

4.1 Aspectos principais relacionados aos sistemas fuzzy ..........................42

4.1.1 Funções de pertinência ........................................................ 43

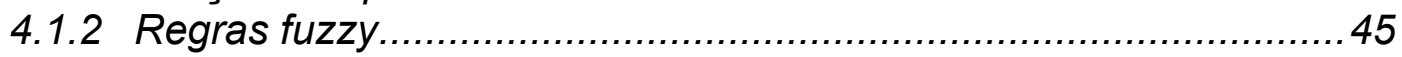

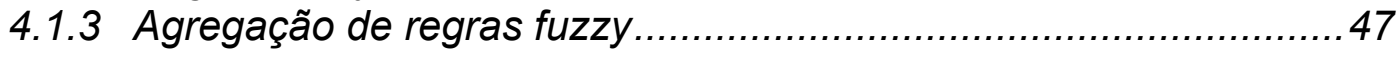

4.1.4 Defuzzificação ................................................................. 50

4.2 Funcionalidades inteligentes agregadas ao relé regulador de tensão ......51

4.3 Características do módulo fuzzy desenvolvido .....................................52

4.4 Relé regulador de tensão com módulo fuzzy ...................................60 


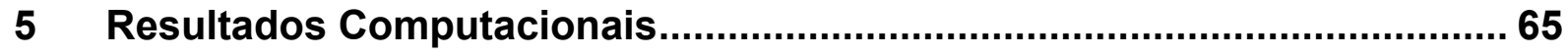

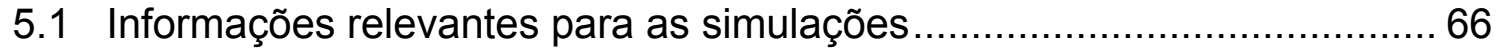

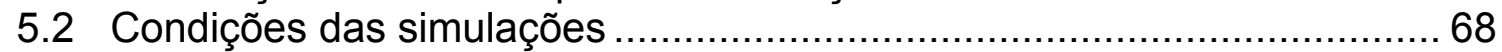

5.3 Resultados computacionais das simulações ........................................ 70

5.3.1 Subestação Votuporanga 1 (transformador 1) ............................ 70

5.3.2 Subestação Votuporanga 1 (transformador 2) ............................ 77

5.3.3 Subestação Ubatuba 2 (transformador 2) .................................. 84

5.4 Análise dos requisitos computacionais do sistema fuzzy desenvolvido.... 91

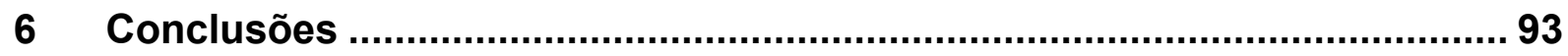

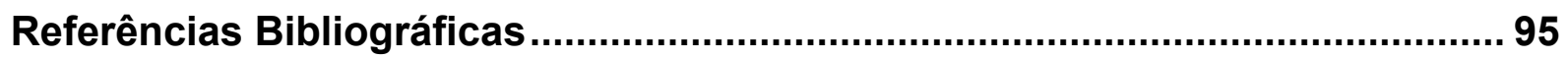




\section{Introdução}

A energia elétrica é um produto indispensável para a manutenção das atividades da sociedade. A constante busca por uma melhor qualidade no fornecimento dos níveis de tensão apenas reforça este fato.

Desde a reestruturação do setor elétrico, que instituiu a Agência Nacional de Energia Elétrica (ANEEL), tendo como uma de suas atribuições a fiscalização dos serviços prestados pelas concessionárias de distribuição de energia elétrica, houvese o estabelecimento de novas regulamentações para a conformidade dos níveis de tensão entregues pelas concessionárias aos consumidores.

Dentre estas regulamentações pode-se citar a Resolução No 505/2001 [1] que estabelece os níveis de tensões considerados operativos e não operativos, bem como o tempo que as concessionárias de distribuição podem fornecer tensões em níveis não operativos. Para atender a referida regulamentação, o controle de tensão tem sido identificado como uma operação fundamental para a qualidade no fornecimento da energia elétrica.

Tal controle de tensão é essencial, pois tanto os equipamentos das concessionárias de distribuição como os pertencentes aos consumidores são projetados para operar em níveis regulados de tensão. A operação prolongada desses equipamentos em uma tensão fora de limites aceitáveis pode afetar o desempenho, além de aumentar as despesas com interrupções programadas realizadas em intervalos menores de tempo. 


\subsection{Estrutura atual do setor elétrico brasileiro}

O novo modelo do setor elétrico brasileiro começou a ser desenhado com a aprovação da Lei № 8987/1995 [2] de concessão de serviços públicos, que permitiu a entrada da iniciativa privada em diversos setores antes controlados apenas pelo governo. Com a aprovação da Lei № 9074/1995 [3] e a criação da ANEEL em 1996 com a Lei No 9427/1996 [4], iniciou-se então uma divisão do setor elétrico em 4 grandes áreas: Geração, Transmissão, Distribuição e Comercialização da energia elétrica.

Esta divisão permitiu a entrada de capital privado para aumentar a oferta de energia elétrica, melhorar a qualidade do fornecimento e promover competitividade entre as concessionárias de energia elétrica.

Dentre estas concessionárias, as de distribuição são as responsáveis pela entrega e comercialização de energia elétrica ao consumidor final, seja ele industrial, comercial, residencial ou rural.

A entrada do capital privado tornou o setor elétrico brasileiro mais competitivo e moderno. As concessionárias passaram a ser comercializadoras de energia elétrica e, como tal, tiveram de se adequar às regulamentações impostas pela ANEEL para que fosse mantida uma qualidade de produto e serviço aos consumidores.

Como exploradoras do sistema elétrico, as concessionárias estão sujeitas às resoluções e recomendações da ANEEL no que diz respeito às conformidades dos níveis de tensão em regime permanente [1]. 


\subsection{Aspectos relativos à conformidade dos níveis de tensão em regime permanente}

As disposições relativas à conformidade dos níveis de tensão em regime permanente no Brasil são regulamentadas pela Resolução No 505 [1] da ANEEL. Essa resolução considera que para o fornecimento adequado é indispensável o estabelecimento de níveis de tensão, bem como o tempo de transgressão para a tensão entregue pela concessionária de distribuição fora dos níveis de operação nominal do sistema.

Para tensões de distribuição maiores que $1 \mathrm{kV}$ e menores que $69 \mathrm{kV}$, foco deste estudo, a Resolução No 505 define vários níveis de tensão, sendo que os mesmos encontram-se ilustrados na FIGURA 1.1 [1].

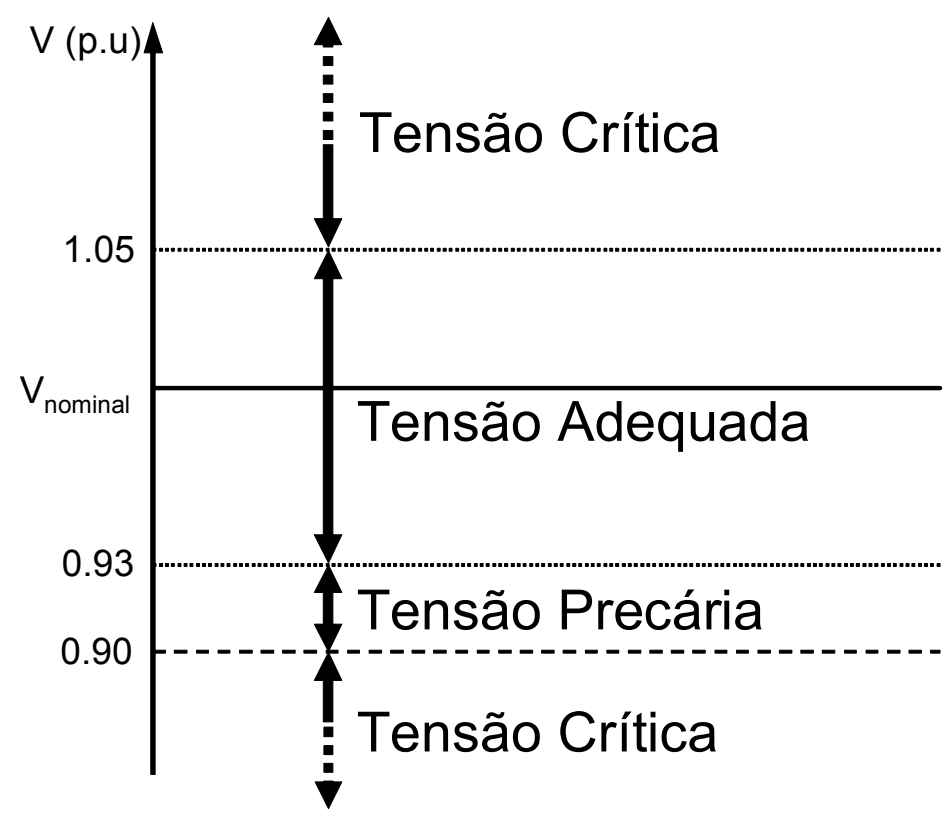

FIGURA 1.1 - Níveis de tensão de distribuição superiores a $1 \mathrm{kV}$ e inferiores a $69 \mathrm{kV}$. 
Da FIGURA 1.1 observa-se que tensões compreendidas entre 0.93 e 1.05 p.u. em relação a uma tensão $V_{\text {nominal }}$ de 1 p.u. encontram-se dentro da faixa de tensão denominada Tensão Adequada, ou seja, faixa operativa dos Sistemas de Distribuição. É importante ressaltar que esta faixa é assimétrica em relação a 1 p.u., sendo o mínimo 0.93 p.u. e o máximo 1.05 p.u.

Valores de tensão acima de 1.05 p.u. enquadram-se na faixa de Tensão Crítica. A entrega de energia nesta faixa pode danificar os equipamentos dos consumidores e também da concessionária. Se o tempo de fornecimento for superior a 1 minuto, pode-se então caracterizar uma sobretensão nos consumidores [5].

Níveis críticos de tensões também são encontrados para valores inferiores a 0.9 p.u. em relação à tensão nominal. $O$ fornecimento de tensão nesta faixa para tempos superiores a 1 minuto submetem os consumidores a situações de subtensões [5].

A faixa de Tensão Precária se encontra entre 0.9 e 0.93 p.u. É importante observar que não há uma faixa de Tensão Precária, acima da Tensão Adequada, para níveis de tensão entre $1 \mathrm{kV}$ e $69 \mathrm{kV}$ [1].

Desta forma, pode-se enquadrar em níveis operativos, valores de tensão compreendidos pela Tensão Adequada. As faixas de Tensão Precária e Crítica são enquadradas em níveis não operativos.

A análise da conformidade dos níveis de tensão deve ser realizada juntamente com o tempo de transgressão máximo permitido para faixas não operativas. Na FIGURA 1.2 se tem uma ilustração de transgressões da tensão entregue pela concessionária de distribuição em função do tempo. 


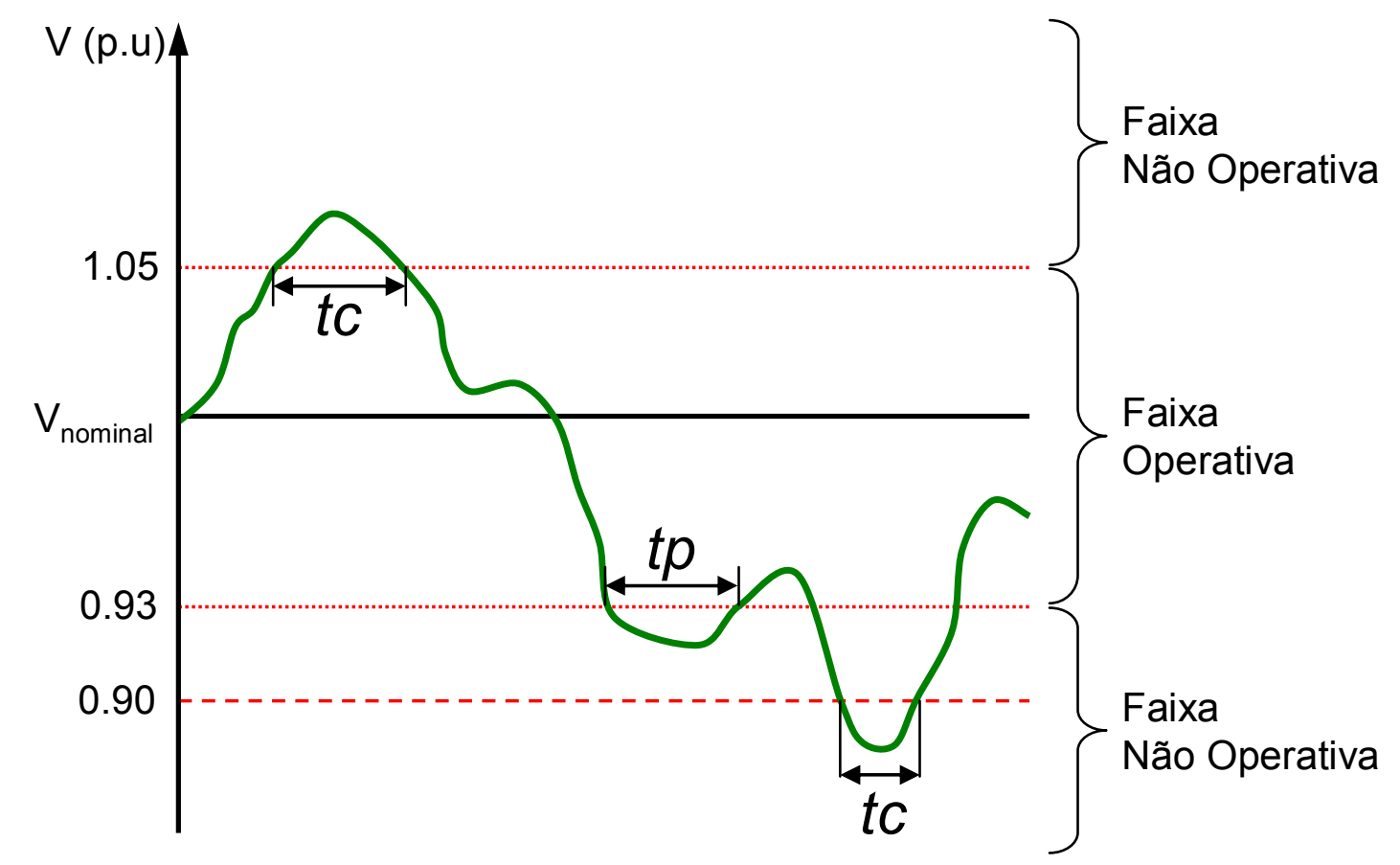

FIGURA 1.2 - Representação dos tempos de transgressão para tensões de distribuição superiores a $1 \mathrm{kV}$ e inferiores a $69 \mathrm{kV}$.

O tempo total de medição para avaliação dos tempos de transgressão é de 7 dias, sendo que as medidas são realizadas a cada 10 minutos. O tempo de transgressão de Tensão Precária não pode ultrapassar 3\% do tempo de medição. Isto significa que o somatório de todos os tempos em tensão precária, tp, ao longo de 7 dias de medição, deve ser menor que 3\%. Este índice foi inicializado em 7\% em 2003 e vem sendo decrementado de $1 \%$ ao ano desde 2004 e se estenderá até 2007, quando será estabilizado em $3 \%$.

Esta é uma medida que visa incrementar a qualidade da energia elétrica entregue aos consumidores. O mesmo acontece para o tempo de transgressão de Tensão Crítica, tanto para níveis superiores a 1.05 p.u quanto para inferiores a 0.9 p.u. Semelhantemente, o somatório de todos os tempos em tensão crítica, tc, deve ser menor que $0.5 \%$. Tal índice foi estabelecido em $1.1 \%$ em 2004 e no período de 2005 à 2007 será decrementado de $0.2 \%$ ao ano, estabilizando-se em 0.5\% [1]. 


\subsection{Proposta do trabalho}

Levando-se em consideração todos os aspectos envolvidos com a conformidade dos níveis de tensões, bem como os tempos de transgressão, este trabalho tem como objetivo propor uma estratégia de controle de tensão que contemple os seguintes aspectos:

- Atuar apenas no transformador da subestação de distribuição, de maneira automática;

- Utilizar de forma mais flexível as comutações de tap, tanto em carga pesada quanto em carga leve;

- Melhorar o perfil de tensão em carga pesada para os consumidores de média tensão.

Para mostrar de forma mais detalhada a proposta do trabalho, encontra-se ilustrado na FIGURA 1.3 uma subestação de distribuição semelhante à que se deseja implementar a estratégia de controle.

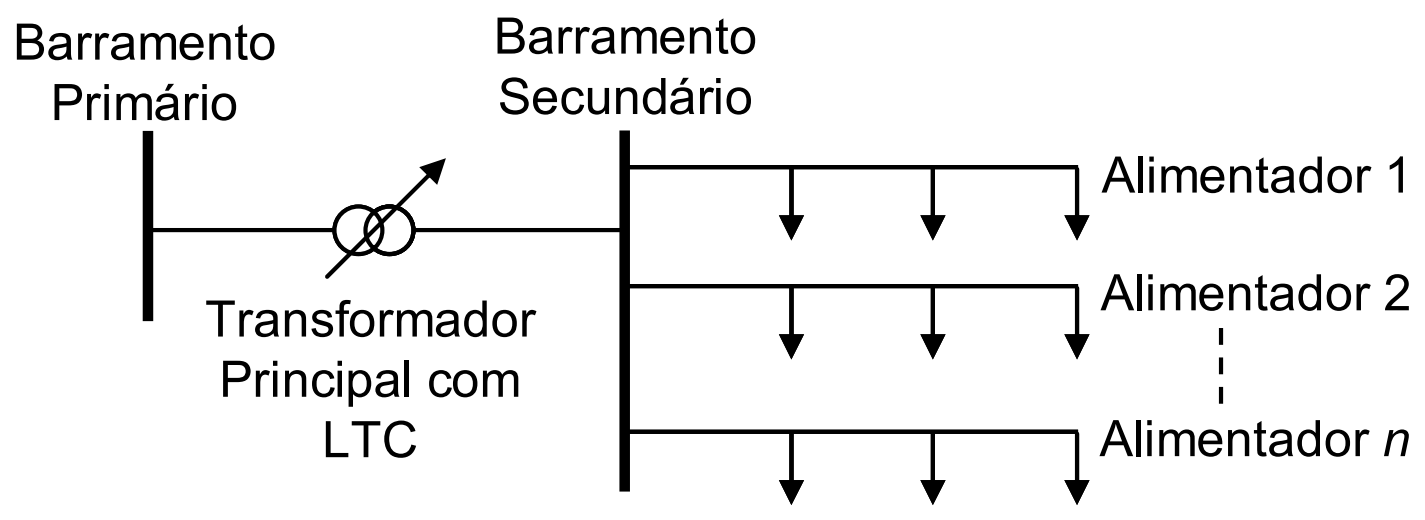

FIGURA 1.3 - Subestação de distribuição do estudo. 
A partir da FIGURA 1.3 se observa que o sistema de distribuição em estudo consiste de um Barramento Primário, um Barramento Secundário, múltiplos alimentadores e um Transformador Principal equipado com comutador de tap sob carga, também denominado Load Tap Changer (LTC). A tensão nominal para o Barramento Primário é fixa em $138 \mathrm{kV}$ e a tensão nominal para o Barramento Secundário é de $13.8 \mathrm{kV}$, sendo esta controlada pelo LTC.

Dispositivos como o LTC, também conhecido por Under Load tap Changer (ULTC), possuem relés responsáveis por realizar a mudança no nível de tensão do secundário do transformador, atuando os mesmos por meio da mudança de tap [6].

O relé regulador de tensão ou AVR (Automatic Voltage Regulator), é empregado para enviar os comandos de mudança de tap ao LTC, que é um dispositivo mecânico e que realizada mudanças na relação de transformação do transformador [7].

Tais relés operam com diversas estratégias de controle que em sua maioria devem ser parametrizadas manualmente pelo operador.

A proposta principal deste trabalho é então implementar funções inteligentes para relés reguladores de tensão de modo que o mesmo se adapte às condições de cada subestação, necessitando para tanto o mínimo possível de parametrizações por parte dos operadores. As funcionalidades inteligentes irão auxiliar o relé na tomada de decisão de comutação do tap do transformador. Na FIGURA 1.4 se encontra ilustrado um diagrama funcional de um relé regulador de tensão com funções inteligentes. 


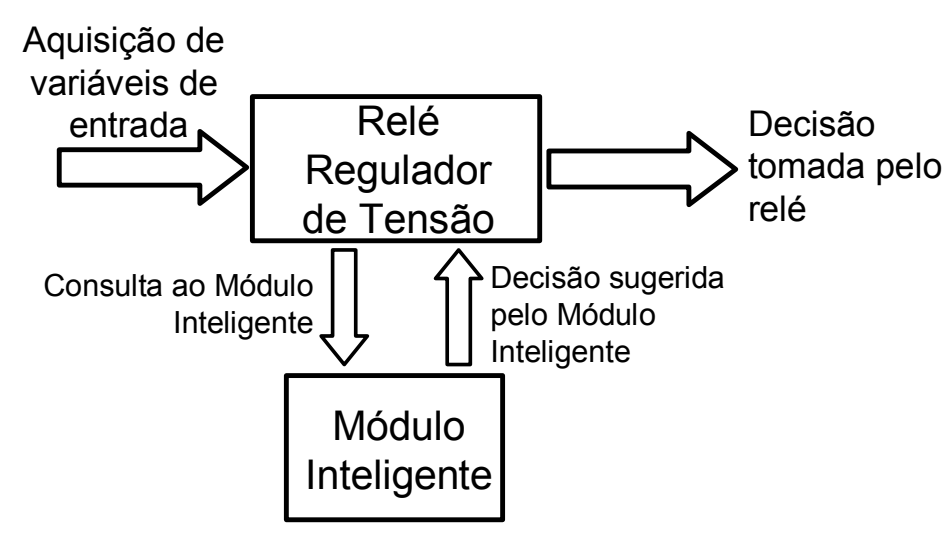

FIGURA 1.4 - Relé regulador de tensão com módulo inteligente.

O relé regulador de tensão proposto nesse trabalho será instalado em uma subestação e irá possuir um Módulo Inteligente para auxílio à tomada de decisão, podendo ou não ser ativado pelo operador. As variáveis de entrada como Tensão, Corrente, Potências, etc, serão adquiridas pelo relé regulador e enviadas ao Módulo Inteligente, que por sua vez irá processar as informações e retornar com uma medida de controle que deverá proporcionar ao relé os subsídios para uma tomada de decisão correta.

Faz parte ainda da estratégia atuar apenas na subestação de distribuição, considerando-se para tanto até o ponto do alimentador onde se encontra instalado o regulador de tensão. Os reguladores de tensão conectados ao longo do alimentador são utilizados para compensar as flutuações de tensão que ocorrem a partir do ponto de sua instalação.

Assim, a leitura de informações, ou mesmo o controle desses dispositivos reguladores de tensão, ao longo do alimentador, serão desconsiderados na abordagem proposta.

Realizando leituras de informações apenas vistas pelo Barramento Secundário da subestação, se pode realizar uma estratégia de controle mais localizada, permitindo contemplar os três objetivos destacados no início desta seção. 
Desta forma visando tais objetivos, as ferramentas pertencentes aos Sistemas Inteligentes são potenciais candidatas para a implementação desta proposta de relé regulador de tensão.

Desde a década de 80, inúmeras são as abordagens envolvendo Sistemas Inteligentes aplicados aos Sistemas Elétricos de Potência (SEP), o que propiciou novas oportunidades no campo da informática aplicada à resolução de problemas dessa área [8].

Mais especificamente, para o propósito deste trabalho, considerou-se os seguintes aspectos na escolha de ferramentas inteligentes para estratégias de regulação de tensão:

- Característica não previsível do comportamento da carga em uma subestação de distribuição, tornando extremamente complexa as modelagens de controle;

- A eficiência elevada dos Sistemas Inteligentes frente ao tratamento de problemas não lineares, bem como seu caráter inovador em aplicações em SEP [8];

- Excelente comportamento dos Sistemas Inteligentes em controles automáticos;

- Empenho de outros pesquisadores com a mesma temática através de trabalhos publicados em literatura da área.

Assim, as propostas de controle realizadas por outros pesquisadores da área serão também estudadas nos capítulos seguintes visando a contextualização da área temática a qual se insere o presente trabalho. 


\subsection{Organização da dissertação}

Uma breve introdução envolvendo os aspectos de regulamentações para os níveis operativos de tensão e, também, a proposta de trabalho encontram-se registrados neste capítulo.

No Capítulo 2 serão apresentados os aspectos principais envolvidos com o controle de tensão em sistemas de distribuição, relatando as diversas técnicas e dispositivos utilizados.

No Capítulo 3 será apresentado o estudo bibliográfico relacionado ao controle de tensão em sistemas de distribuição equipados com comutadores de tap e relés reguladores de tensão, dando um enfoque especial aos trabalhos envolvendo Sistemas Inteligentes.

No Capítulo 4 se encontram as principais características do Sistema Inteligente proposto neste trabalho, destacando-se os fundamentos teóricos, as variáveis de entrada / saída e também o relacionamento do módulo inteligente com o relé regulador de tensão.

No Capítulo 5 serão apresentados e discutidos os resultados computacionais obtidos com o módulo inteligente no controle do perfil de tensão em subestações de distribuição reais.

No Capítulo 6 serão feitas as considerações finais a respeito deste trabalho, denotando quais os ganhos desta pesquisa para os sistemas de distribuição estudados. 


\section{Aspectos relacionados ao melhoramento do} perfil de tensão em sistemas de distribuição

\section{de energia elétrica}

Uma das principais responsabilidades das distribuidoras de energia elétrica é fornecer aos consumidores tensões em faixas adequadas, pois muitas atividades exigem níveis regulados de tensões. Nos tópicos a seguir serão discutidos os principais problemas envolvidos com níveis de tensão, bem como as estratégias de regulação e compensação, as quais são fundamentadas nos limites operativos estabelecidos na seção anterior.

\subsection{Queda de tensão ao longo do alimentador de distribuição}

Os principais problemas relatados pelos consumidores são tensões abaixo do valor nominal, comprometendo a qualidade no fornecimento de energia elétrica.

As quedas de tensão podem ser caracterizadas em termos dos distúrbios que comprometem a qualidade da energia elétrica e também pela modelagem do sistema elétrico. Tais fenômenos associados à queda de tensão podem ser de curta duração, geralmente menor que um minuto; ou longa duração, superiores a 1 minuto $[5]$. 
Os distúrbios de curta duração tem uma amplitude típica que varia de 0.1 p.u. à 0.9 p.u e são denominados Afundamento de Tensão ou “Voltage Sag". Já os de longa duração são chamados de Subtensão ou "Voltage Drop" e caracterizam-se por uma amplitude típica entre 0.8 p.u e 0.9 p.u. [5].

Para solucionar problemas de queda de tensão ao longo do alimentador, primeiramente deve certificar-se de que o problema não se encontra no barramento primário do transformador. Se constatado que a queda de tensão no alimentador está sendo ocasionada por algum problema no secundário do transformador, então a verificação deve contemplar a ligação do neutro do secundário, carregamento do transformador, tempo de atuação dos capacitores e ajustes dos reguladores instalados ao longo do alimentador [9].

A queda de tensão ao longo do alimentador pode ser aproximada pela Expressão (2.1) [9], ou seja:

$$
V_{\text {queda }}=\left|V_{s}\right|-\left|V_{r}\right| \approx I_{R} \cdot R+I_{X} \cdot X
$$

onde:

- $\quad V_{\text {queda }} \rightarrow$ Queda de tensão ao longo do alimentador (V).

- $\left|V_{s}\right| \rightarrow$ Tensão no barramento secundário da subestação (V).

- $\left|V_{r}\right| \rightarrow$ Tensão regulada na carga (V).

- $\quad R \rightarrow$ Resistência da linha $(\Omega)$.

- $\quad X \rightarrow$ Reatância da linha $(\Omega)$.

- $\quad I_{R} \rightarrow$ Corrente devida ao fluxo de potência ativa, em fase com a tensão $(A)$.

- $\quad I_{X} \rightarrow$ Corrente devida ao fluxo de potência reativa, defasada em $90^{\circ}$ em relação à tensão $(A)$. 
Em termos de fator de potência, pode-se escrever as correntes como sendo [9]:

$$
\begin{gathered}
I_{R}=I \cdot f p=I \cdot \cos \theta \\
I_{X}=I \cdot \operatorname{sen} \theta=I \cdot \operatorname{sen}\left(\cos ^{-1}(f p)\right)
\end{gathered}
$$

onde:

- $\quad I \rightarrow$ Magnitude da corrente do alimentador (A).

- $\quad f p \rightarrow$ Fator de potência.

- $\theta \rightarrow$ Ângulo entre a tensão e a corrente no alimentador.

A aproximação realizada na Expressão (2.1) apresenta boa precisão para a maioria das situações de distribuição, proporcionando erros menores que 1\% [9].

Também a partir dessa aproximação se pode tirar duas conclusões: Para fatores de potência elevados, a queda de tensão depende fortemente da resistência do alimentador; ao passo que, para fatores de potência ativa de médio a baixo, a queda de tensão depende principalmente da reatância do alimentador [9].

Como conseqüência, um baixo fator de potência acaba por acentuar a queda de tensão ao longo do alimentador, que é maior em sistemas de distribuição de baixa tensão, circuitos fase-única e circuitos desbalanceados.

O planejamento de novos alimentadores em sistemas de distribuição permite diminuir a queda de tensão utilizando-se uma ou mais medidas tais como [9]:

- Redimensionar o condutor para suportar uma carga maior e oferecer menor resistência;

- Balancear os circuitos;

- Converter as seções de fase-única para trifásicas; 
- Reduzir a carga;

- Reduzir o comprimento do alimentador.

\subsection{Principais estratégias utilizadas na regulação de tensão}

Diversas estratégias podem ser empregadas para realizar a regulação de tensão em sistemas de distribuição. A partir da área de operação do sistema constata-se que a maioria delas se fundamenta na Compensação por Queda de Linha ou Line-Drop Compensation (LDC), que realiza um ajuste com base na impedância do alimentador. Já na área de planejamento existem estratégias fundamentadas na execução de Fluxo de Carga para distribuição, que são utilizadas para prever mudanças na topologia e carregamento da rede quando do projeto do sistema [9].

\subsubsection{Modelagem por fluxo de carga}

A realização do fluxo de carga permite avaliar o perfil de tensão quando se está projetando novos circuitos de distribuição.

Diversos programas computacionais para a realização de fluxo de carga em distribuição oferecem funcionalidades como traçar a tensão em função da distância da fonte, fornecendo um elevado nível de detalhamento.

A maioria dos circuitos de distribuição pode ser modelada com relativa precisão se for dividido entre 10 e 20 setores, tendo cargas aglomeradas em cada setor. A correta modelagem das cargas por fase permite um perfil melhorado de 
tensão, para cada fase. Isso porque se a corrente fluir de forma desigual por fase, cargas pesadas irão proporcionar maiores quedas de tensão, já que a impedância vista por elas é maior se comparada à impedância vista por uma carga balanceada [9].

As principais formas de se modelar uma carga em um sistema de distribuição são: Potência da Carga Constante, Corrente da Carga Constante e Impedância da Carga Constante.

Para uma modelagem com Potência da Carga Constante, as potências reativas e ativas se mantêm constantes mesmo que a tensão varie, o que obriga a carga a solicitar mais corrente do sistema caso a tensão diminua. Este tipo de modelagem privilegia sistemas com motores de indução e acentua a queda de tensão.

Já uma modelagem à Corrente da Carga Constante, a corrente se mantém constante, sendo que a variação da potência acompanha a da tensão. Se a tensão diminui, a potência também diminui para manter a corrente constante, o que não altera a queda de tensão.

Em uma modelagem à Impedância da Carga Constante, a potência aumenta com o quadrado da tensão, já que a impedância da carga não varia com a tensão. Esta abordagem é interessante para se modelar cargas puramente resistivas, uma vez que a corrente acompanha a variação da tensão de forma linear, diminuindo a queda de tensão.

Normalmente, um circuito de distribuição pode ser modelado como tendo de $40 \%$ à $60 \%$ de cargas com potência constante e de $40 \%$ à $60 \%$ de cargas com impedância constante. Modelar todas as cargas como sendo de corrente constante é uma boa aproximação para a maioria dos circuitos. Modelar todas as cargas como 
sendo de potência constante conserva a queda de tensão à medida que a tensão diminui e a corrente aumenta [9].

Trabalhar com tensões mais elevadas privilegia modelagens à potência constante, pois reduzem o carregamento dos condutores e conseqüentemente as perdas elétricas. Para modelagens à Impedância da Carga Constante níveis mais elevados de tensão resultam em aumento da receita para as concessionárias, uma vez que a potência comercializada varia com o quadrado da tensão.

Na TABELA 2.1 a seguir encontram-se diversas configurações de cargas para aproximações na realização de fluxo de carga.

TABELA 2.1 - Aproximações recomendadas para modelagem de cargas.

\begin{tabular}{|c|c|c|}
\hline $\begin{array}{c}\text { Tipo do } \\
\text { Alimentador }\end{array}$ & $\begin{array}{c}\text { Potência } \\
\text { Constante (\%) }\end{array}$ & $\begin{array}{c}\text { Impedância } \\
\text { Constante (\%) }\end{array}$ \\
\hline Residencial e comercial (Pico do verão) & 67 & 33 \\
\hline Residencial e comercial (Pico do inverno) & 40 & 60 \\
\hline Urbano & 50 & 50 \\
\hline Industrial & 100 & 0 \\
\hline Países em Desenvolvimento & 25 & 75 \\
\hline
\end{tabular}

Fonte: Willis, H. L., "Characteristics of Distribution Loads," Electrical Transmission and Distribution Reference Book. Raleigh, NC, ABB Power T\&D Company, 1997.

\subsubsection{Compensação por queda de linha (LDC)}

O objetivo principal do LDC é manter a tensão constante, não no barramento secundário do transformador, mas no consumidor [6]. Sem a utilização do LDC, ao final do alimentador haverá uma variação de tensão que dependerá da impedância do alimentador para uma condição de carga pesada, e da variação da corrente de carga para uma condição de carga leve [9]. 
O LDC utiliza um modelo interno de impedância do alimentador de distribuição para encontrar a impedância da linha, cujos ajustes relativos à resistência e a reatância são realizados pelo controlador.

Na FIGURA 2.1 [9] se pode visualizar o circuito básico de um LDC.

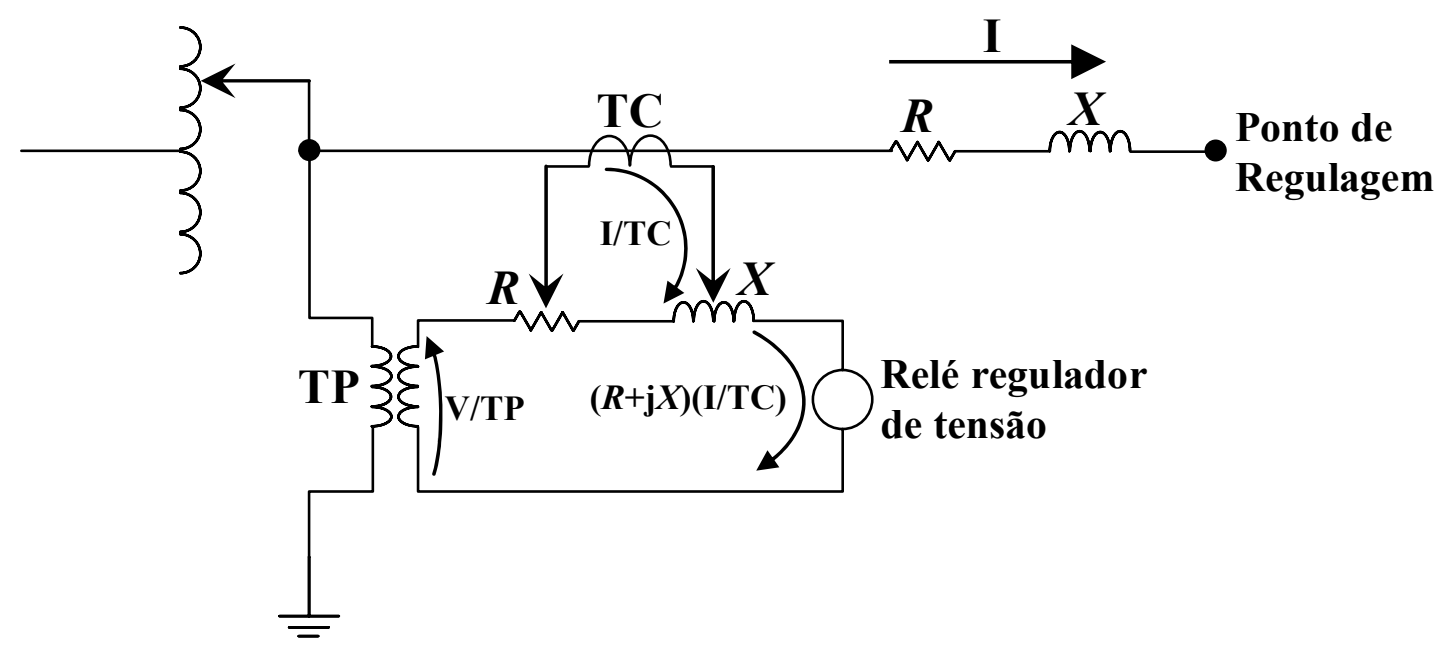

FIGURA 2.1 - Circuito básico de um LDC.

Em uma linha de distribuição típica, os compensadores $R$ e $X$ são escolhidos para que a máxima elevação de tensão seja obtida sob carga pesada, enquanto que a tensão mínima seja obtida para a carga leve. Estes parâmetros são ajustes de tensões que representam a resistência e a reatância da linha, submetida a uma corrente $I$.

O controlador ajusta o tap fundamentado na tensão do relé regulador de tensão, que é a tensão do TP (Transformador de Potencial) adicionado com a tensão do circuito compensador de queda de linha. Se não há compensação por queda de linha, o relé regulador ajusta o tap com base nas informações do TP.

Pode-se utilizar o centro de carga para se ajustar os parâmetros do regulador para cada Ponto de Regulagem de tensão dado. 
A entrada de bancos de capacitores próximos à subestação eleva o fator de potência, dificultando a aplicação deste método. No entanto, a compensação por queda de linha produz menores flutuações de tensão para os consumidores ao longo do alimentador.

\subsubsection{Compensação por queda de linha utilizando o centro de carga}

O caminho clássico para se ajustar o LDC é utilizar o método do Centro de Carga. Considera-se que a linha tenha impedâncias $R_{L}$ e $X_{L}$ e uma carga sem seu final. Os parâmetros $R_{\text {ajuste }}$ e $X_{\text {ajuste }}$ do regulador podem então ser encontrados por meio das seguintes expressões:

$$
\begin{aligned}
& R_{\text {ajuste }}=\frac{I_{T C}}{N_{T P}} \cdot R_{L} \\
& X_{\text {ajuste }}=\frac{I_{T C}}{N_{T P}} \cdot X_{L}
\end{aligned}
$$

Onde:

- $R_{\text {ajuste }} \rightarrow$ Ajuste do regulador para compensação resistiva (V).

- $\quad X_{\text {ajuste }} \rightarrow$ Ajuste do regulador para compensação reativa (V).

- $I_{T C} \rightarrow$ Valor do primário do transformador de corrente (A).

- $\quad N_{T P} \rightarrow$ Razão de transformação do transformador de potencial (tensão no primário / tensão no secundário).

- $\quad R_{L} \rightarrow$ Resistência da linha para o ponto de regulação $(\Omega)$.

- $\quad X_{L} \rightarrow$ Reatância da linha para o ponto de regulação $(\Omega)$. 
Na FIGURA 2.2 se pode visualizar o efeito das flutuações de tensão com e sem a atuação do LDC.

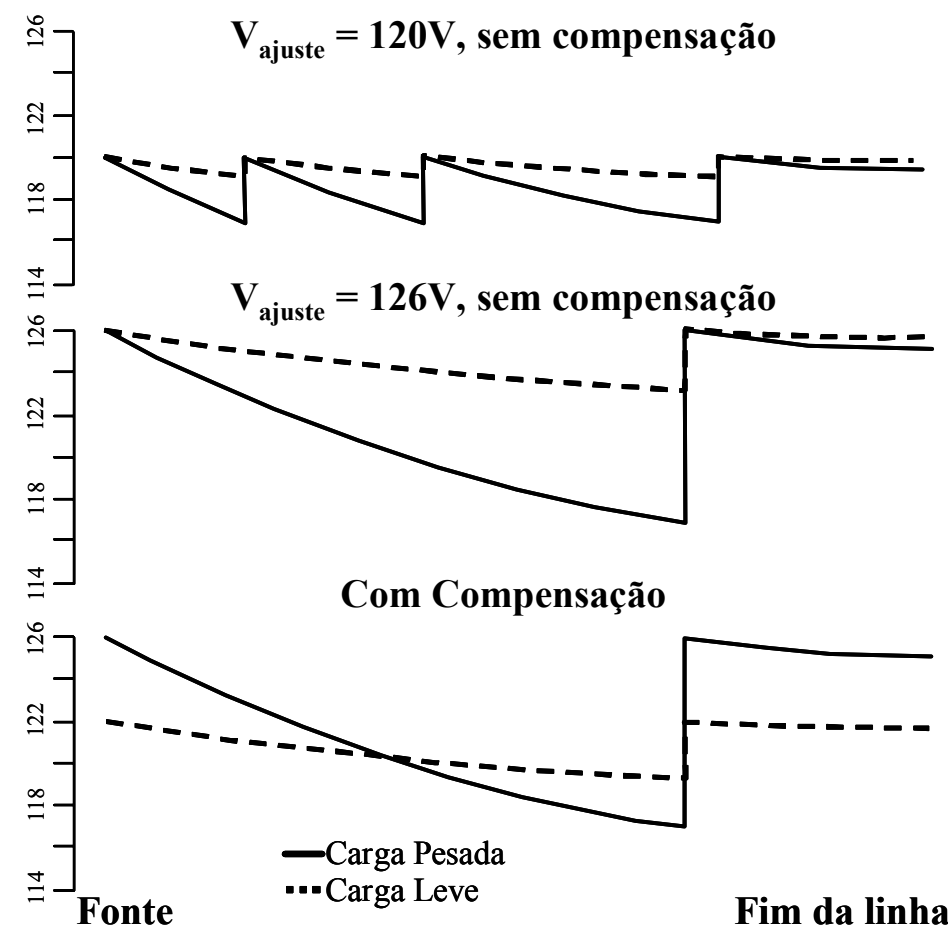

FIGURA 2.2 - Perfis de tensão com e sem atuação do LDC.

A tensão de ajuste ou referência, representada por $V_{\text {ajuste, é valor de tensão }}$ que deve ser fornecido pela subestação (fonte) para que o consumidor receba uma tensão nominal dentro dos limites operativos. Para a situação onde a tensão de ajuste é de 120 V e não há compensação, pode-se contemplar a variação de tensão que ocorre ao longo da linha para a Carga Pesada. Já para a Carga Leve esta flutuação não é tão grande; no entanto, é necessária a presença de vários reguladores ao longo do alimentador para atender os consumidores.

Para a situação em que a tensão de ajuste é de $126 \mathrm{~V}$, assume-se uma postura de elevar a tensão no secundário para que ao fim do alimentador seja entregue ao consumidor a tensão contratada. Essa tensão maior é observada tanto em Carga Pesada quanto em Carga Leve. Com a utilização do LDC, a tensão em 
Carga Leve não será mais tão elevada, fazendo assim que os consumidores mais próximos da subestação não sofram com sobretensões em situações fora da Carga Pesada. Tanto a estratégia de deixar a tensão do secundário mais elevada quanto o LDC permitem um menor uso de reguladores de tensão ao longo do alimentador, mas estão sujeitas às regulamentações sobre níveis de tensão não operativos [1].

O método de compensação por queda de linha funciona perfeitamente para uma carga ao final da linha. Caso existam cargas distribuídas uniformemente ao longo do alimentador, com uma impedância de linha também uniforme, pode-se manter a tensão constante no ponto médio do alimentador.

Para isso, deve-se então ajustar a compensação utilizando-se a "Regra dos 3/8" da impedância total da linha [9]. Um circuito com uma carga uniformemente distribuída tem uma queda de tensão na extremidade do alimentador igual à metade da que ocorreria caso todas as cargas fossem modeladas como uma só carga ao final da linha. A compensação segura é possível apenas para certa quantidade, pois sobretensões ocorrerão caso uma compensação excessiva seja realizada pelo regulador.

A tensão do relé regulador não pode ficar acima dos limites. A tensão máxima pode ser calculada segundo Expressão 2.6:

$$
V_{\text {max }}=V_{\text {ajuste }}+\left(f p \cdot R_{\text {ajuste }}+f q \cdot X_{\text {ajuste }}\right) \cdot I_{\text {max }}
$$

Onde:

- $V_{\text {ajuste }} \rightarrow$ Tensão ajustada do regulador (V).

- $R_{\text {ajuste }} \rightarrow$ Ajuste do regulador para compensação resistiva (V).

- $\quad X_{\text {ajuste }} \rightarrow$ Ajuste do regulador para compensação reativa (V).

- $f p \rightarrow$ Fator de potência ativa. 
- $\quad f q \rightarrow$ Fator de potência reativa.

- $\quad I_{\max } \rightarrow$ Máxima corrente de carga em p.u. relativa ao TC do regulador.

Assim, pode-se ajustar $R_{\text {ajuste }}$ e $X_{\text {ajuste }}$ para atingir os limites desejados.

De maneira simplificada, a queda de tensão nos alimentadores é refletida no relé de controle de tensão como sendo a relação entre a variação de tensão no barramento regulado da subestação e a variação da somatória das correntes de carga dos alimentadores. Essa relação define a impedância réplica, equivalente a um centro de carga fictício [10]. Assim, para uma condição de carga pesada (FIGURA 2.3), tem-se [9]:

$$
Z \cdot I_{C P}=V_{C P}-V_{R E G}
$$

Onde:

- $\quad V_{C P} \rightarrow$ Tensão em carga pesada.

- $\quad I_{C P} \rightarrow$ Corrente em carga pesada.

- $\quad V_{R E G} \rightarrow$ Tensão regulada.

- $\quad Z \rightarrow$ Impedância réplica.

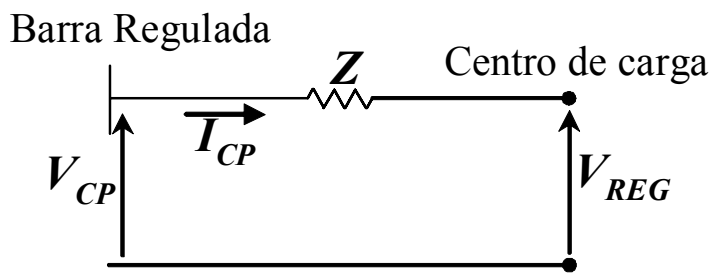

FIGURA 2.3 - Centro de carga para uma condição de carga pesada.

Já para uma condição de carga leve (FIGURA 2.4), obtém-se [9]:

$$
Z \cdot I_{C L}=V_{C L}-V_{R E G}
$$


Onde:

- $\quad V_{C L} \rightarrow$ Tensão em carga leve.

- $\quad I_{C L} \rightarrow$ Corrente em carga leve.

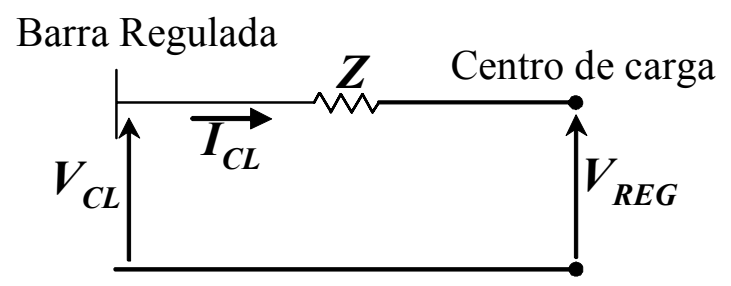

FIGURA 2.4 - Centro de carga para uma condição de carga leve.

Subtraindo (2.8) de (2.7) tem-se:

$$
\begin{aligned}
& Z\left(I_{C P}-I_{C L}\right)=V_{C P}-V_{C L} \\
& Z=\frac{V_{C P}-V_{C L}}{I_{C P}-I_{C L}}=\frac{\Delta V}{\Delta I}[\Omega]
\end{aligned}
$$

Na prática, considera-se a tensão em carga leve como sendo a tensão nominal e a corrente em carga leve como sendo nula [10], ou seja:

$$
Z=\frac{V_{C P}-V_{N}}{I_{C P}}
$$

A impedância encontrada em (2.11), por meio do centro de carga fictício, fornece subsídios para o cálculo dos parâmetros $R_{\text {ajuste }}$ e $X_{\text {ajuste }}$ de regulação do LDC, os quais foram vistos anteriormente [10]. 


\subsection{Dispositivos utilizados em sistemas de distribuição para controle da tensão}

As concessionárias de distribuição de energia elétrica têm a seu dispor diversos dispositivos e métodos para controlar a tensão e não transgredir as resoluções impostas pela ANEEL. Dentre os métodos, o mais empregado é o LDC.

Já os dispositivos de controle incluem transformadores de subestações com comutação de tap, reguladores de tensão e banco de capacitores. A interação entre esses dispositivos pode ser controlada em tempo-real ou por meio de préprogramação.

\subsubsection{Bancos de capacitores}

O emprego de Bancos de Capacitores em sistemas de distribuição promove inúmeros benefícios. Isso porque ao compensar a potência reativa indutiva de motores ou outras cargas com baixo fator de potência, a corrente no alimentador reduz, o que também diminui as perdas. Desta forma, um mesmo circuito pode suprir mais cargas. Os capacitores também elevam a tensão no alimentador, reduzindo parte das perdas produzidas pelas cargas do sistema [9].

Em sistemas de distribuição se pode empregar capacitores tanto na barra da subestação como ao longo dos alimentadores, conforme ilustrado na FIGURA 2.5. 


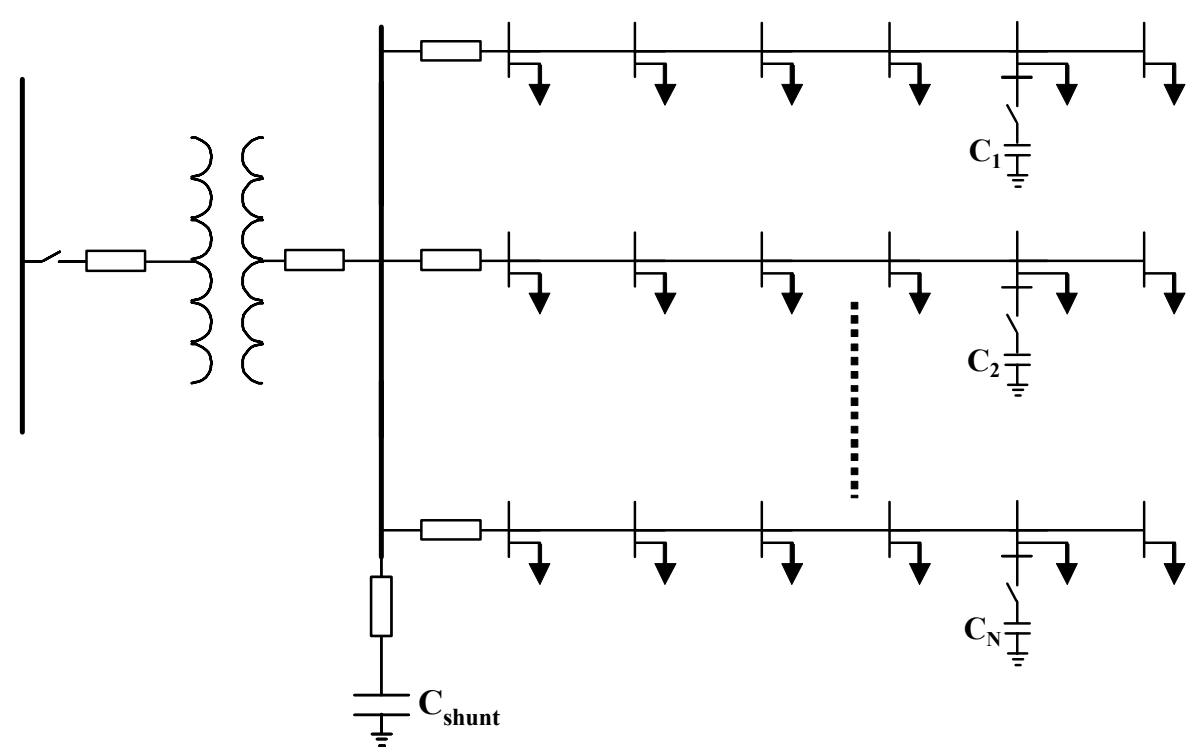

FIGURA 2.5 - Capacitores instalados ao longo do alimentador e na barra da subestação.

Os capacitores $\mathrm{C}_{1}, \mathrm{C}_{2}, \ldots, \mathrm{C}_{\mathrm{N}}$ são instalados no alimentador para compensar reativos na linha. $\mathrm{O}$ capacitor $\mathrm{C}_{\text {shunt }}$ é instalado na barra da subestação para compensar reativos em todo o sistema e elevar o fator de potência do secundário.

Os capacitores instalados ao longo do alimentador e no barramento secundário da subestação têm sua operação diária acompanhada por sistemas supervisórios remotos ou por controladores locais.

Os métodos utilizados para a inserção e controle de capacitores em sistemas de distribuição podem utilizar técnicas convencionais, como relatado em [9], ou mesmo técnicas inteligentes como aquelas apresentadas em [11,12].

\subsubsection{Reguladores de tensão de linha}

Os reguladores de tensão de linha são transformadores com um enrolamento em série com o outro. Também são conhecidos por autotransformadores e possuem uma faixa de ajuste que permite regular a tensão em sua saída de $-10 \%$ a $+10 \%$, em relação à tensão de entrada. 
Instalados ao longo dos alimentadores, elevam os níveis de tensão, diminuindo a flutuação de tensão no consumidor. Os reguladores possuem várias entradas, permitindo a configuração do número de enrolamentos de acordo com a variação da tensão [9].

Tal ajuste é feito por meio de uma chave rotatória ou um comutador de tap. Neste dispositivo o enrolamento Primário se encontra em paralelo com a linha e, o Secundário, em série com a linha. O enrolamento em série possui taps que permitem que a tensão possa ser somada ou subtraída à tensão do primário. Isto resulta em valores de tensão que se mantêm aproximadamente constantes mesmo que a tensão do primário varie [13].

Se nenhum regulador estiver instalado ao longo da linha, a queda de tensão máxima deve estar dentro da faixa de operação do transformador da subestação. $\mathrm{Na}$ FIGURA 2.6 se pode contemplar a ação de um regulador instalado ao longo da linha de um sistema de distribuição.
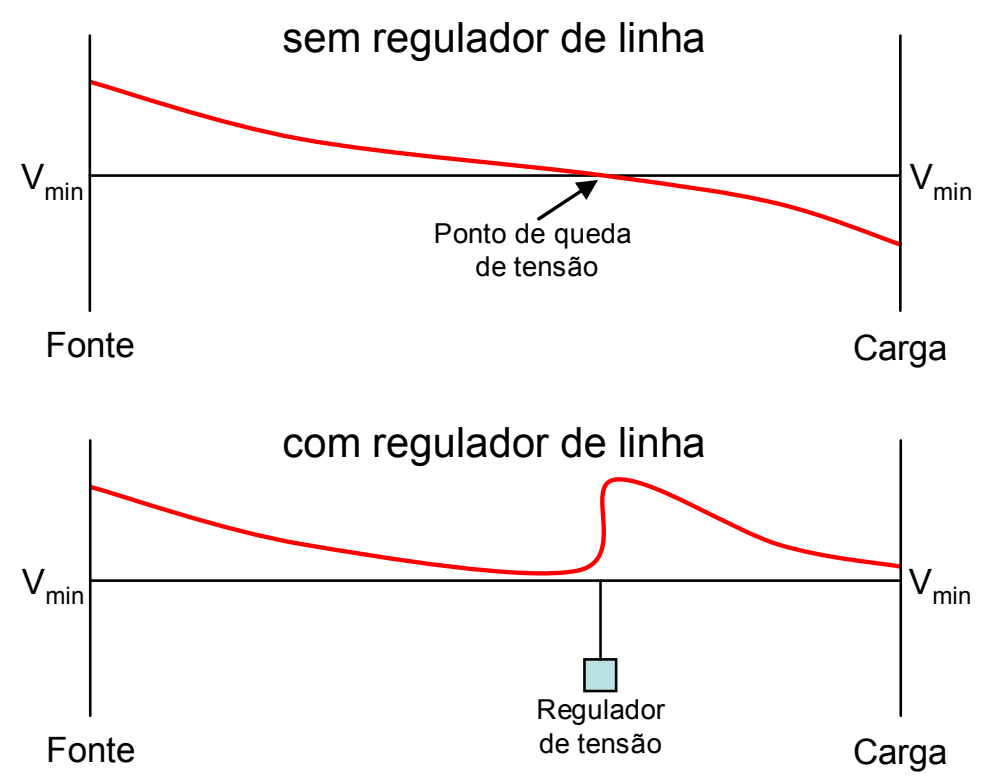

FIGURA 2.6 - Alimentador de distribuição com e sem regulador de tensão. 
Em um alimentador de distribuição sem regulador, o Ponto de queda de tensão representa o local em que a subestação já não é mais capaz de compensar a queda de tensão na linha. Para que a tensão não fique fora dos níveis operativos, a partir deste ponto, é então necessário a instalação de um regulador, que irá elevar os níveis de tensão novamente para os níveis operativos [9].

Com um regulador instalado ao longo da linha, pode-se cobrir até duas vezes a queda de tensão suportada pelo primário. Similarmente, com dois reguladores se pode cobrir até três vezes a máxima queda de tensão do primário e assim sucessivamente [9].

Para cargas uniformemente distribuídas ao longo do alimentador, pode-se empregar a "Regra dos 3/8" e instalar o regulador a 3/8 da distância da subestação. Para dois reguladores, pode-se instalar o primeiro a $20 \%$ da distância da subestação e o segundo a $50 \%$ da distância da subestação [9].

A instalação de reguladores ao longo do alimentador cabe à equipe de planejamento do sistema de distribuição, que deve estudar o ponto do alimentador onde a subestação já não pode mais compensar a queda de tensão.

\subsubsection{Transformadores com comutador de tap}

Em uma rede de distribuição a carga varia durante o dia todo. Esse fato ocasiona flutuações de tensões que podem transgredir os níveis operativos e submeter os consumidores a sobretensões ou subtensões.

Para realizar o controle da tensão ao longo do dia, os transformadores de distribuição são equipados com LTC's que permitem a mudança da relação de transformação do primário em relação ao secundário, sob carga. 
Tais transformadores possuem taps e usualmente permitem um ajuste de \pm $10 \%$ na magnitude da tensão. Também há transformadores capazes de alterar o ângulo da fase. Ambos são importantes dispositivos em um sistema de distribuição [9]. Cada LTC possui um Relé Regulador de Tensão (AVR) que monitora as grandezas elétricas do sistema e comanda as operações de comutação de tap.

A comutação é realizada sem a interrupção da corrente devido à existência de um conjunto especial de dispositivos que apenas mudam a posição do tap do transformador quando toda a seqüência mecânica for completada. Ainda há a utilização de temporização para prevenir comutações desnecessárias.

O desgaste dos contatos do LTC, que pode provocar falhas de operações, está associado ao número de comutações e à corrente sobre os contatos quando da comutação. Por isto, quanto maior a taxa de comutação dos taps, maior será o desgaste do LTC e menor será a vida útil deste dispositivo [10].

Por ser eletromecânico, os contatos do LTC são os componentes mais sensíveis e caros do sistema regulador [14]. Essa característica torna, portanto, imprescindível ao sistema de controle gerenciar de forma mais racional possível o número de comutações.

Os LTC's são projetados para realizar 1 milhão de operações em sua vida útil. Em condições normais são realizadas em média 70 comutações de tap em um dia, um total de 25 mil por ano.

A cada 100 mil comutações é necessária uma manutenção preventiva, o que ocorre em aproximadamente 4 anos com 70 comutações por dia [15].

As concessionárias de energia, no entanto, podem adotar seus próprios limites de comutações diárias, buscando baixar os custos de manutenção. Este é o caso da Taiwan Power Company [16] que permite no máximo 30 comutações de tap 
por dia, o que aumenta para aproximadamente 9 anos o tempo entre cada manutenção preventiva.

\subsection{Relé regulador de tensão (AVR)}

O relé regulador de tensão (AVR) é o dispositivo responsável por controlar as comutações do LTC. Estes relés, como o próprio AVR da empresa TreeTech ou o M-2667 da Beckwith Electric, além de manter a tensão na carga dentro dos limites estabelecidos têm inúmeras outras funcionalidades $[17,18]$, tais como:

- Compensação de queda de tensão na linha;

- Proteções para o comutador contra curtos e sobrecargas;

- Proteger a carga contra a ocorrência de sobretensões;

- Função multimedidor: tensão, corrente, potência ativa, reativa, potência aparente, fator de potência, etc;

- Memória de massa;

- Medição da posição do tap e controle do comutador;

- Controle de transformadores em paralelo;

- Contador do número de comutações;

- Coordenação com capacitores e reguladores instalados ao longo do alimentador;

- Diversos modos de programação e temporização.

O princípio básico de funcionamento deste tipo de relé segue um fluxo de execução semelhante ao da FIGURA 2.7. 


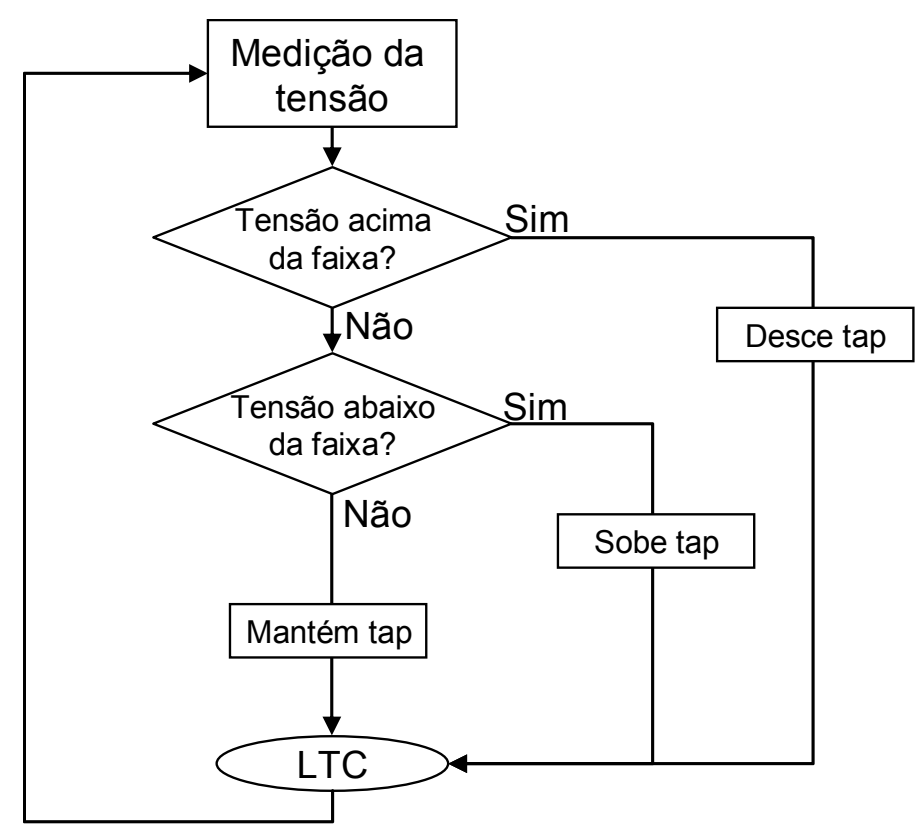

FIGURA 2.7 - Fluxo de execução do AVR.

O AVR realiza medições da tensão do barramento secundário do transformador e as compara com a tensão de referência. Se a tensão medida estiver fora da faixa de operação, então o relé verifica se deve enviar ao LTC um comando de subir ou descer o tap do transformador. Se a tensão medida não estiver fora da faixa, conhecida também como Zona Morta, então o relé envia um comando para o LTC manter o TAP na posição atual. Como estas medições são realizadas no barramento secundário do transformador, faz-se um ajuste local visando compensar as flutuações de tensões que ocorrem ao longo do alimentador ou até o primeiro regulador de tensão. Desta forma, o AVR toma decisões com base apenas na medição da tensão, não levando em consideração outros aspectos.

Os AVR's podem ser parametrizados com diversos modelos de temporização, podendo até mesmo ser realizados despachos programados de acordo com a hora e o dia [17].

A primeira comutação geralmente ocorre após a espera de um Tempo Morto, que é utilizado para evitar comutações prematuras. Quando há necessidade 
de uma seqüência de comutações, a $2^{a}, 3^{a}, \ldots, N^{a}$ comutações ocorrem em um tempo menor, conforme ilustrado na FIGURA 2.8.

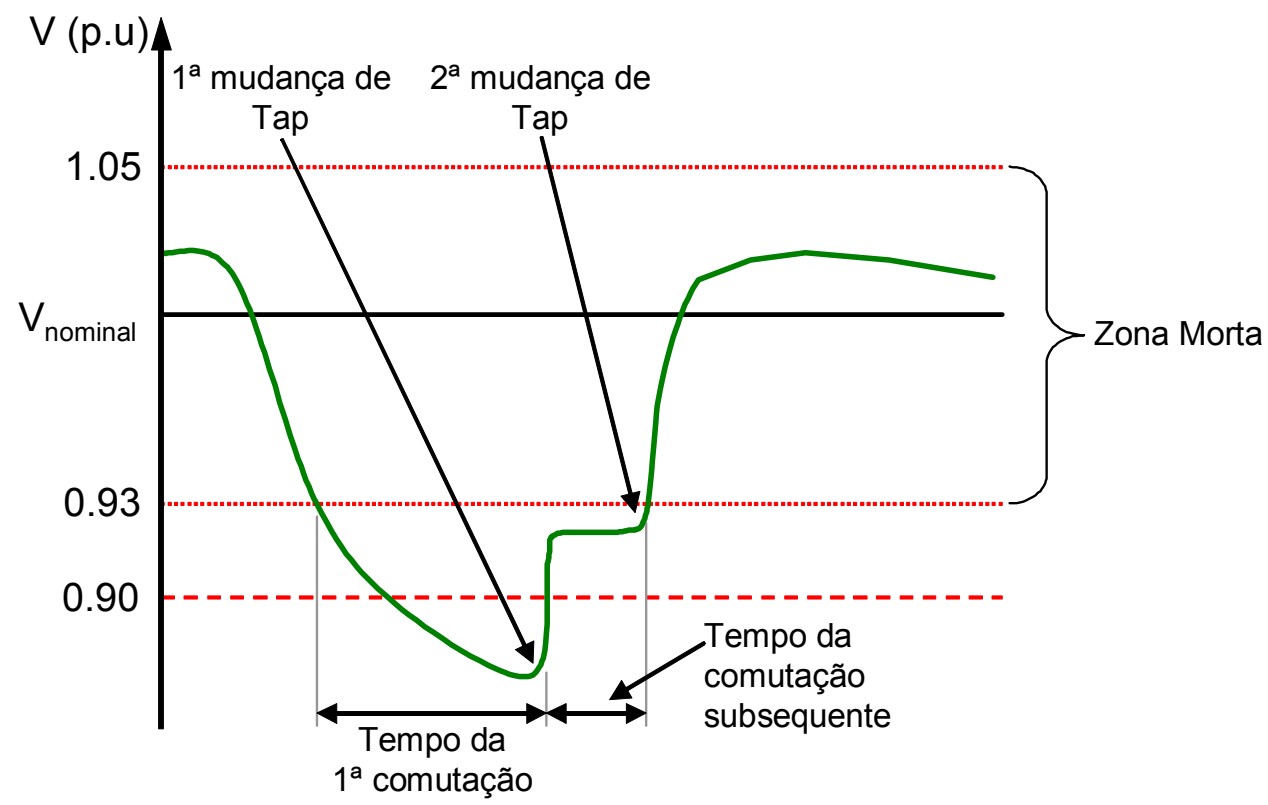

FIGURA 2.8 - Tempos de comutação no AVR.

A Zona Morta representa a faixa de operação dos níveis de tensão, onde não ocorre nenhuma comutação de tap. Quando a tensão sai fora dos limites de operação, então se inicia a contagem de um Tempo de $1^{a}$ comutação previamente parametrizado no AVR. Este tempo é empregado para garantir que comutações prematuras não sejam acionadas, por exemplo, em situações de manobra. Após uma primeira comutação, se a tensão ainda estiver fora da faixa de operação, então o AVR realiza as demais comutações com um tempo reduzido, até que a tensão retorne para os níveis operativos.

Para melhorar a eficiência da regulação, os AVR's podem ser equipados com temporizações diferenciadas de acordo com programações realizadas pelo usuário [17]. Na FIGURA 2.9 é ilustrada a temporização linear de um AVR. 


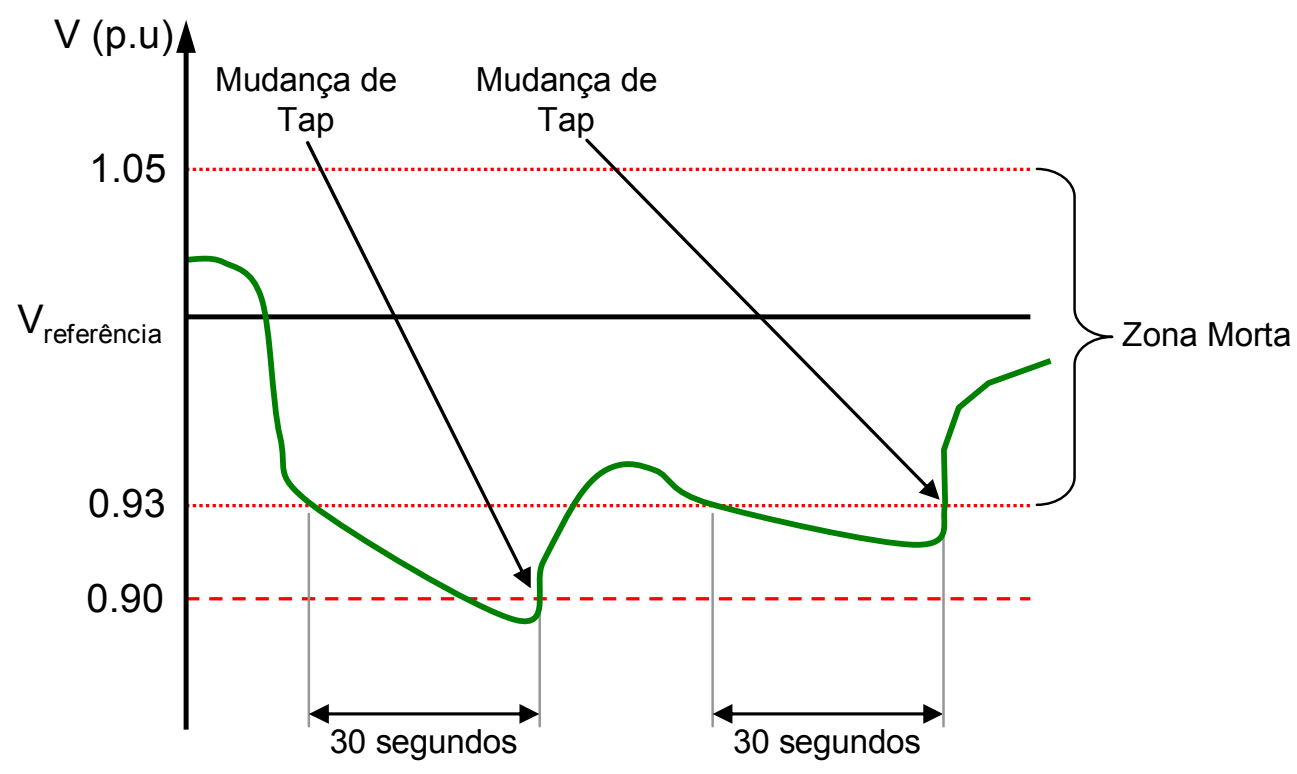

FIGURA 2.9 - Temporização linear do AVR.

A temporização linear aguarda o mesmo tempo para realizar uma $1^{\text {a }}$ comutação, independente do desvio da tensão em relação à tensão de referência.

Já a temporização inversa aguarda, para realizar uma $1^{a}$ comutação, um tempo que varia de acordo com o desvio da tensão em relação à tensão de referência (FIGURA 2.10).

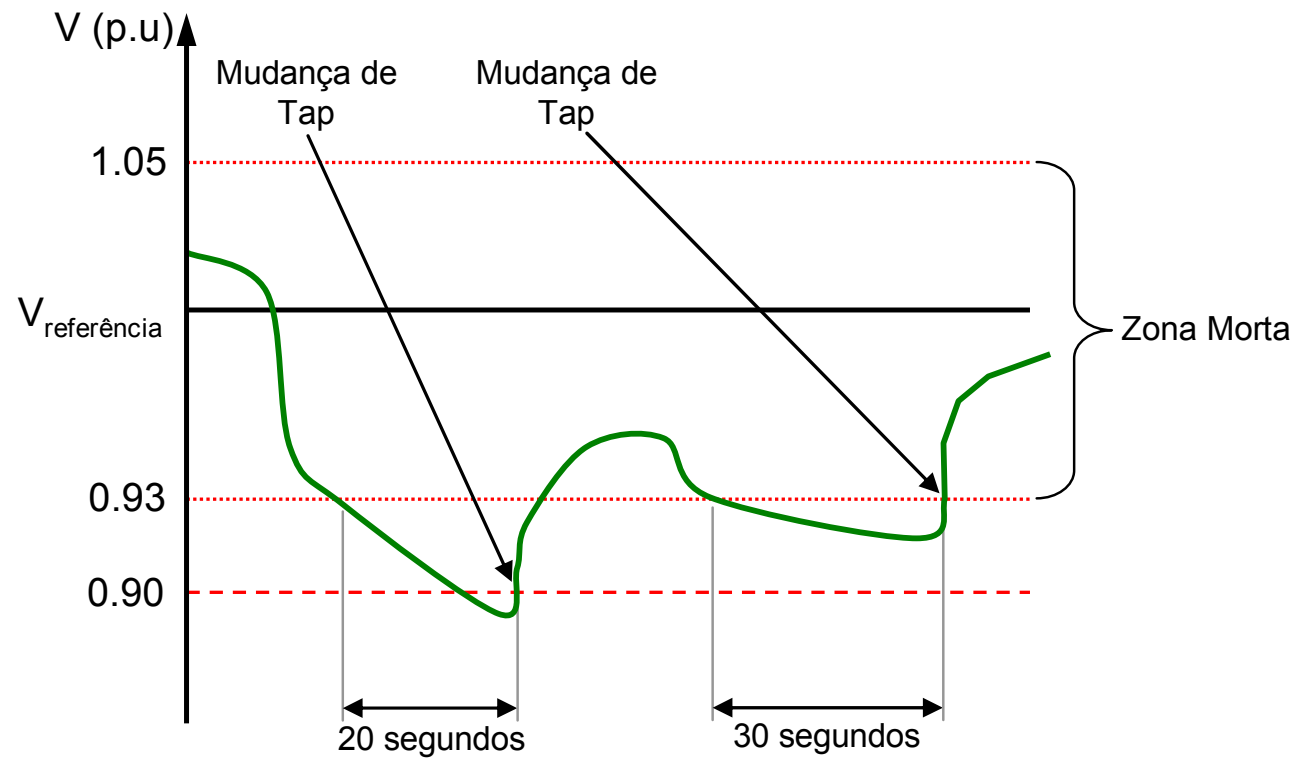

FIGURA 2.10 - Temporização inversa do AVR. 
Há ainda uma temporização linear flexível, que varia de acordo com a faixa de transgressão em que se encontra a tensão medida pelo AVR.

O método do LDC também pode ser implementado no AVR para compensar a queda de tensão. Nesse caso, o AVR realiza o cálculo da impedância réplica da linha para encontrar os melhores ajustes de tensão, conforme visto anteriormente.

Através dos conjuntos de programação presentes nos AVRs mais modernos é possível realizar despachos programados, prevendo feriados, situações de carga pesada, etc.

Assim, o AVR enquadra a tensão medida em um desses conjuntos e toma a decisão de acordo com as parametrizações previamente definidas pelo usuário, que pode ajustar a tensão de referência, a largura da faixa, tipo de temporização e o tempo morto. 


\section{Estado da arte referente à aplicação de}

\section{sistemas inteligentes no controle de tensão}

A natureza não previsível da carga em um sistema de distribuição torna o controle de tensão extremamente complexo. Em literatura da área é possível encontrar diversos pesquisadores buscando soluções para resolver este tipo de problema. Os Sistemas Inteligentes vêm cada vez mais se destacando no controle de tensão em Sistemas de Distribuição.

No entanto, técnicas convencionais como a utilizada em [6] ainda são largamente pesquisadas. Os objetivos desta proposta consistem em encontrar as melhores posições do tap do transformador em função do tempo, de acordo com as necessidades dos consumidores, minimizar o erro entre a tensão de referência e a tensão do consumidor final e reduzir a freqüência de comutações do tap do transformador.

Esta estratégia realiza uma otimização real para avaliar a tensão de referência ótima. Em seguida, faz-se um arredondamento para encontrar uma solução inteira plausível, uma vez que as posições do tap são inteiras. Deste processo resultam duas posições candidatas: a inteira imediatamente maior e a inteira imediatamente menor. Avalia-se então dentre estas duas posições candidatas 
do tap a solução ótima, verificando-se o erro entre a tensão de referência desejada e os produzidos pela otimização.

O referido trabalho apresentou excelentes resultados de regulação, minimizando com eficiência o desvio da tensão em relação à referência. Entretanto, o número de comutações do tap foi relativamente maior.

Já em [19] uma proposta utilizando Sistemas Inteligentes foi estudada para determinar o despacho programado nas operações de chaveamento de capacitores e comutação de tap, conforme a previsão de carga para o próximo dia. Nesta proposta se busca a coordenação ótima entre comutadores de tap, banco de capacitores ligados ao barramento secundário da subestação e também espalhados ao longo do alimentador, minimizando-se as operações de comutação de tap e chaveamento dos bancos de capacitores.

Foram utilizados os Algoritmos Genéticos para particionar a curva de carga e também encontrar o escalonamento ótimo. Esta estratégia reduziu o número de operações de LTC e Banco de Capacitores, além de melhorar o perfil de tensão e minimizar as perdas de potência.

Uma maneira de diminuir a complexidade do problema é dividi-lo em dois: um com os controles da subestação e o outro com o controle dos alimentadores. Este é o caso da proposta apresentada em [20], que utiliza Programação Dinâmica para resolver o problema do lado da subestação e sistemas fuzzy para o do lado dos alimentadores. Os objetivos principais desta estratégia são minimizar as perdas de potência e melhorar o perfil de tensão.

A subestação em questão é equipada com AVR's e bancos de capacitores conectados ao barramento secundário. Também há bancos de capacitores instalados ao longo do alimentador. Esta divisão em dois subproblemas proporciona 
uma simplificação considerável da Programação Dinâmica se comparada à utilização desta ferramenta para solucionar o problema completo. A coordenação entre os dois subproblemas é realizada por algoritmos convencionais, que resultaram em diminuição das perdas de potência e considerável melhora no perfil de tensão.

Uma outra maneira de se solucionar o problema de controle de tensão é a utilização de Sistemas Híbridos, que combinam duas ou mais ferramentas inteligentes. Como exemplo, esta é a proposta apresentada em [21], que utiliza uma Rede Neural e uma Programação Dinâmica fuzzy para realizar um despacho programado para as 24 horas do dia seguinte.

Trata-se de um Sistema Híbrido do tipo seqüencial, que realiza um despacho preliminar por meio das Redes Neurais e, em seguida, utiliza a Programação Dinâmica fuzzy para encontrar o Despacho Final. O Sistema Híbrido é responsável por definir quais as posições do tap do transformador da subestação e também o status do banco de capacitores instalado no barramento secundário.

Este despacho programado utilizando Sistemas Híbridos tem como objetivos os seguintes:

1. Manter a tensão do barramento secundário o mais próximo possível do valor especificado para toda as horas do dia;

2. O fator de potência do transformador principal deve ser o maior possível;

3. O número de comutações do tap e chaveamentos do capacitor devem ser o mínimo possível. 
Estes três objetivos são definidos com incertezas, inerentes aos termos "o mais próximo possível", "o maior possível" e "o mínimo possível". Para atender tais objetivos é necessário uma Programação Dinâmica fundamentada em lógica fuzzy, que é capaz de tratar as informações de forma qualitativa.

Os dados de potência ativa, reativa, tensão do primário e do secundário são apresentados a uma Rede Neural, que disponibiliza na saída a posição ideal do tap e o status do capacitor da subestação. São utilizadas 24 Redes Neurais, uma especialista em cada hora do dia. Cada Rede Neural pode produzir até 3 valores de posições de tap, dependendo do método de arredondamento utilizado, uma vez que a posição do tap é inteira e a saída da rede é real. Para o capacitor, pode-se assumir os status de "on" ou "off".

Portanto, para cada despacho preliminar produzido pela Rede Neural, são obtidos 6 estados possíveis. Assim, para escolher o melhor estado, a Programação Dinâmica fuzzy, com base nos três objetivos já mencionados, seleciona qual a posição do tap e o status do capacitor mais adequados para cada hora do dia.

Essa proposta permite um planejamento diário da operação do transformador principal e também do capacitor instalado na barra da subestação. A partir dos resultados obtidos se constata uma significativa melhora do perfil de tensão e do fator de potência, mas o número de comutações do tap foi relativamente maior, se comparado a um método tradicional.

A proposta de se investigar o controle de tensão e potência reativa em [16] é encontrar um despacho ótimo para o comutador de tap do transformador, bem como o estado dos capacitores instalados ao longo dos alimentadores e também no barramento secundário da subestação, observando-se algumas horas no futuro. 
As considerações para a aplicação desta estratégia são também definidas em termos qualitativos, que podem ser demonstradas nos objetivos principais do seu controle coordenado, ou seja:

1. O desvio de tensão no barramento secundário deve ser mantido "tão pequeno quanto possível";

2. O fluxo de potência reativa através do transformador deve ser mantido "tão pequeno quanto possível";

3. A perda real total nos alimentadores deve ser mantida a "tão pouco quanto possível”;

4. O número de comutações de tap e operações de chaveamento de capacitores deve ser "a menor possível".

Esses objetivos possuem imprecisão, pois são modelados por meio de expressões lingüísticas como "tão pequeno quanto possível", que obviamente não podem ser tratadas por um algoritmo de otimização numérico. Utiliza-se então uma lógica fuzzy e uma técnica de Recozimento Simulado para acelerar a resolução do problema. O Recozimento Simulado é uma técnica de otimização combinatorial [16].

Primeiramente, a função objetivo é formulada por meio de sistemas fuzzy. Então, o algoritmo de Recozimento Simulado é empregado para resolver o problema e encontrar um despacho programado ótimo para o LTC, assim como o estado dos capacitores em um dia.

O método de Recozimento Simulado será empregado para refinar a saída do sistema fuzzy. As variáveis de controle para cada hora incluem 1 posição para o tap e 11 status para capacitores, totalizando 12 variáveis. Assim, para 24 horas devem 
ser solucionadas $288(12 \times 24)$ situações. Uma função chamada de "Função Energia" é adotada para mensurar o quão boa é a solução.

A estratégia proposta apresentou bons resultados tanto para o refinamento do sistema fuzzy como para a solução do controle de tensão e potência reativa em sistemas de distribuição.

Em [22] é apresentada uma forma inovadora de coordenação entre os dispositivos de controle de tensão em um sistema de distribuição. Nesta proposta se utiliza o comportamento da potência reativa para coordenar de forma automática a ação do LTC, capacitores e reguladores de tensão instalados ao longo do alimentador. Tal estratégia melhorou o desempenho do sistema e a entrega de energia para o consumidor final, pois a corrente total foi reduzida. Pelo fato de não requerer intervenção humana e com a diminuição do número de operações do tap do transformador e chaveamentos dos capacitores, há uma diminuição dos custos de manutenção e operação do sistema.

Dentre as propostas estudadas, apenas a apresentada em [6] realiza medições e controle somente no barramento secundário da subestação.

As demais apresentam estratégias eficientes, mas que não contemplam os objetivos principais deste trabalho, pois não atuam somente na subestação e a preocupação da melhora do perfil da tensão está restrita a manter a tensão o mais próxima possível da tensão de referência. Uma avaliação ampla de todas as estratégias estudadas mostrou que a maioria delas obteve sucesso na melhora do perfil de tensão mediante um número maior de comutações de tap.

Isto se deve ao fato de que a estratégia de controle convencional não realiza comutações para tensões que se encontram dentro da faixa de operação parametrizada pelo usuário. Assim, qualquer medida de controle que visa melhorar o 
perfil de tensão, dentro da chamada zona morta dos relés, irá resultar em um número maior de comutações de tap.

Esses estudos motivaram ainda mais a busca por uma ferramenta inteligente que possa racionalizar as comutações do tap do transformador e melhorar o perfil de tensão, atuando-se apenas na subestação de distribuição. 



\section{Modelagem das funções inteligentes para}

\section{relés reguladores de tensão}

Conforme abordado no capítulo anterior, a aplicação de ferramentas inteligentes no controle de tensão já é bastante estudada, pois o objetivo de destaque da aplicação dessas técnicas consiste no alcance de tratabilidade, robustez, baixo custo e altas taxas de eficiência.

Este trabalho também irá investigar o desempenho dos Sistemas Inteligentes para controlar a tensão em um sistema de distribuição, mais especificamente os sistemas fuzzy, devido à sua elevada habilidade de mapear sistemas não-lineares e tratar incertezas.

De fato, fundamentado em resultados já alcançados e que serão mostrados no capítulo posterior, torna-se bastante promissor que a utilização dessas tecnologias recentes, apresentando resultados cada vez mais eficientes e seguros, possam contribuir nos processos envolvidos com o controle de tensão em níveis satisfatórios. 


\subsection{Aspectos principais relacionados aos sistemas fuzzy}

A lógica fuzzy é o ramo da matemática que suporta os modos de raciocínio que são aproximados ao invés de exatos. É considerada como a melhor representação do raciocínio humano, que é feito através de forma aproximada e qualitativa em sua essência, por meio da linguagem natural. Foi proposta por Lofti A. Zadeh em 1965 [23].

Modelagem e controle fuzzy de sistemas são técnicas para o tratamento de informações qualitativas de uma forma rigorosa. Derivada do conceito de conjuntos fuzzy, a lógica fuzzy constitui a base para o desenvolvimento de métodos e algoritmos de modelagem e controle de processos, permitindo a redução da complexidade de projeto e implementação, tornando-se uma alternativa para a solução de problemas de controle e modelagem de sistemas.

Esta forma de estruturação do raciocínio é capaz de tomar decisões racionais mesmo estando em um ambiente de incertezas e imprecisões, onde dados desta natureza e até mesmo conflitantes são tratados [24].

Através da lógica fuzzy, um sistema pode ser representado através de conceitos imprecisos tais como "rápido", "baixo" e "pequeno". Essas propriedades são responsáveis, entre outras, pela facilidade na extração do conhecimento de um sistema a partir de observações realizadas sobre este.

Em um sistema de inferência fuzzy, os valores de entrada são normalizados e convertidos para uma representação fuzzy. Este processo é denominado de fuzzificação das variáveis de entrada. As regras do sistema fuzzy serão executadas em paralelo, conseqüentemente, uma região fuzzy será produzida para cada variável. A criação desta região fuzzy através das regras ativas do sistema é 
conhecida por agregação. Depois do processamento das regras de inferência, as regiões fuzzy são convertidas em valores não fuzzy, também conhecidos como valores "crisp", determinando assim, o valor de cada variável de saída do sistema. O processo de se converter tal região fuzzy em um valor real é conhecido por defuzzificação.

\subsubsection{Funções de pertinência}

Na teoria de conjuntos clássica, um elemento pertence ou não a uma classe. Isso pode ser evidenciado na FIGURA 4.1 que mostra a classificação das velocidades de um determinado automóvel, quanto pertencer à classe de Velocidade Alta.

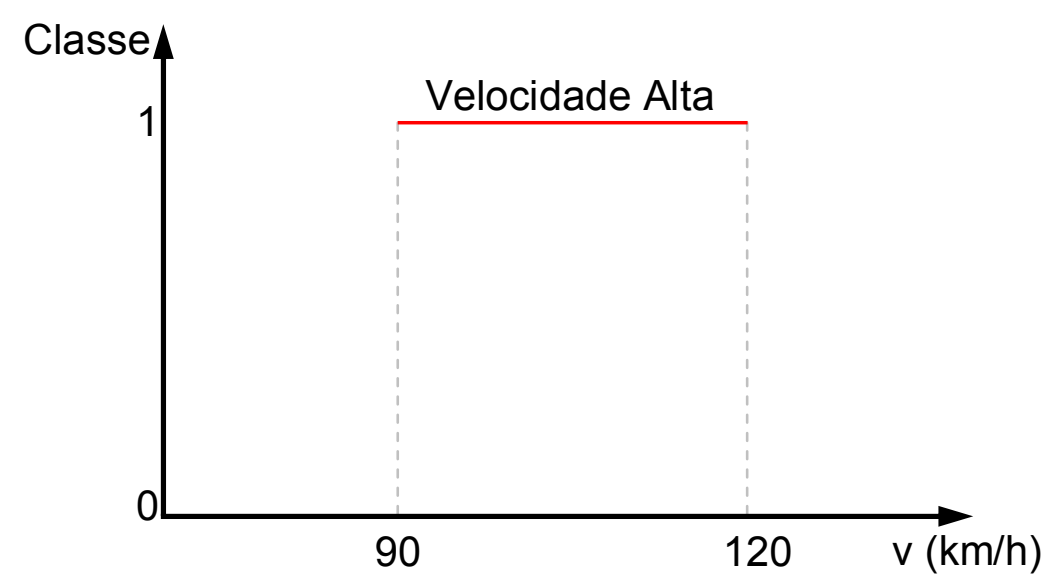

FIGURA 4.1 - Classes de conjuntos na lógica clássica.

Tomando-se dois exemplos de valores de velocidades, sendo eles $90 \mathrm{~km} / \mathrm{h}$ e $120 \mathrm{~km} / \mathrm{h}$, fica evidenciado na FIGURA 4.1, que valores menores, mas muito próximos de $90 \mathrm{~km} / \mathrm{h}$, não pertencem à classe de Velocidade Alta. O mesmo ocorre para velocidades maiores, mas muito próximas a $120 \mathrm{~km} / \mathrm{h}$. Este tipo de raciocínio 
da lógica clássica não permite identificar o quão incluído a uma classe de velocidades um determinado valor estaria.

Zadeh [25] propôs uma caracterização mais ampla, na medida em que sugere que alguns elementos são mais membros de um conjunto do que outros. $O$ grau de pertinência pode então assumir qualquer valor entre o intervalo [0,1], sendo que o valor 0 indica uma completa exclusão e um valor 1 representa completa pertinência. Esta abordagem pode ser melhor compreendida através das funções de pertinência da lógica fuzzy, como a ilustrada na FIGURA 4.2.

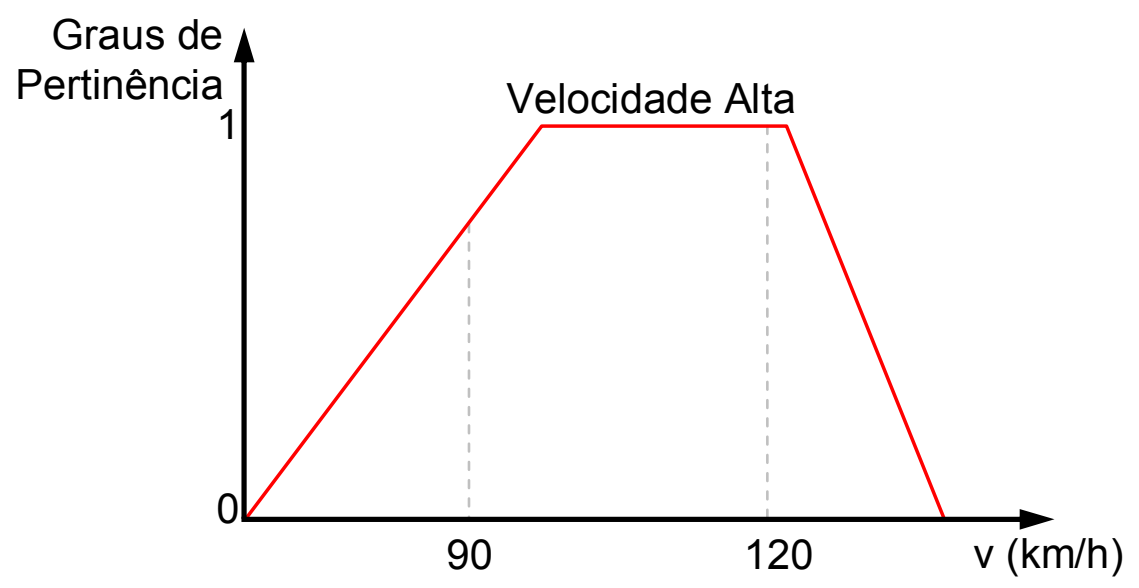

FIGURA 4.2 - Função de pertinência da lógica fuzzy.

Na FIGURA 4.2 se pode observar que a velocidade de $120 \mathrm{~km} / \mathrm{h}$ possui um grau de pertinência na classe de Velocidade Alta maior que a velocidade de 90 $\mathrm{km} / \mathrm{h}$. Desta forma, valores próximos a $120 \mathrm{~km} / \mathrm{h}$ ou $90 \mathrm{~km} / \mathrm{h}$ também pertencem a classe de Velocidade Alta, mas com diferentes graus de inclusão na classe.

Utiliza-se então de conjuntos de funções de pertinência que permitem mapear o universo de discurso em que se deseja atuar, representando-se os diferentes graus de inclusão, como pode ser observado na FIGURA 4.3. Cada 
função de pertinência recebe o nome de Termo Lingüístico, pois irá mapear um evento qualitativo, descrito através de linguagem natural.

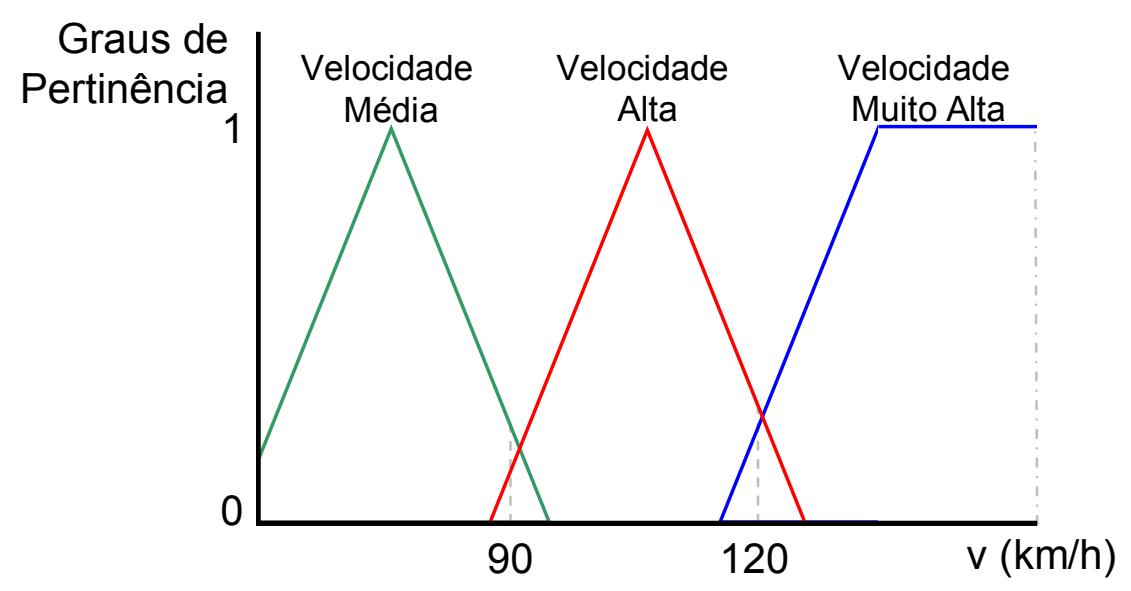

FIGURA 4.3 - Conjuntos de funções de pertinência da lógica fuzzy.

Com este tipo de tratativa, a velocidade de $90 \mathrm{~km} / \mathrm{h}$ pode ser Média e Alta ao mesmo tempo, mas com diferentes graus de inclusão nestas classes. O mesmo se aplica a velocidade de $120 \mathrm{~km} / \mathrm{h}$, que pode ser alta e muito alta ao mesmo tempo.

Dentre os principais formatos de funções de pertinência utilizados na lógica fuzzy se destacam as triangulares, trapezoidais e gaussianas.

\subsubsection{Regras fuzzy}

Para expressar conceitos ou relacionamentos através de elementos da linguagem natural é muito comum o uso de elementos qualitativos ao invés de valores quantitativos. Elementos lingüísticos típicos incluem expressões do tipo "mais ou menos", "alto", "não muitos", "médios", etc. Estas idéias são capturadas pela definição de variáveis lingüísticas.

Uma variável lingüística tem por característica assumir valores dentro de um conjunto de Termos Lingüísticos, ou seja, palavras ou frases. Assim, ao invés de 
assumir instâncias numéricas, estas variáveis assumem instâncias lingüísticas. Por exemplo, uma variável lingüística "Velocidade" poderá assumir como valor um dos termos do conjunto \{"Velocidade Média”, "Velocidade Alta”, "Velocidade Muito Alta”\}, FIGURA 4.3.

Para se atribuir um significado aos termos lingüísticos, associa-se a cada um destes termos um conjunto fuzzy definido sobre um universo de discurso comum.

A forma mais comum de expressar o conhecimento é por meio de regras do tipo "Se-Então". Neste tipo de regra, um conjunto de condições descrevendo o comportamento das entradas do sistema é associado com uma ação de saída que irá manter ou levar o sistema às condições desejadas, ou ainda, expressar o conhecimento especialista envolvido em um sistema e permitir que a modelagem seja mais flexível e comporte informações qualitativas do processo.

A idéia embutida junto às regras fuzzy de representar o conhecimento por meio de um conjunto de termos lingüísticos associados às variáveis de saída e entrada do processo é absorvida pelos sistemas de inferência fuzzy. São exemplos de regras fuzzy:

1. Se "Velocidade" é Alta então "Pressão no Freio" é Grande;

2. Se "Velocidade" é Muito Alta então "Pressão no Freio" é Muito Grande;

3. (..)

Quando a entrada de dados sensibilizar mais de um Termo Lingüístico, ou seja, mais de uma regra estando ativa, a ação de controle consistirá da união de todas as funções fuzzy ativadas. Para uma velocidade de $90 \mathrm{~km} / \mathrm{h}$, observa-se na 
FIGURA 4.4 que as funções de pertinência Velocidade Média e Velocidade Alta estarão ativas ao mesmo tempo. Desta forma, faz-se necessário o uso de uma operação de agregação de regras.

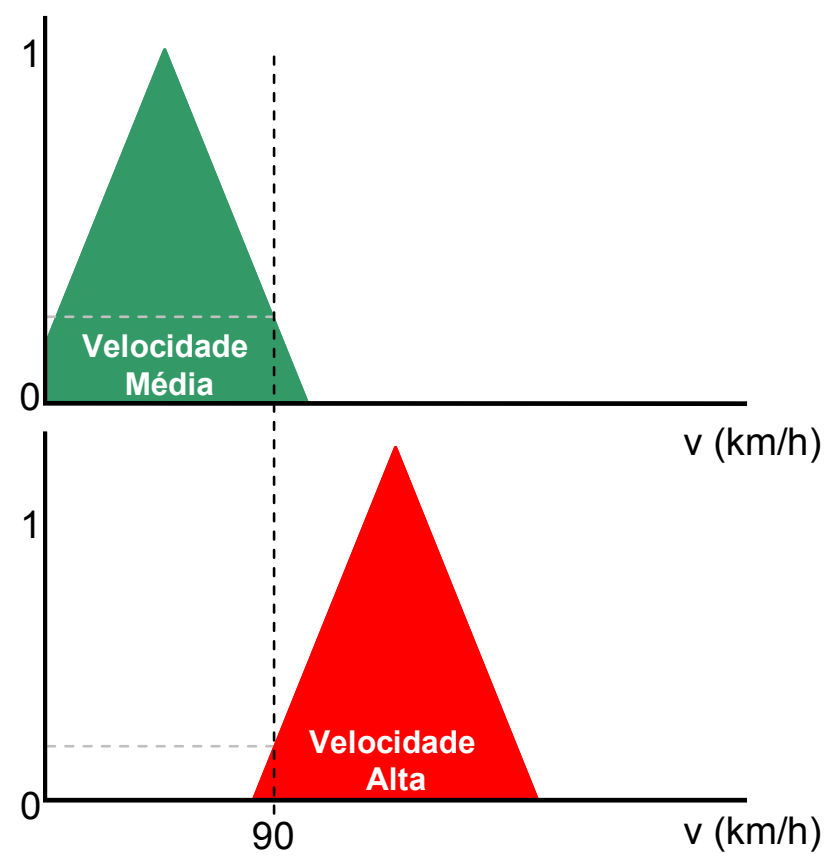

FIGURA 4.4 - Ativação de regras fuzzy.

\subsubsection{Agregação de regras fuzzy}

Em uma base de regras, quando mais de uma regra é acionada, as contribuições das diversas regras após a inferência são combinadas pelo operador de agregação. Como exemplo tem-se na FIGURA 4.5 a representação da entrada de um sistema fuzzy, responsável por mapear a velocidade de um automóvel. 


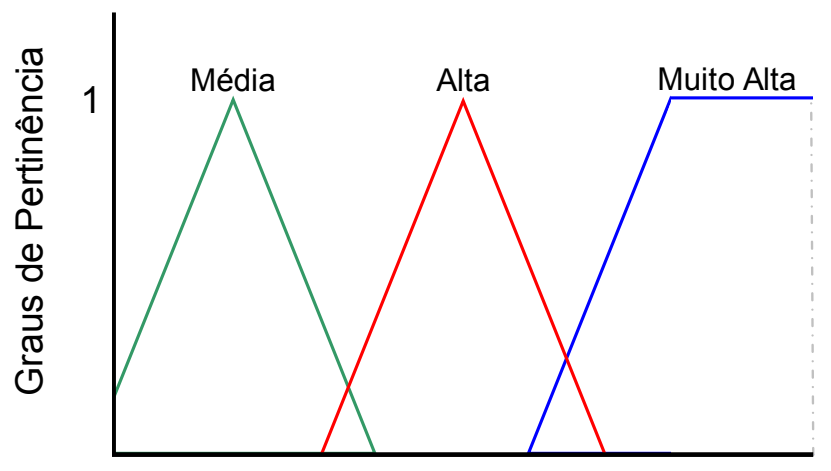

Entrada - Velocidade $(\mathrm{km} / \mathrm{h})$

FIGURA 4.5 - Entrada do sistema fuzzy de exemplo.

O universo de discurso da variável Velocidade foi mapeado com três termos lingüísticos triangulares: \{Média, Alta, Muito Alta\}. A saída deste sistema fuzzy pode ser visualizada na FIGURA 4.6.

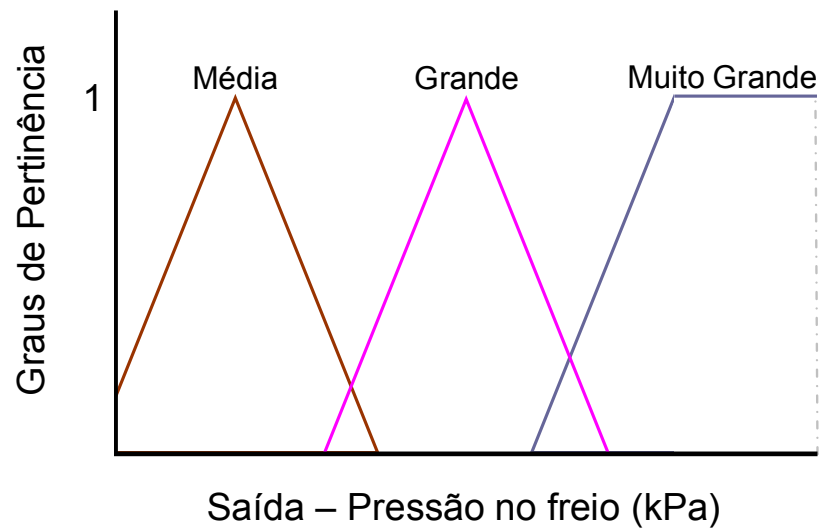

FIGURA 4.6 - Saída do sistema fuzzy de exemplo.

A pressão no freio foi mapeada também com três termos lingüísticos triangulares: \{Média, Grande, Muito Grande\}. Para este exemplo, adotou-se o seguinte conjunto de regras fuzzy:

Regra 1 - Se Velocidade é Média então Pressão no Freio é Média;

Regra 2 - Se Velocidade é Alta então Pressão no Freio é Grande;

Regra 3 - Se Velocidade é Muito Alta então Pressão no Freio é Muito Grande. 
Supondo-se que uma velocidade de $90 \mathrm{~km} / \mathrm{h}$ ative as regras 1 e 2 , pois essa velocidade é Média e Alta ao mesmo tempo, teríamos 2 regras ativas, cada uma inferindo uma região de saída.

Assim, a regra 1 ativa teria uma região fuzzy de saída Média e a regra 2 ativa teria uma região de saída Grande. O processo de agregação das regras para a formação de uma única região fuzzy de saída pode ser visualizado na FIGURA 4.7.

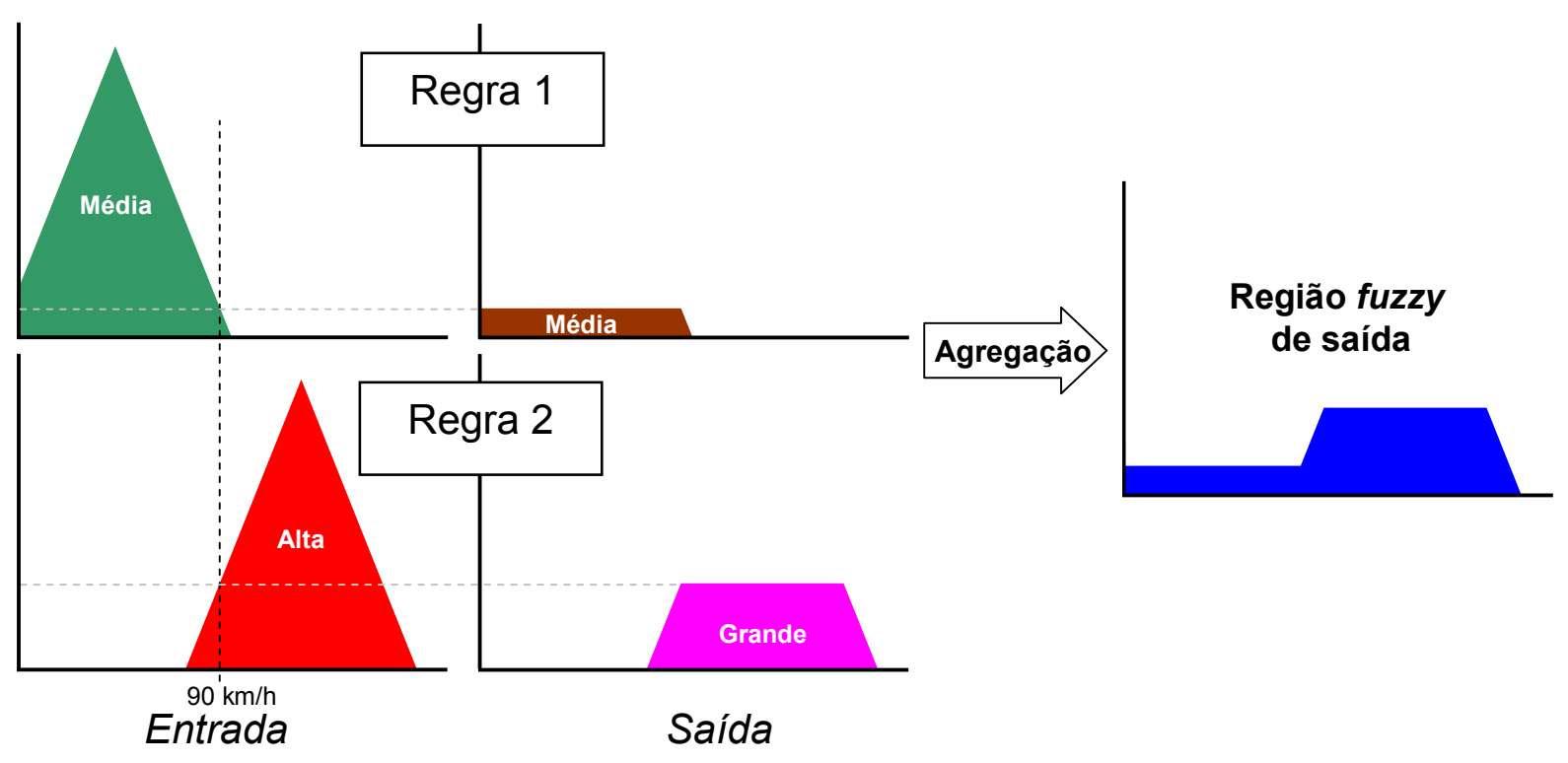

FIGURA 4.7 - Agregação de regras fuzzy.

Cada regra gera uma região de saída, que após a agregação, resultam em uma única região fuzzy de saída.

Essa região fuzzy de saída ainda não pode ser empregada em um sistema de controle. É necessário o processo de defuzzificação para se encontrar o valor de saída que representa a região fuzzy de saída. 


\subsubsection{Defuzzificação}

O processo de defuzzificação é responsável por atribuir à região fuzzy de saída um valor numérico "crisp" que represente quantitativamente o que o sistema fuzzy inferiu de forma qualitativa.

O valor real então obtido após o processo de defuzzificação pode ser utilizado no sistema de controle ou para propósitos de estimação.

Dentre os métodos existentes para o processo de defuzzificação se pode empregar o do centro de área, que consiste em encontrar a coordenada abscissa do centro de área da região fuzzy de saída, como pode ser contemplado na FIGURA 4.8.

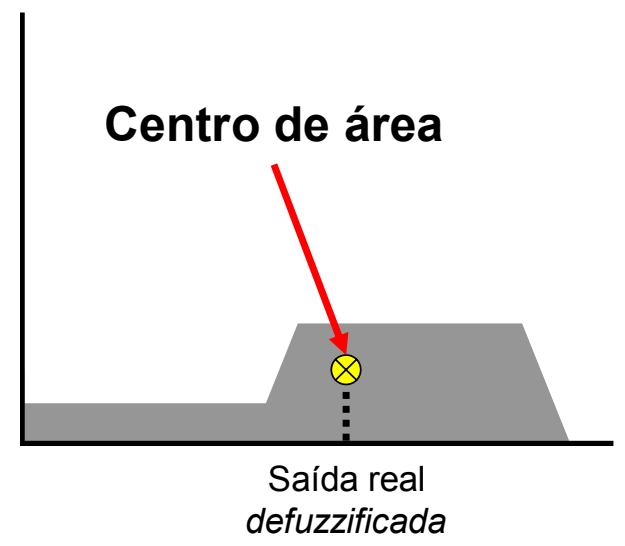

FIGURA 4.8 - Método de defuzzificação através do centro de área.

O método de defuzzificação através do centro de área permite se contabilizar de maneira proporcional as contribuições obtidas para a região fuzzy de saída. 


\subsection{Funcionalidades inteligentes agregadas ao relé regulador de tensão}

A agregação de funcionalidades inteligentes aos atuais relés reguladores de tensão visa sobretudo não alterar a estrutura já desenvolvida para tais dispositivos. Assim, não seria necessária a construção de um relé totalmente novo, mas apenas a implementação de módulos capazes de dar aos atuais relés características fuzzys inerentes aos sistemas inteligentes.

Isso significa que o relé regulador de tensão continuaria sendo o mecanismo responsável por tomar as decisões de comutações de tap. Tal medida permite explorar todas as suas funcionalidades disponíveis.

O sistema fuzzy implementado para este estudo atua na variável de referência de tensão do relé regulador. A cada intervalo de tempo previamente estabelecido, ou de acordo com a última resposta do módulo fuzzy, a tensão de referência do relé regulador de tensão é atualizada com a saída atual do módulo fuzzy. Na FIGURA 4.9 se tem uma ilustração do módulo inteligente fuzzy que será agregado ao relé regulador de tensão.

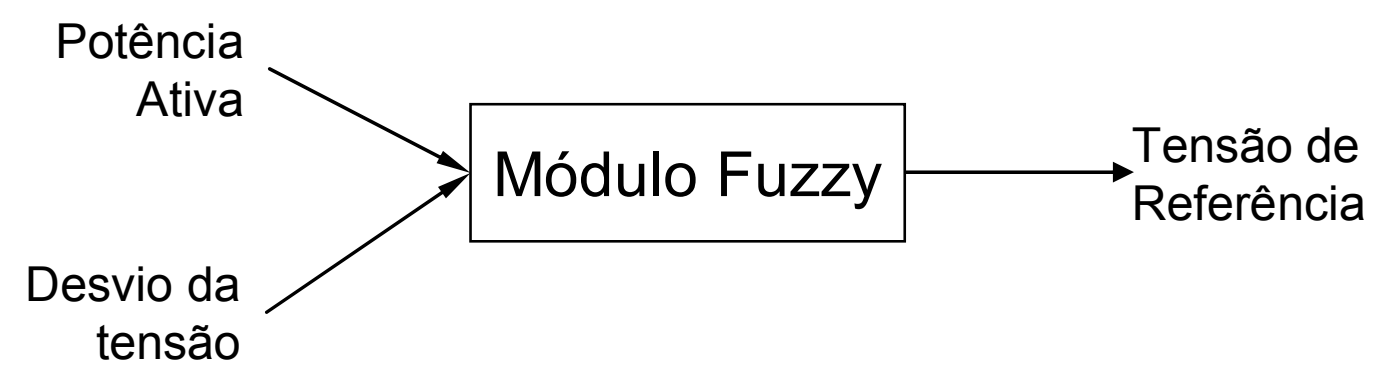

FIGURA 4.9 - Módulo inteligente agregado ao relé regulador de tensão. 
O módulo inteligente recebe do relé regulador de tensão as variáveis de potência ativa e desvio entre a tensão de referência e a tensão do barramento secundário da subestação. Essas variáveis são processadas pelo sistema fuzzy que infere em sua saída uma nova tensão de referência. Tal valor é apresentado ao relé regulador de tensão, que eventualmente toma a decisão de comutação do tap com base na atualização da tensão de referência.

\subsection{Características do módulo fuzzy desenvolvido}

A estratégia inteligente que será utilizada para o controle de relés reguladores de tensão propõe um sistema auxiliar de tomada de decisão a ser integrado aos relés já existentes.

Esse sistema tem como objetivo tornar dinâmico o ajuste da tensão de referência do AVR.

Nesse caso, o sistema fuzzy é empregado como um módulo inteligente auxiliar ao relé convencional, como pôde ser vislumbrado na FIGURA 4.9.

O relé com módulo inteligente irá monitorar o desvio da tensão e a carga (Potência Ativa). A saída do módulo fuzzy é um estímulo de incremento ou decremento sobre a referência atual do relé regulador de tensão. Desta forma, a inserção deste módulo inteligente em um relé convencional torna dinâmica sua tensão de referência.

A tensão de referência utilizada para o cálculo do desvio é um valor fixo (1 p.u.), não havendo realimentação entre este valor e a tensão de referência atual do relé regulador de tensão. Esta medida foi tomada para diminuir o número de comutações. 
Assim, o módulo inteligente irá incrementar / decrementar a tensão de referência de acordo com os limites da Resolução 505/2001 [1] e também de acordo com os objetivos do trabalho, de elevar a tensão média e racionalizar o número de comutações de tap.

Busca-se então a racionalização da utilização do tap do transformador se elevando a tensão em carga Pesada, por meio da incrementação da tensão de referência; e uma diminuição no número de comutações em carga mínima, não se alterando ou alterando-se pouco a tensão de referência. Ainda através do sistema fuzzy é possível evitar comutações prematuras, não se alterando a tensão de referência.

Conforme apresentado na FIGURA 4.9, as variáveis de entrada são processadas pelo módulo inteligente de forma que os resultados das saídas possam ser inferidos pelo mesmo. As entradas foram definidas como a potência ativa normalizada para valores entre 0.5 e 1.5 e o desvio da tensão dado em p.u. A normalização da potência ativa foi feita em relação a um valor médio, por meio de estudos baseados em dados históricos. Assim, para o funcionamento desta estratégia é necessário o ajuste deste valor de potência média, tendo por objetivo que o sistema fuzzy possa se adaptar a qualquer subestação. Este valor de ajuste pode ser parametrizado diretamente pelo usuário, ou poderá ser obtido através de um módulo que seja capaz de calcular a potência média, tendo base em dados históricos.

A outra entrada é o desvio da tensão em relação a uma tensão de referência, calculada como se segue:

$$
\text { Desvio }=V_{\text {medido }}-V_{\text {referencia }}
$$


Onde:

$V_{\text {medido }}$ é a magnitude da tensão de fase medida pelo TP.

$V_{\text {referência }}$ é a tensão de referência do sistema parametrizada pelo usuário.

$\mathrm{Na}$ FIGURA 4.8 se pode visualizar a topologia do Sistema Fuzzy desenvolvido.

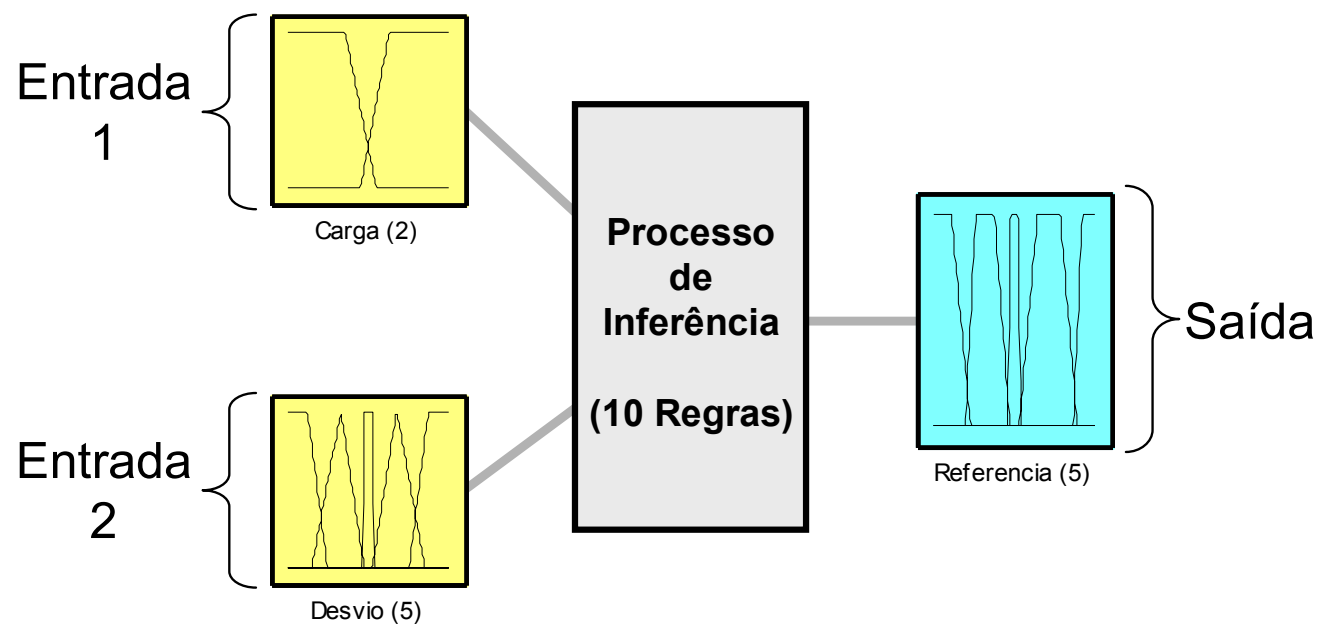

FIGURA 4.10 - Topologia do sistema fuzzy desenvolvido.

Como pode ser observado na FIGURA 4.10, as variáveis Carga (Potência Ativa) e Desvio entre a tensão medida e a referência fixa foram utilizadas como entradas do sistema fuzzy. A variável de Entrada 1 (Carga), foi representada em seu universo de discurso através de duas funções de pertinência como mostra a FIGURA 4.11. 


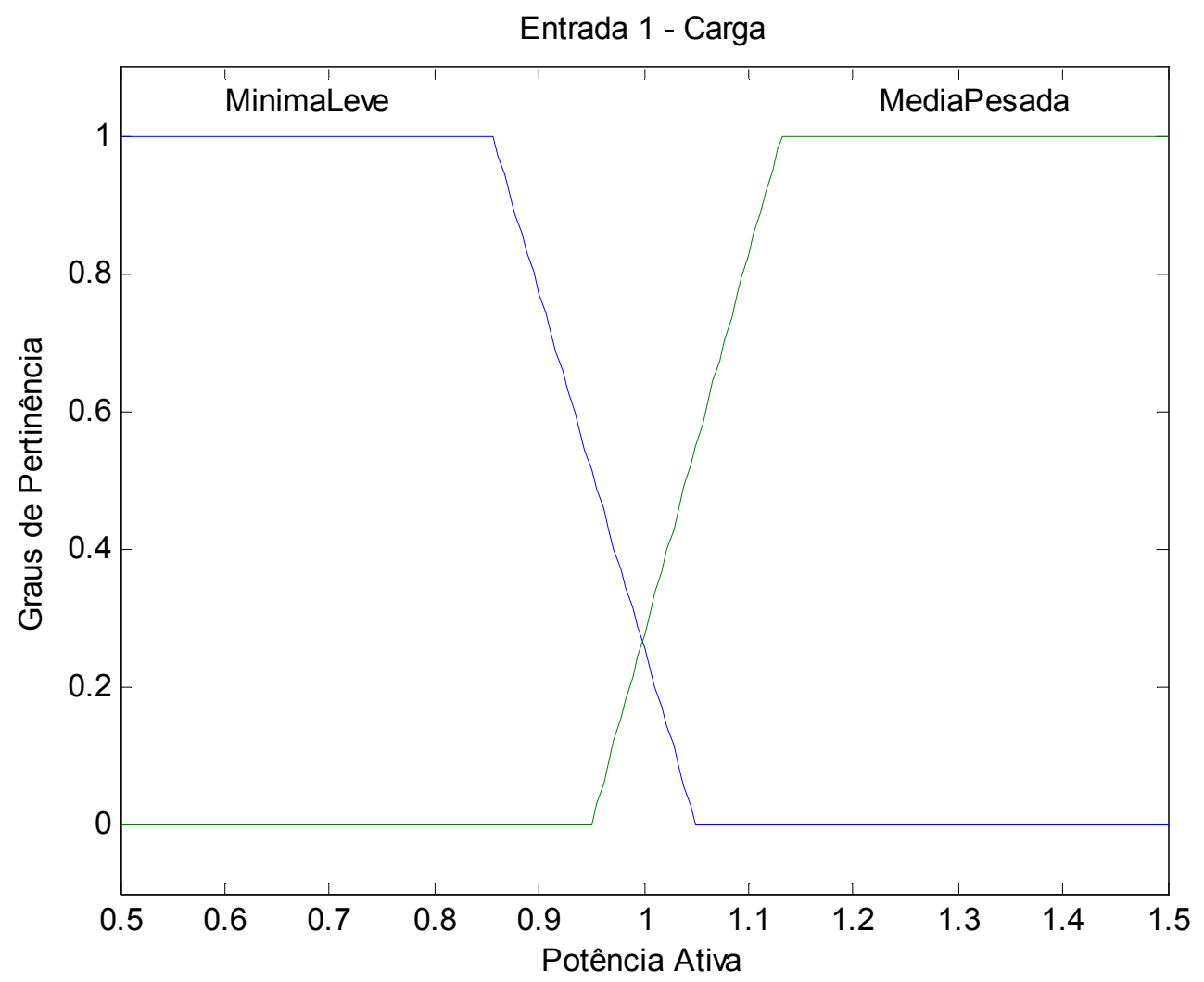

FIGURA 4.11 - Entrada 1 do sistema fuzzy desenvolvido.

Assim, a Entrada 1 (Carga), representada pela potência ativa, foi modelada com apenas duas funções de pertinência, pois deseja-se que o comportamento do sistema fuzzy consiga distinguir duas situações básicas: Em carga Mínima/Leve, deve-se preservar a comutação de tap; em carga Média/Pesada, deve-se manter a tensão mais elevada, sempre levando-se em consideração os limites impostos pela Resolução 505/2001 [1].

Pode-se observar na FIGURA 4.11 que todos os valores de potência vindos da medição são normalizados em torno de um valor médio.

Assim, quanto mais próximo da média histórica de carga da subestação estiver um valor de medição, mais próximo de 1 estará o valor normalizado. 
Uma grande região de indecisão entre as situações de carga Mínima/Leve e Média/Pesada foi implementada, FIGURA 4.11, pois dessa forma haverá maiores contribuições das regras ativas para a composição da saída.

Por conseguinte, a Entrada 2 (Desvio), indicando o desvio da tensão medida em relação à referência fixa, foi representada em todo o seu universo de discurso através de cinco funções de pertinência como mostra a FIGURA 4.12. Os termos utilizados para essa variável lingüística foram: "NegativoGrande”, "NegativoMedio", "Pequeno", "PositivoMedio" e "PositivoGrande".

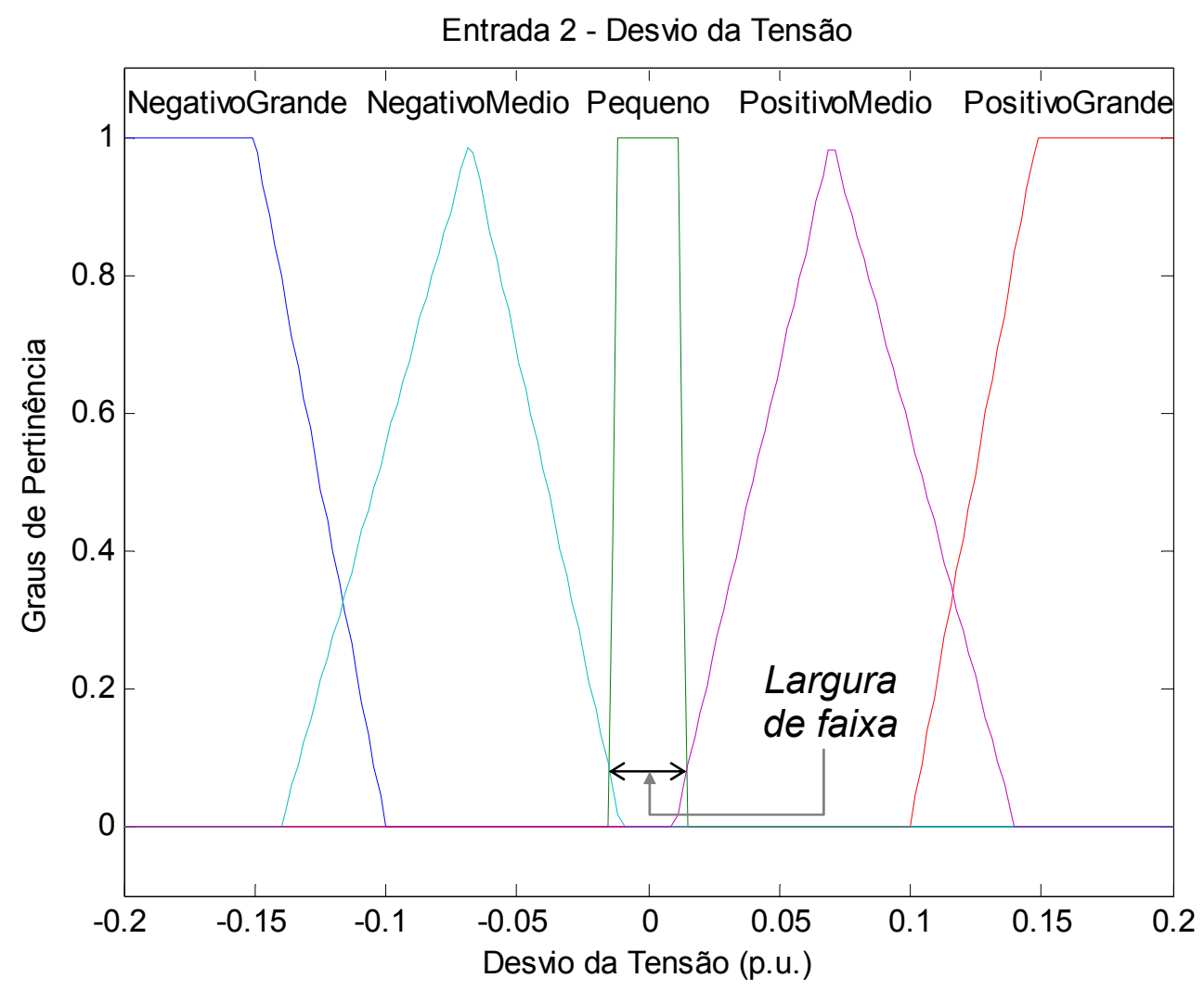

FIGURA 4.12 - Entrada 2 do sistema fuzzy desenvolvido.

A utilização de 5 funções de pertinência para essa entrada permite a utilização de uma combinação maior de regras para elevar a tensão em carga Pesada e diminuir a comutação em carga Mínima. 
A Largura de faixa de atuação do relé fuzzy é definida por meio dos pontos de cruzamento das funções de pertinência da entrada de Desvio de tensão. O ponto comum entre "Pequeno" e "PositivoMédio" indica o limite superior da faixa, enquanto que o ponto comum entre "NegativoMédio" e "Pequeno" indica o limite inferior da faixa.

É importante salientar que a largura de faixa varia de acordo com cada subestação e filosofia de controle de tensão empregada pela concessionária.

A variável lingüística de saída, ou seja, a variável Referência, foi mapeada por meio de cinco funções de pertinência: "INGde" (Incremento Negativo Grande), "INMed" (Incremento Negativo Médio), “Mantém", “IPMed” (Incremento Positivo Médio) e "IPGde" (Incremento Positivo Grande). A FIGURA 4.13 mostra as funções de pertinência da variável de saída do sistema fuzzy desenvolvido.

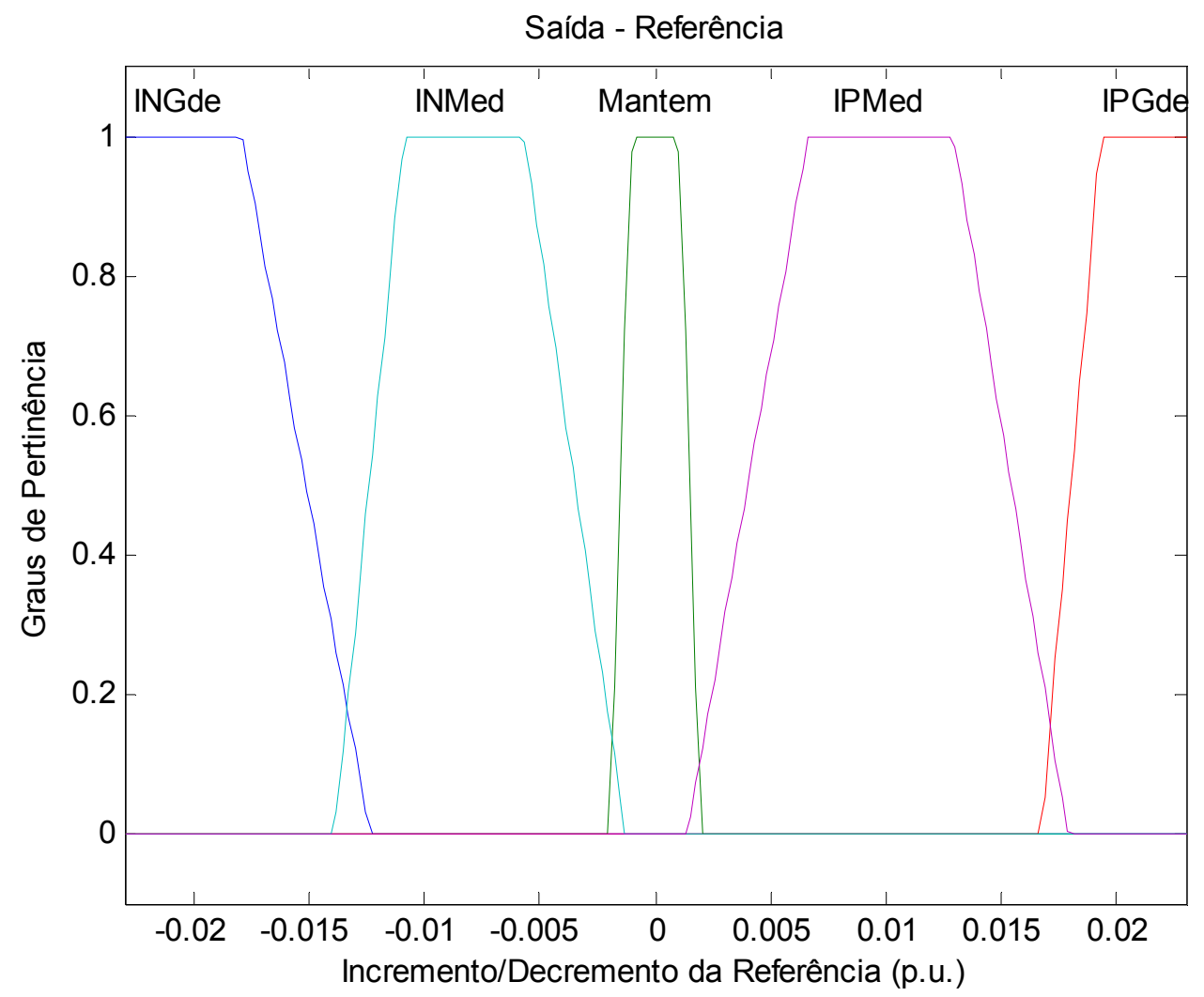

FIGURA 4.13 - Saída do sistema fuzzy desenvolvido. 
Nesta estratégia a saída do sistema fuzzy é um número real, que será enviado diretamente ao relé, visando alterar a tensão de referência. Quando o incremento estiver dentro da faixa "Mantém", a tensão de referência do relé não será alterada.

A base de conhecimento do sistema proposto se encontra armazenada em 10 regras fuzzy do tipo "Se-Então". A seguir encontram-se representadas estas regras fuzzy.

1 - "Se Carga é Mínima/Leve e Desvio é Negativo Grande então a Referência é IPGde" 2 - "Se Carga é Mínima/Leve e Desvio é Negativo Médio então a Referência é Mantém" 3 - "Se Carga é Mínima/Leve e Desvio é Pequeno então a Referência é Mantém" 4 - "Se Carga é Mínima/Leve e Desvio é Positivo Médio então a Referência é Mantém" 5 - "Se Carga é Mínima/Leve e Desvio é Positivo Grande então a Referência é INGde" 6 - "Se Carga é Média/Pesada e Desvio é Negativo Grande então a Referência é IPGde" 7 - "Se Carga é Média/Pesada e Desvio é Negativo Médio então a Referência é IPGde" 8 - "Se Carga é Média/Pesada e Desvio é Pequeno então a Referência é IPMed" 9 - "Se Carga é Média/Pesada e Desvio é Positivo Médio então a Referência é INMed" 10 - "Se Carga é Média/Pesada e Desvio é Positivo Grande então a Referência é INMed"

As regras de 2 à 4 são responsáveis pela redução de comutações em carga Mínima/Leve, não se alterando a tensão de referência. Já as regras 6 e 7 indicam que os incrementos positivos, ou seja, para elevar a tensão em carga pesada, serão sempre grandes; ao passo que os decrementos, regras 9 e 10, são sempre médios, mantendo assim a tensão mais elevada e dentro da largura de faixa operativa. As demais regras são utilizadas para manter a tensão de acordo com os níveis estabelecidos pela resolução 505/2001 e não realizar comutações prematuras. 
As regras podem ser mais bem sintetizadas através da TABELA 4.1.

TABELA 4.1 - Regras do sistema fuzzy desenvolvido.

\begin{tabular}{|c|c|c|c|c|c|}
\hline & \multicolumn{5}{|c|}{ Desvio da Tensão } \\
\hline $\begin{array}{c}\text { Carga } \\
\text { (Potência Ativa) }\end{array}$ & $\begin{array}{c}\text { Negativo } \\
\text { Grande }\end{array}$ & $\begin{array}{c}\text { Negativo } \\
\text { Médio }\end{array}$ & Pequeno & $\begin{array}{c}\text { Positivo } \\
\text { Médio }\end{array}$ & $\begin{array}{c}\text { Positivo } \\
\text { Grande }\end{array}$ \\
\hline Mínima/Leve & IPGde & Mantém & Mantém & Mantém & INGde \\
\hline Média/Pesada & IPGde & IPGde & IPMed & INMed & INMed \\
\hline
\end{tabular}

A superfície fuzzy que representa o relacionamento entre as entradas e a saída é apresentada na FIGURA 4.14.

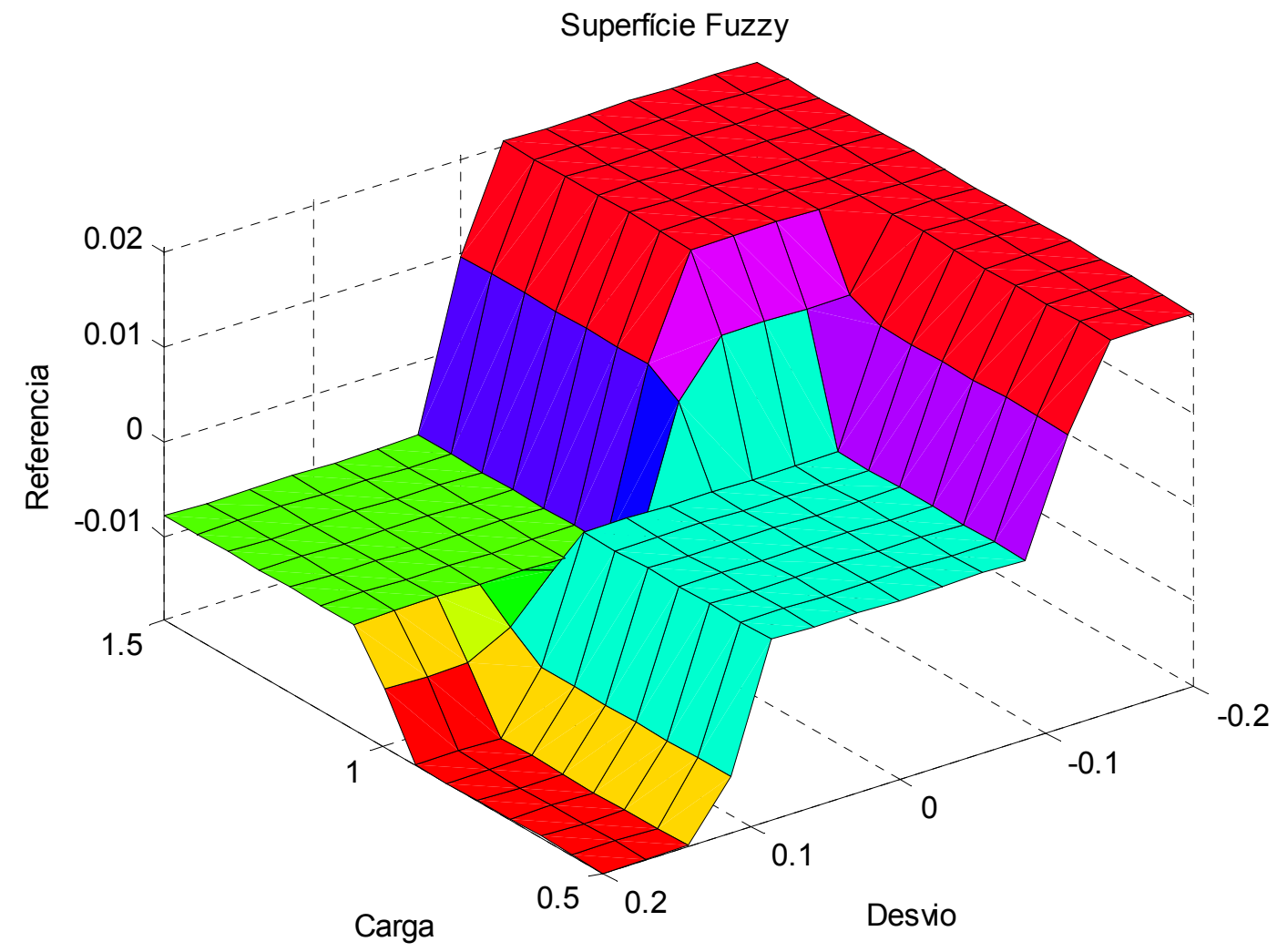

FIGURA 4.14 - Superfície de relacionamento entre entradas e saída do sistema fuzzy desenvolvido. 
Da superfície fuzzy é possível se constatar a complexidade presente no relacionamento entre as entradas e a saída e como o sistema fuzzy é capaz de tratar estas informações de maneira eficiente.

$\mathrm{Na}$ TABELA 4.2 se encontra registrado um resumo das principais características do sistema fuzzy desenvolvido.

TABELA 4.2 - Resumo das principais características do sistema fuzzy desenvolvido.

\begin{tabular}{|l|c|}
\hline \multicolumn{1}{|c|}{ Parâmetro } & Operador \\
\hline Tipo de sistema fuzzy & Não Paramétrico \\
\hline Método de composição "E” & MIN \\
\hline Método de Implicação & MANDANI (MIN) \\
\hline Método de Agregação & Máximo \\
\hline Defuzzificação & Centro de Área \\
\hline
\end{tabular}

\subsection{Relé regulador de tensão com módulo fuzzy}

Para o funcionamento do módulo inteligente incorporado ao relé regulador de tensão são necessárias poucas mudanças no fluxo de execuções apresentado na FIGURA 2.7. Primeiramente é necessário se expandir os blocos do fluxo de execuções do AVR responsáveis pela atualização dos registradores de tempo, para se evidenciar alguns detalhes da tomada de decisão. Estes blocos se situam dentro dos blocos de programa que verificam se a tensão encontra-se acima ou abaixo da faixa parametrizada pelo usuário, como apresentado na FIGURA 2.7.

Após verificar se a tensão se encontra acima, ou abaixo da faixa, o AVR incrementa o contador de tempo de $1^{\mathrm{a}}$ comutação, o chamado tempo morto do relé. 
Se após $n$ segundos a tensão não se normalizar, então é enviado ao LTC o comando para comutação. Na FIGURA 4.15 se encontra representado o bloco de software do AVR convencional responsável por verificar se a tensão encontra-se acima da faixa permitida.

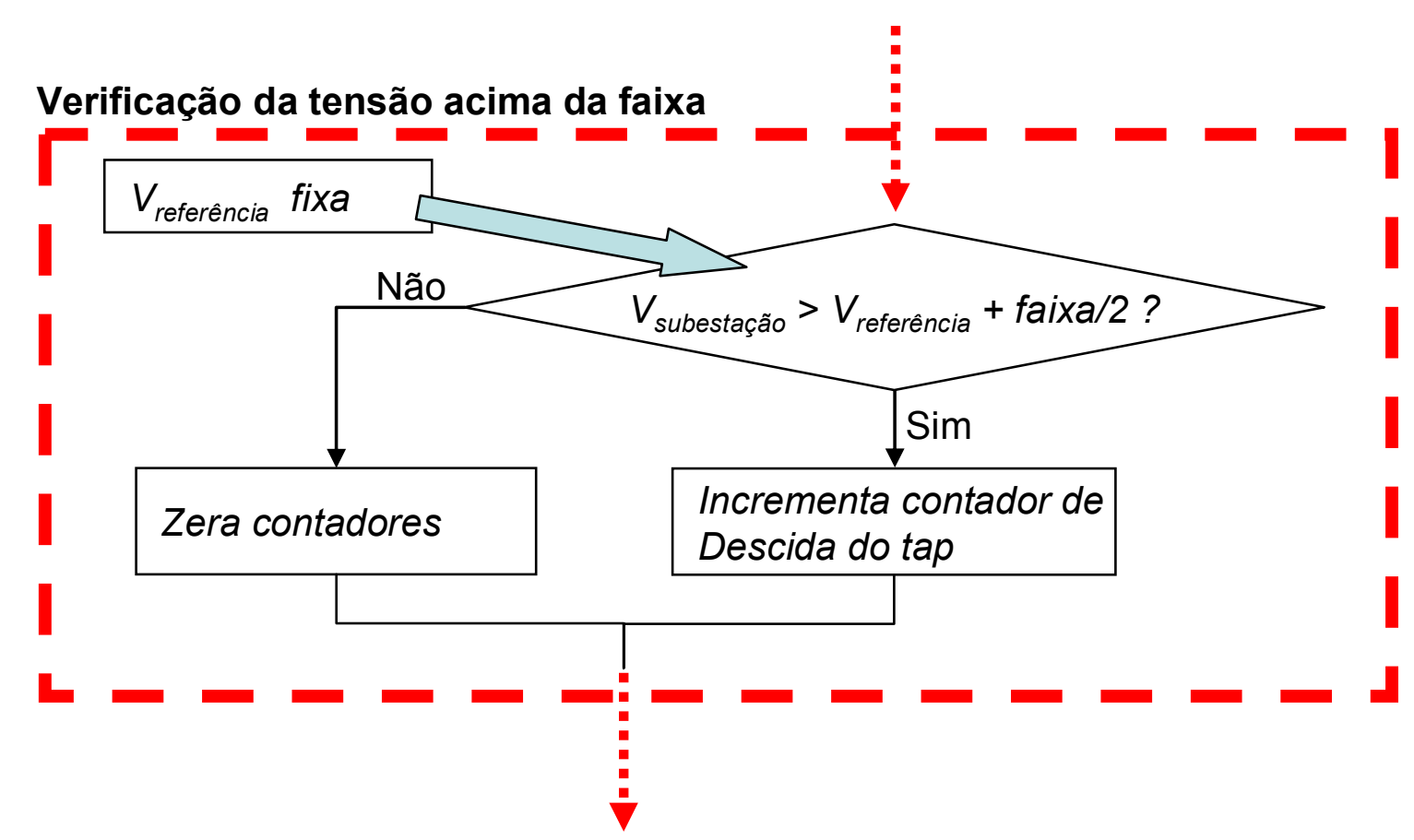

FIGURA 4.15 - Bloco de software que verifica se a tensão está acima da faixa para o AVR convencional.

Com os dados de medição da tensão o AVR convencional compara a tensão na subestação ( $\left.V_{\text {subestação }}\right)$ com a tensão máxima permitida, que é obtida através da soma da tensão de referência ( $\left.V_{\text {referência }}\right)$ com o desvio superior, representado pela metade da largura de faixa, ou seja, faixa/2.

Através desta figura fica evidenciado que as concessionárias adotam faixas de tensões simétricas e que também são mais estreitas que a especificada pela ANEEL. Tal prática visa garantir uma boa qualidade na energia elétrica.

A cada ciclo de verificação da tensão o AVR analisa a tensão da subestação e decide por incrementar ou zerar os contadores de tempo. Ao se incrementar o contador de descida, quando este atingir o limite parametrizado é enviado ao LTC o 
comando para comutação. Para averiguar se a tensão se encontra abaixo da faixa, apenas verifica-se se a tensão da subestação é menor que a tensão mínima permitida $\left(V_{\text {referência }}\right.$ - faixa/2), incrementando-se então o registrador para subir o tap.

Quando a tensão se normaliza, os dois registradores de tempo, tanto de subida quanto de descida, são então zerados.

A grande diferença do AVR convencional para o AVR com módulo fuzzy é o fato da tensão de referência não ser mais fixa, e sim dinâmica, de acordo com a saída do módulo fuzzy. Isto pode ser contemplado na FIGURA 4.16, que contém o bloco de software responsável por verificar se a tensão se encontrae acima da faixa, para o AVR com módulo fuzzy.

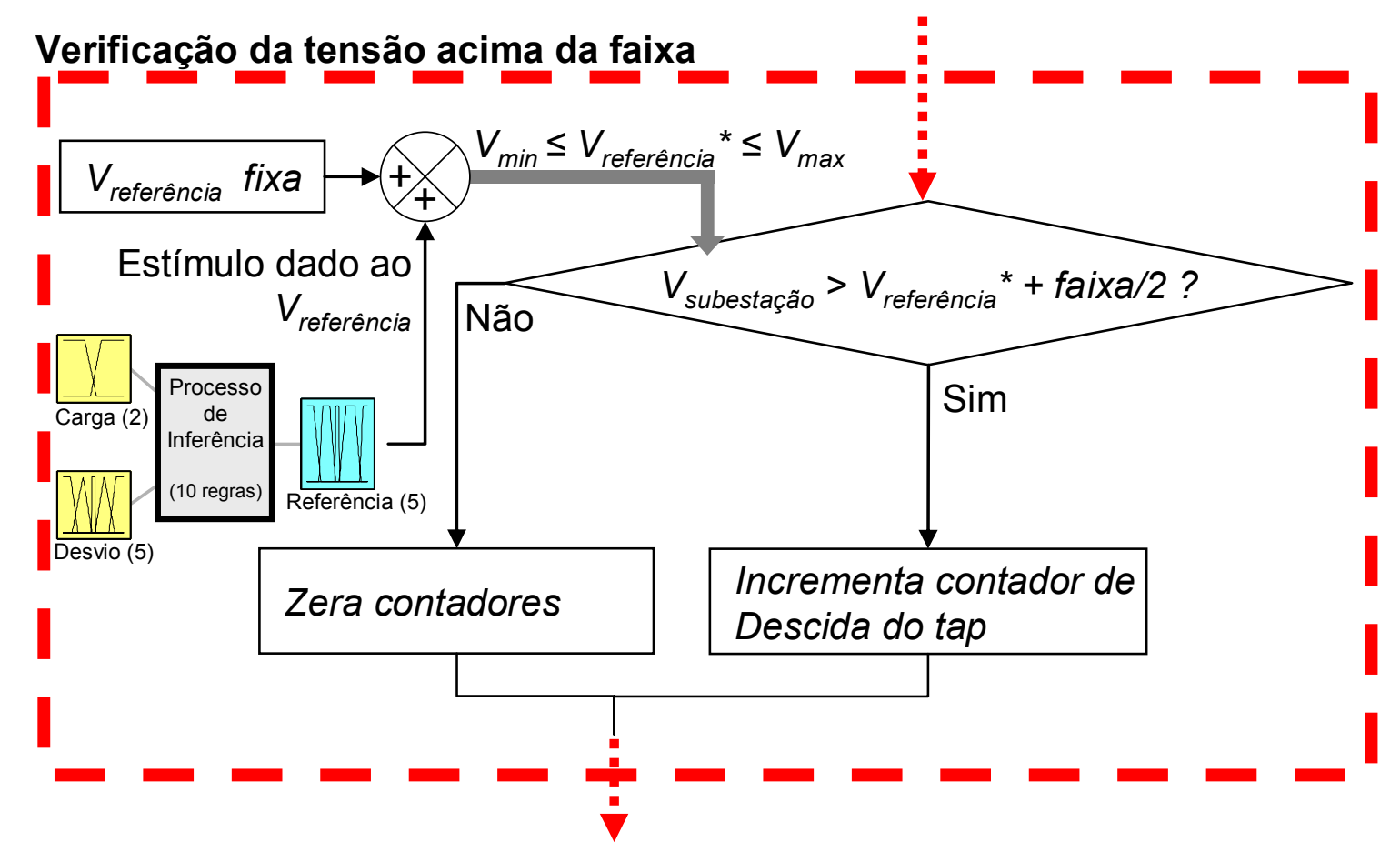

FIGURA 4.16 - Bloco de software que verifica se a tensão está acima da faixa para o AVR com módulo fuzzy.

Desta forma, $V_{\text {referência }}{ }^{*}$ varia de acordo com os estímulos fornecidos pelo sistema fuzzy à tensão de referência fixa, parametrizada pelo usuário. Há um pós- 
processamento aplicado em $V_{\text {referência }}{ }^{*}$ para limitar o valor mínimo $\left(V_{\min }\right)$ e máximo, $\left(V_{\max }\right)$, que a tensão de referência dinâmica pode atingir, respeitando-se os limites impostos pela faixa.

Os demais blocos de tomada de decisão do AVR permanecem sem nenhuma alteração, o que mostra que esta estratégia de controle de tensão é pouco invasiva em termos de modificações de software.

A taxa de atualização da tensão de referência, ou seja, a velocidade com que o módulo fuzzy fornece estímulos à tensão de referência fixa depende do módulo do estímulo fornecido. Quanto menores as sugestões de mudanças na tensão de referência, maior será o tempo em que esta permanecerá sem atualizações. Ao passo que para sugestões maiores de mudança, o tempo entre as atualizações será menor. 



\section{Resultados Computacionais}

Para estudar o comportamento do módulo inteligente agregado ao relé regulador de tensão se utilizou o software Matlab. Foram implementados um relé regulador de tensão com funcionalidades inteligentes e um relé regulador de tensão convencional. As simulações tiveram como base as curvas de carga ativa e reativa de subestações reais da ELEKTRO Eletricidade e Serviços S/A.

A partir destas curvas de cargas reais de subestações, realizou-se um fluxo de carga simplificado para determinar a tensão na subestação para cada valor de potência ativa e reativa fornecidos. Estes valores de tensão na subestação são então apresentados às simulações dos relés que realizam suas operações matemáticas para decidir sobre comutar ou não o tap. O fluxo de carga simplificado empregado nas simulações adota os seguintes passos para encontrar a tensão na subestação:

1. Recebe potência ativa $(P)$, reativa $(Q)$, tensão do primário $(V p)$, dados do transformador (trafo) e tap atual (Tap);

2. Por intermédio de $P$ e $Q$ calcule a potência aparente base do sistema (Sbase);

3. Com Sbase e Vp calcule a impedância base do sistema (Zbase);

4. Calcule a impedância da carga (Zload) através de P, Q e Sbase; 
5. De posse de todas as informações do sistema, incluindo Zload, calcule a tensão no secundário da subestação através de um processo interativo, que pára quando a precisão desejada é obtida.

Os novos valores de tensão obtidos das comutações de tap realimentam então o fluxo de carga simplificado, que passa conseqüentemente a conter dados dinâmicos de tensão.

A utilização do fluxo de carga simplificado foi necessária para se poder estimar a tensão na subestação e realizar uma simulação dinâmica bem eficiente, pois como deseja-se apenas atuar na subestação, a modelagem completa das subestações, incluindo todos os detalhes do alimentador, deixariam extremamente complexo o modelo de simulação.

Utilizando-se de dados reais de potência ativa e reativa em função do tempo, vistos pelo barramento secundário das subestações, foi então possível realizar simulações muito eficientes e extremamente rápidas.

\subsection{Informações relevantes para as simulações}

As curvas de carga das subestações são utilizadas para o cálculo do fluxo de carga simplificado, que determina a tensão na subestação de acordo com a potência ativa e reativa medidas. Este valor de tensão é então apresentado aos relés fuzzy e convencional, que tomam a decisão de comutar ou não o tap, visando manter a tensão em níveis operativos.

As subestações utilizadas para simulações foram Votuporanga 1 (Transformador 1 e 2) e Ubatuba 2 (Transformador 2). Estas subestações foram 
escolhidas devido à qualidade das informações fornecidas pela ELEKTRO em relação às curvas de carga, que compreendem um período total de 7 dias entre 19/06/2006 e 26/06/2006, com medições de potência ativa e reativa tomadas em intervalos de 10 minutos.

Para uma melhor caracterização da simulação das estratégias é necessário utilizar-se um intervalo de tempo menor. Uma reamostragem feita com intervalo de 10 segundos entre as medições foi realizada, utilizando-se o método numérico de interpolação linear para transformar as informações originais com intervalo de medição de 10 minutos em dados discretizados de 10 em 10 segundos. Após este processo, as informações de potência ativa e reativa podem então ser aplicadas nas simulações.

Também foram testadas simulações com passo de 1 segundo. No entanto os resultados obtidos foram os mesmos que aqueles com passo de 10 segundos, exceto pelo tempo de simulação que cresceu de maneira proibitiva para simulações de diversas subestações.

Deve-se destacar um aspecto importantíssimo em relação ao intervalo de tempo de medição. Ao se realizar o processo de reamostragem, indispensável para as simulações, a cada 1 ponto original fornecido pela ELEKTRO, são acrescentados 60 pontos (10 minutos, de 10 em 10 segundos) com comportamento linear.

Como conseqüência deste procedimento, espera-se um número de comutações menor que os registrados pelos dispositivos da concessionária, tanto para as simulações convencionais como para as inteligentes, uma vez que a reamostragem irá substituir o comportamento desconhecido para os 10 minutos entre cada ponto original por pontos espaçados linearmente e com intervalos de 10 segundos. 
Dessa forma, apesar dos números de comutações estarem distantes do número de comutações reais, as simulações convencionais e fuzzy encontram-se na mesma base de tempo e podem então ser comparadas em termos percentuais.

\subsection{Condições das simulações}

A estratégia inteligente desenvolvida utiliza sistemas fuzzy e para que o universo de discurso das funções de pertinência se ajuste de maneira adequada a todas as subestações simuladas, é necessária uma normalização dos dados, como já foi descrito anteriormente.

A entrada de potência ativa é normalizada em relação à potência ativa média associada à subestação, sendo que a entrada de desvio de tensão é normalizada em relação à tensão de referência utilizada para simulação. Na TABELA 5.1 encontram-se representadas as potências médias associadas a cada uma das subestações simuladas.

Nesta mesma tabela se encontra representado o número de comutações semanais médio, bem como o tempo estimado de manutenção dos comutadores de tap com base na comutação média e o limite máximo de comutações associado à cada subestação. A empresa ELEKTRO adota para seu processo de manutenção de comutadores 100 mil comutações ou 6 anos, o que ocorrer primeiro. 
TABELA 5.1 - Informações do transformador de cada subestação simulada.

\begin{tabular}{|l|c|c|c|c|c|}
\hline \multicolumn{1}{|c|}{ Subestação } & $\begin{array}{c}\text { Potência } \\
\text { Ativa } \\
\text { Média (MW) }\end{array}$ & $\begin{array}{c}\text { Número de } \\
\text { Taps no } \\
\text { Transformador }\end{array}$ & $\begin{array}{c}\text { Variação } \\
\text { Máxima de } \\
\text { Tensão (\%) }\end{array}$ & $\begin{array}{c}\text { Número de } \\
\text { Comutações } \\
\text { Semanais } \\
\text { Médio }\end{array}$ & $\begin{array}{c}\text { Estimativa } \\
\text { de } \\
\text { Manutenção } \\
\text { (anos) }\end{array}$ \\
\hline $\begin{array}{l}\text { Votuporanga 1 } \\
\text { (Transformador 1) }\end{array}$ & 9.716 & 21 & \pm 12.698 & 148 & 13.138 \\
\hline $\begin{array}{l}\text { Votuporanga 1 } \\
\text { (Transformador 2) }\end{array}$ & 10.586 & 21 & \pm 12.698 & 183 & 10.625 \\
\hline $\begin{array}{l}\text { Ubatuba 2 } \\
\text { (Transformador 2) }\end{array}$ & 1.781 & 33 & \pm 17.594 & 70 & 27.778 \\
\hline
\end{tabular}

Observa-se da TABELA 5.1 que a estimativa de manutenção dos comutadores de tap para todas as subestações de interesse ultrapassam os 6 anos. Isto significa que a manutenção nos comutadores será realizada no tempo mínimo de 6 anos, mesmo sem se ter atingido as 100 mil comutações a que o LTC foi projetado para suportar. Uma utilização mais eficiente do comutador, para que as 100 mil comutações fossem realizadas em um período de 6 anos seria obtida com 325 comutações semanais.

Desta forma, tem-se como limites para não alterar os cronogramas de manutenção dos LTCs a realização de 325 comutações por semana, em média.

As simulações envolvidas com a estratégia inteligente e a convencional foram realizadas para um período de 7 dias, com todas as subestações mostradas na TABELA 5.1. Observa-se uma grande diferença no carregamento entre as subestações de Votuporanga 1 e Ubatuba 2. Isso se deve ao fato de Ubatuba 2 se encontrar no litoral e estar sujeita a cargas mais elevadas nos períodos de férias. Já Votuporanga 1 possui uma característica rural e urbana, sem interferências sazonais, por isso sua carga média encontra-se em torno de $10 \mathrm{MW}$.

A variação máxima da tensão permitida para as subestações se refere a uma tensão de $13.8 \mathrm{kV}$. 
A tensão de referência adotada para as simulações foi de $14.1 \mathrm{kV}$, com largura de faixa de $340 \mathrm{~V}$ e temporização de comutação de 90 segundos. É importante salientar que estes valores foram ajustados de acordo com informações da própria concessionária de energia, que realiza diversos estudos sobre as cargas conectadas aos alimentadores.

Desta forma, mesmo que a tensão fique muito próxima do limite superior da faixa $(14270 \mathrm{~V})$, os consumidores mais próximos não estarão sujeitos a tensões críticas superiores. O mesmo se observa para o limite inferior (13930 V).

Portanto a tensão de referência e a faixa especificada pela empresa representam valores seguros de operação, evitando submeter os consumidores a tensões fora de níveis operativos.

\subsection{Resultados computacionais das simulações}

Nas seções que se seguem serão apresentados os principais resultados computacionais envolvidos com as simulações das subestações.

\subsubsection{Subestação Votuporanga 1 (transformador 1)}

Na FIGURA 5.1 se encontra registrado o histórico de comutações de tap para a subestação Votuporanga 1 (transformador 1). 

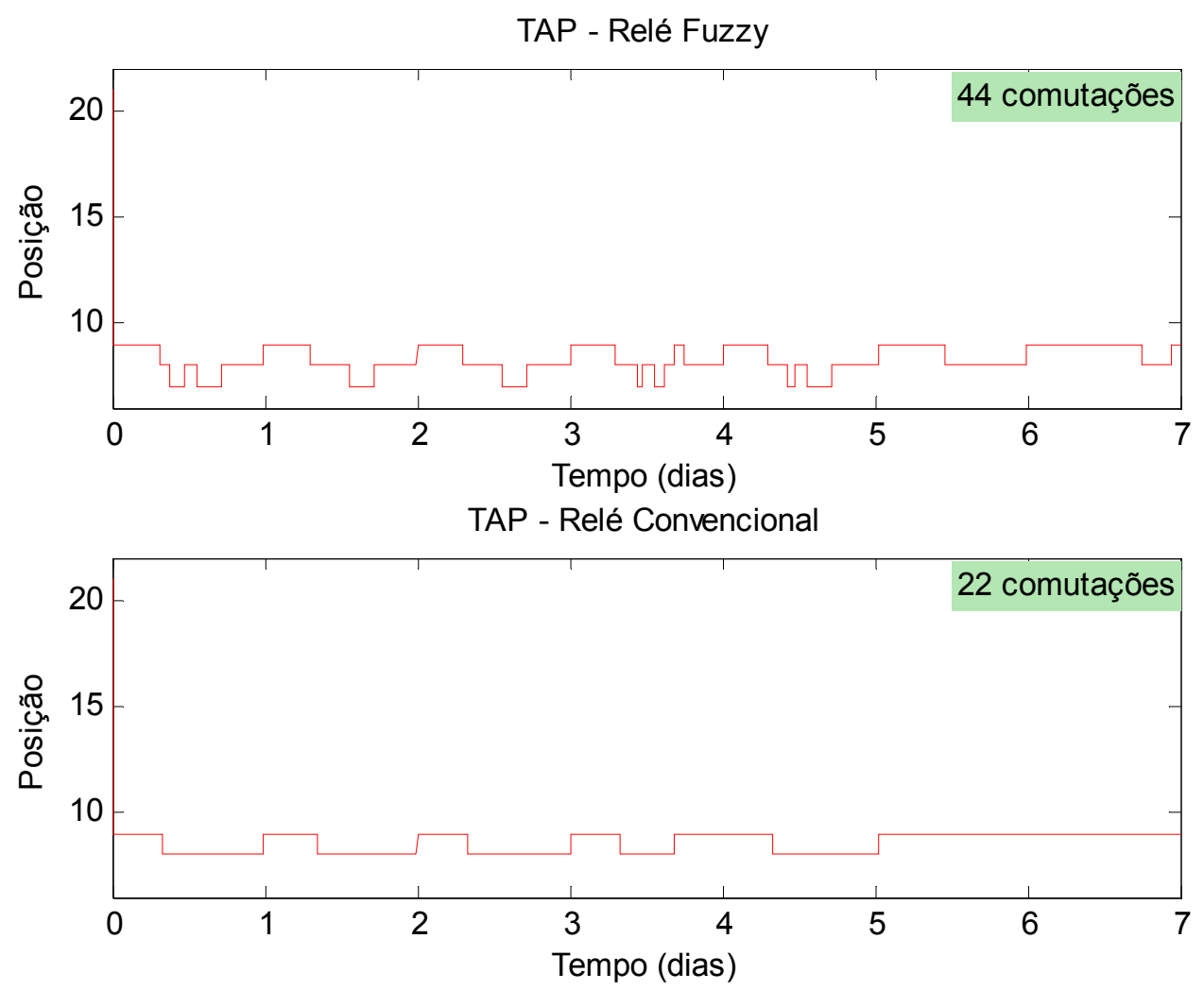

FIGURA 5.1 - Histórico de comutações de tap para Votuporanga 1 (transformador 1).

A partir da FIGURA 5.1, pode-se contemplar que o relé com módulo fuzzy, denominado Relé Fuzzy, realizou o dobro de comutações que o relé convencional. Isto ocorre porque a chamada zona morta de atuação, de $340 \mathrm{~V}$, não existe para o relé fuzzy. O módulo fuzzy sugere alterações na referência para manter a tensão mais elevada em carga pesada, ao passo que sugere poucas alterações em carga leve visando economizar comutações. Desta maneira, espera-se um número de comutações maior para o relé com módulo fuzzy.

Os ganhos efetivos desta estratégia podem ser comprovados através da FIGURA 5.2. 

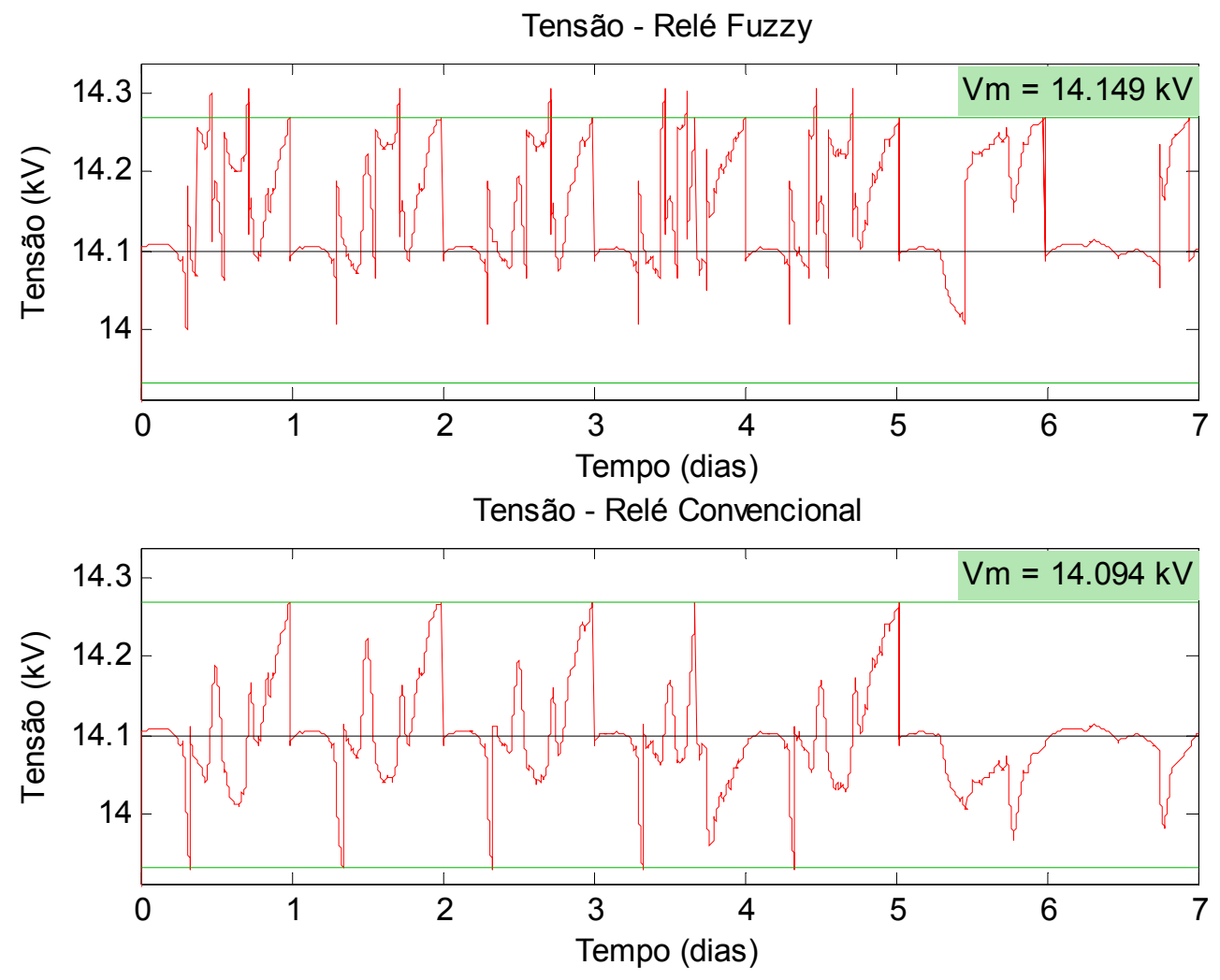

FIGURA 5.2 - Perfis de tensão para Votuporanga 1 (transformador 1).

Encontra-se registrado também na FIGURA 5.2 as tensões médias $(\mathrm{Vm})$ para a subestação Votuporanga 1 (transformador 1), tanto para o relé convencional como para o fuzzy.

Visualmente é possível se comprovar que o relé com módulo fuzzy manteve a tensão mais elevada, se comparado ao convencional. A tensão média dos 7 dias de simulação foi de 14.149 kV para a estratégia fuzzy, contra 14.094 kV da estratégia convencional tendo então, um ganho de $55 \mathrm{~V}$ de tensão média.

A filosofia da estratégia com módulo fuzzy não utiliza uma faixa fixa, mas sim dinâmica, isto porque a referência é dinâmica. Desta forma, uma verificação de tensão fora da faixa só pode ser realizada através do gráfico dinâmico da referência, conforme apresentado na FIGURA 5.3. 


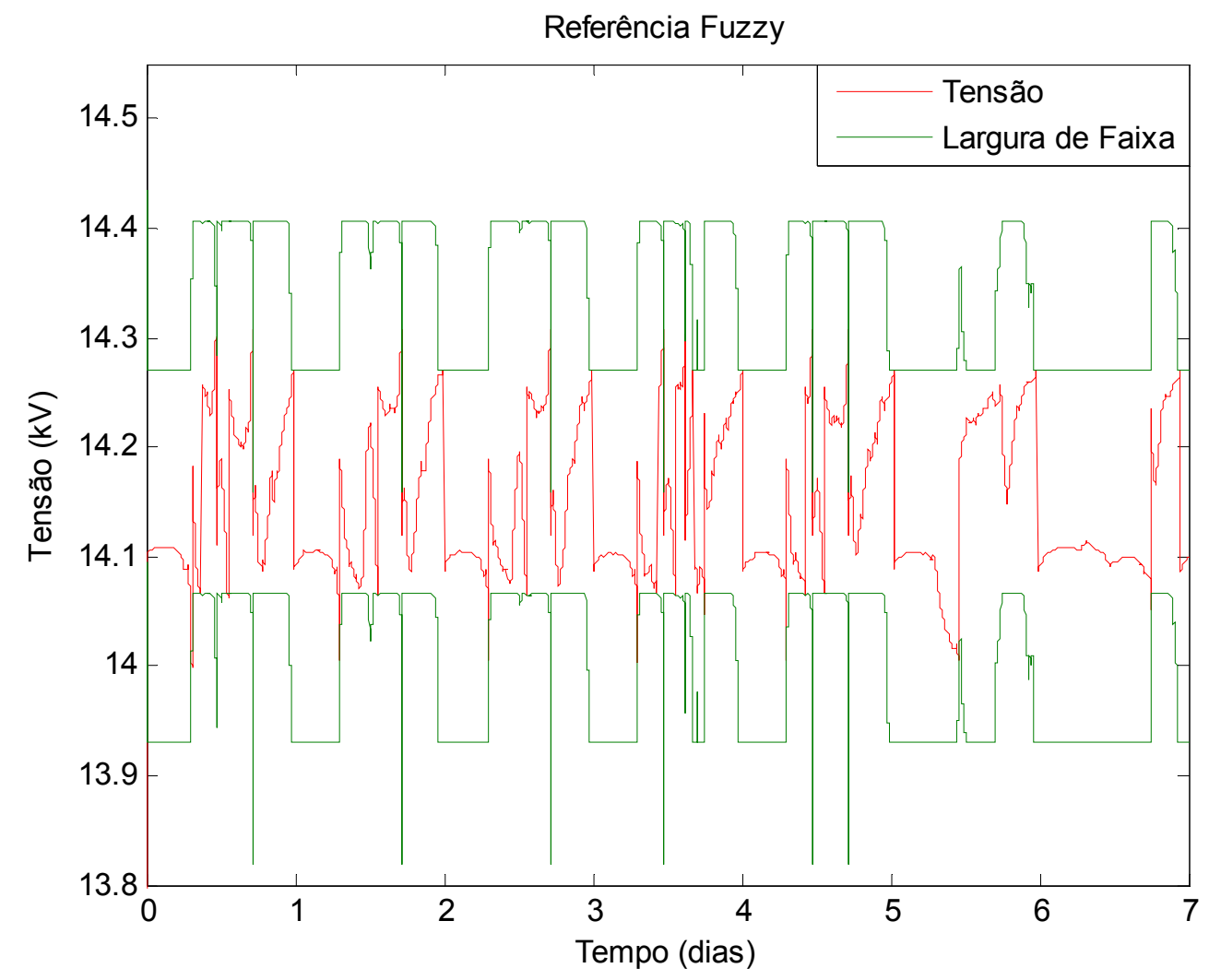

FIGURA 5.3 - Referência fuzzy para Votuporanga 1 (transformador 1).

Pode-se comprovar através da FIGURA 5.3 que a tensão não sai fora da faixa em nenhum momento. Isto porque com a referência fuzzy, para evitar comutações prematuras, a faixa dinâmica acompanha a evolução da carga pesada e da carga leve.

Na FIGURA 5.4 se encontra registrado o perfil de tensão para o relé fuzzy, juntamente com a curva de carga ativa de Votuporanga 1 (transformador 1). 


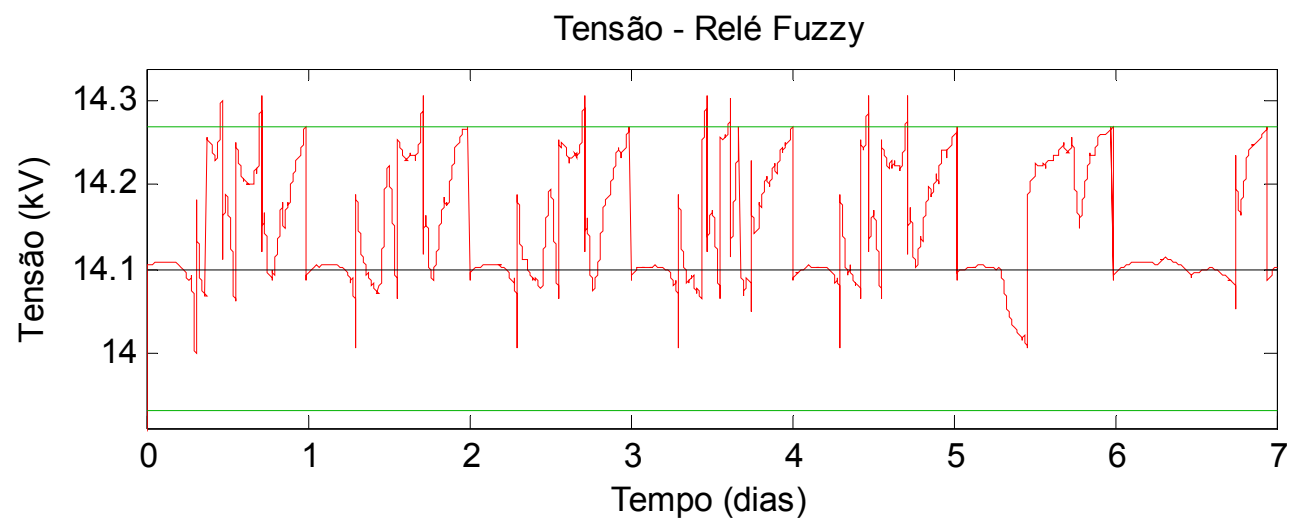

Potência Ativa - Relé Convencional

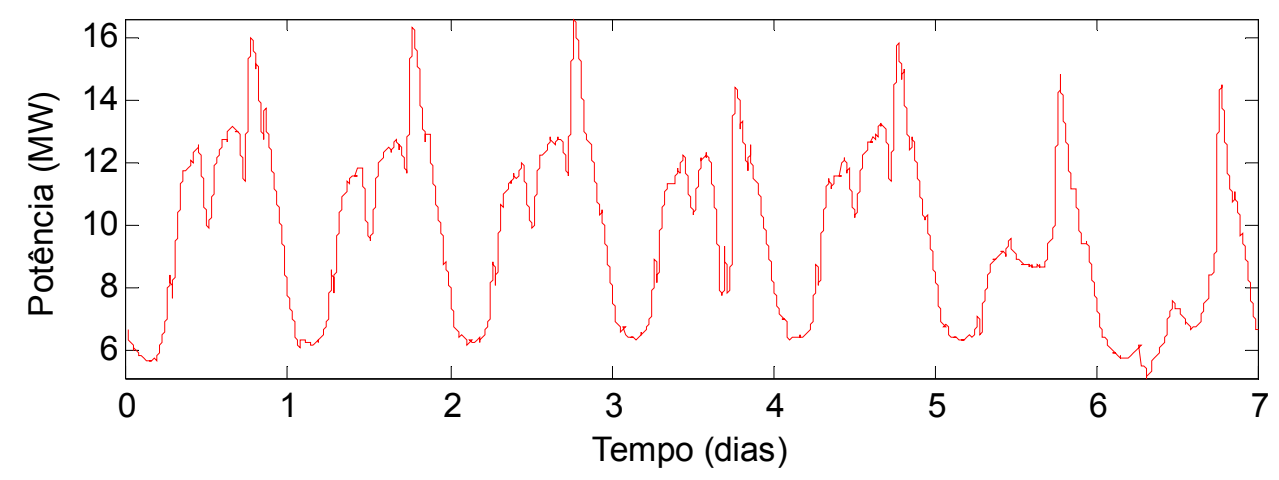

FIGURA 5.4 - Perfil de tensão em carga pesada para Votuporanga 1 (transformador 1).

Através da estratégia com módulo fuzzy, todos os trechos de carga pesada tiveram a tensão acima da tensão de referência, como pode ser comprovado através da FIGURA 5.4.

O relé com módulo fuzzy também foi capaz de manter a tensão, na maior parte do tempo, na principal faixa de interesse de atuação: entre 14.1 kV e 14.27 kV, como pode ser contemplado na FIGURA 5.5. 


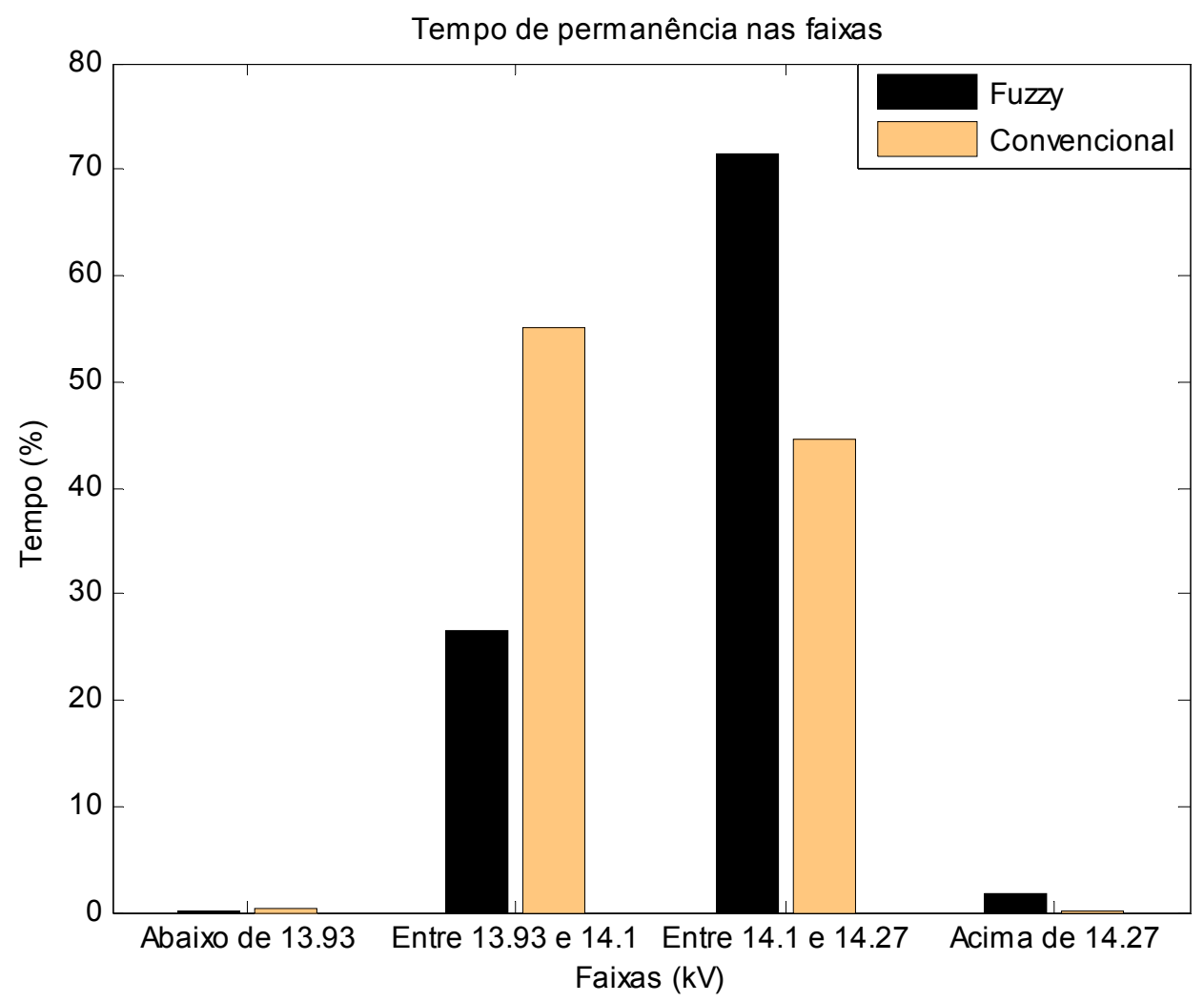

FIGURA 5.5 - Tempo de permanência nas faixas para Votuporanga 1 (transformador 1).

Analisando-se a tensão média em carga pesada o relé fuzzy também teve um excelente desempenho, principalmente na faixa de potência ativa compreendida por 12.2 MW e 13.7 MW, onde a tensão média para a estratégia fuzzy foi $75 \mathrm{~V}$ mais elevada que a convencional. Estas informações podem ser comprovadas na FIGURA 5.6. 


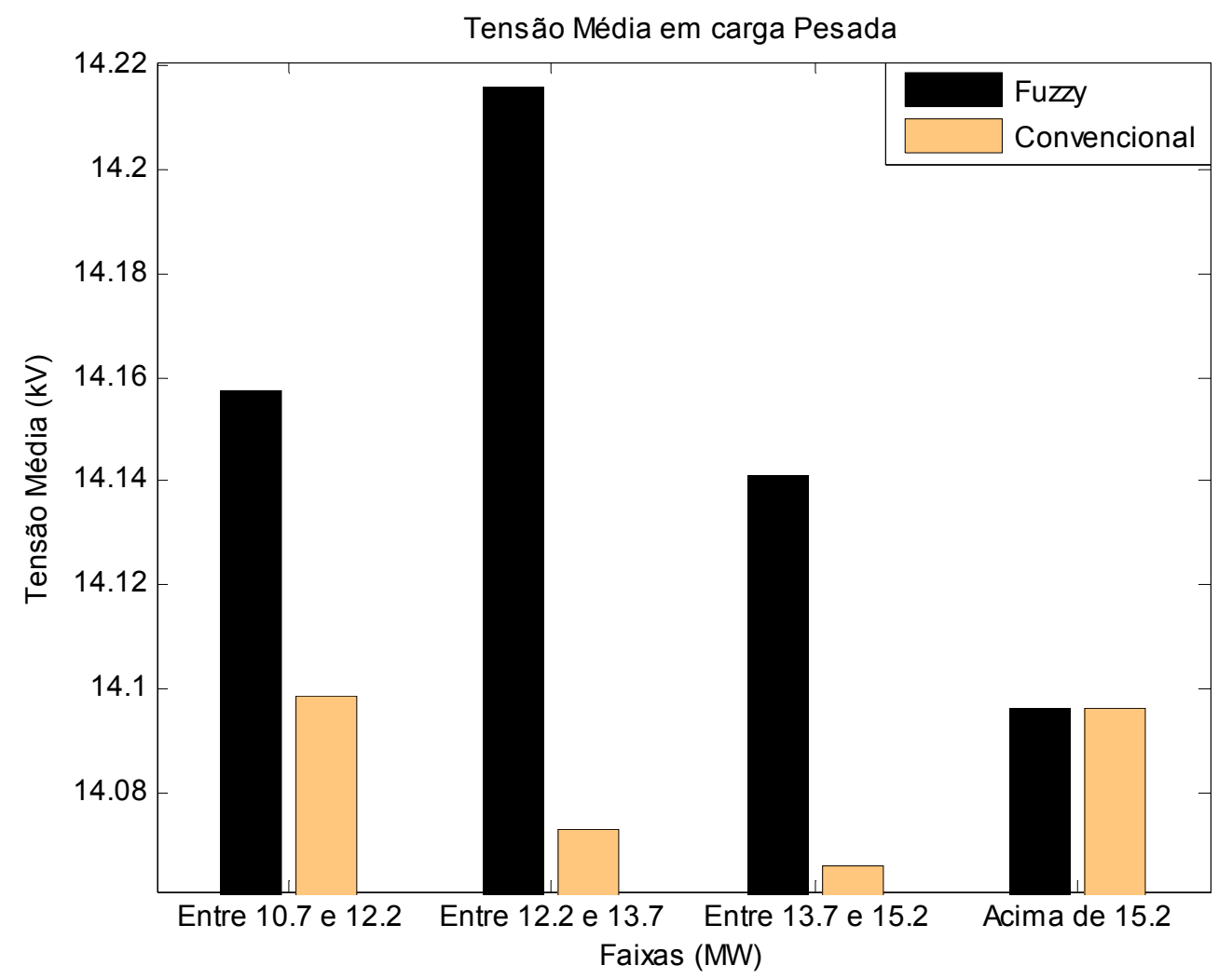

FIGURA 5.6 - Tensão média em carga pesada para Votuporanga 1 (transformador 1).

Na TABELA 5.2 encontram-se os principais resultados de simulação obtidos para Votuporanga 1 (transformador 1). Os resultados de comutações de tap foram convertidos para a base de tempo representada na TABELA 5.1, onde o tap comuta em média 148 vezes por semana.

TABELA 5.2 - Resumo dos resultados computacionais obtidos para Votuporanga 1 (transformador 1).

\begin{tabular}{|l|c|c|}
\hline \multicolumn{1}{|c|}{ Parâmetros de Regulação } & $\begin{array}{c}\text { Resultados } \\
\text { Fuzzy }\end{array}$ & $\begin{array}{c}\text { Resultados } \\
\text { Convencional }\end{array}$ \\
\hline Tensão Média (kV) & 14.149 & 14.094 \\
\hline Tempo em Tensão Crítica Superior (\%) & 0.000 & 0.000 \\
\hline Tempo em Tensão Crítica Inferior (\%) & 0.059 & 0.059 \\
\hline Tempo em Tensão Precária (\%) & 0.044 & 0.044 \\
\hline Comutações de tap obtidas em simulação & 44 & 22 \\
\hline $\begin{array}{l}\text { Comutações de tap convertidas para a base } \\
\text { de 148 comutações por semana }\end{array}$ & 296 & 148 \\
\hline
\end{tabular}


Na TABELA 5.2 é possível se observar a diferença na tensão média da subestação e no número de comutações de tap. Os tempos em tensão precária e crítica são calculados com base na tensão de referência. Para fins de fiscalização, estas medidas são feitas nos consumidores, portanto, analisar tais tempos na subestação apenas fornecem um parâmetro de comparação para desempenho das estratégias.

Mesmo que a estratégia com módulo fuzzy tenha obtido o dobro de comutações que a convencional, ainda não é ultrapassado o limite de 325 comutações por semana conforme foi citado anteriormente.

Desta forma, pode-se comprovar que os ganhos obtidos com tensão são acompanhados de um uso mais racional do tap, tanto em carga pesada quanto em carga leve.

\subsubsection{Subestação Votuporanga 1 (transformador 2)}

Na FIGURA 5.7 se encontra registrado o histórico de comutações de tap para a subestação Votuporanga 1 (transformador 2). 


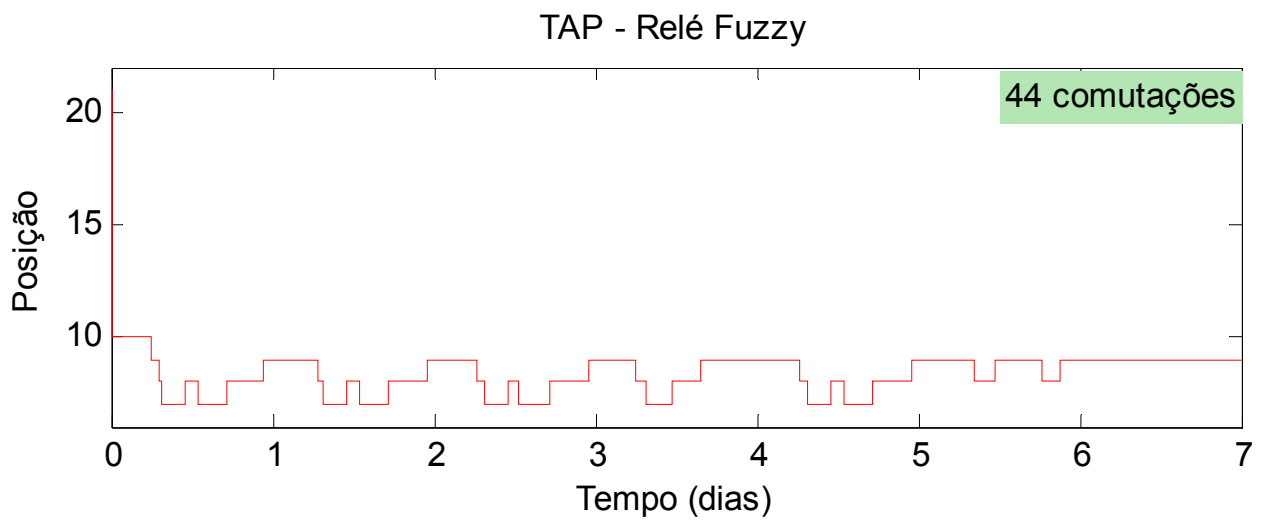

TAP - Relé Convencional

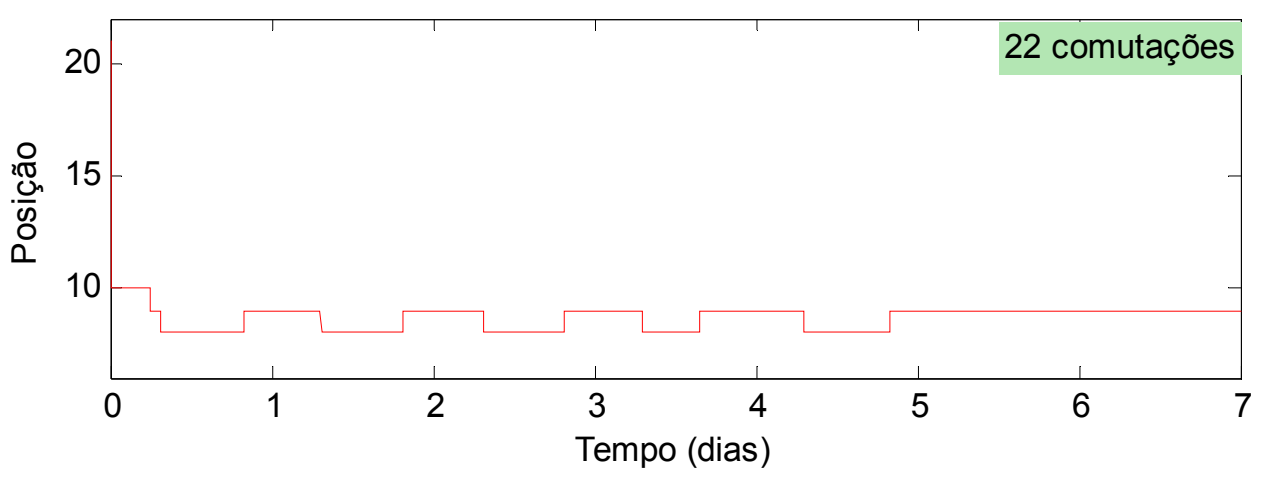

FIGURA 5.7 - Histórico de comutações de tap para Votuporanga 1 (transformador 2).

A partir da FIGURA 5.7, pode-se contemplar que o relé com módulo fuzzy, denominado Relé Fuzzy, também realizou o dobro de comutações que o relé convencional. Isto ocorre porque a chamada zona morta de atuação, de $340 \mathrm{~V}$, não existe para o relé fuzzy. O módulo fuzzy sugere alterações na referência para manter a tensão mais elevada em carga pesada, ao passo que sugere poucas alterações em carga leve, visando economizar comutações. Desta maneira, espera-se um número de comutações maior para o relé com módulo fuzzy.

Os ganhos efetivos desta estratégia podem ser comprovados através da FIGURA 5.8. 

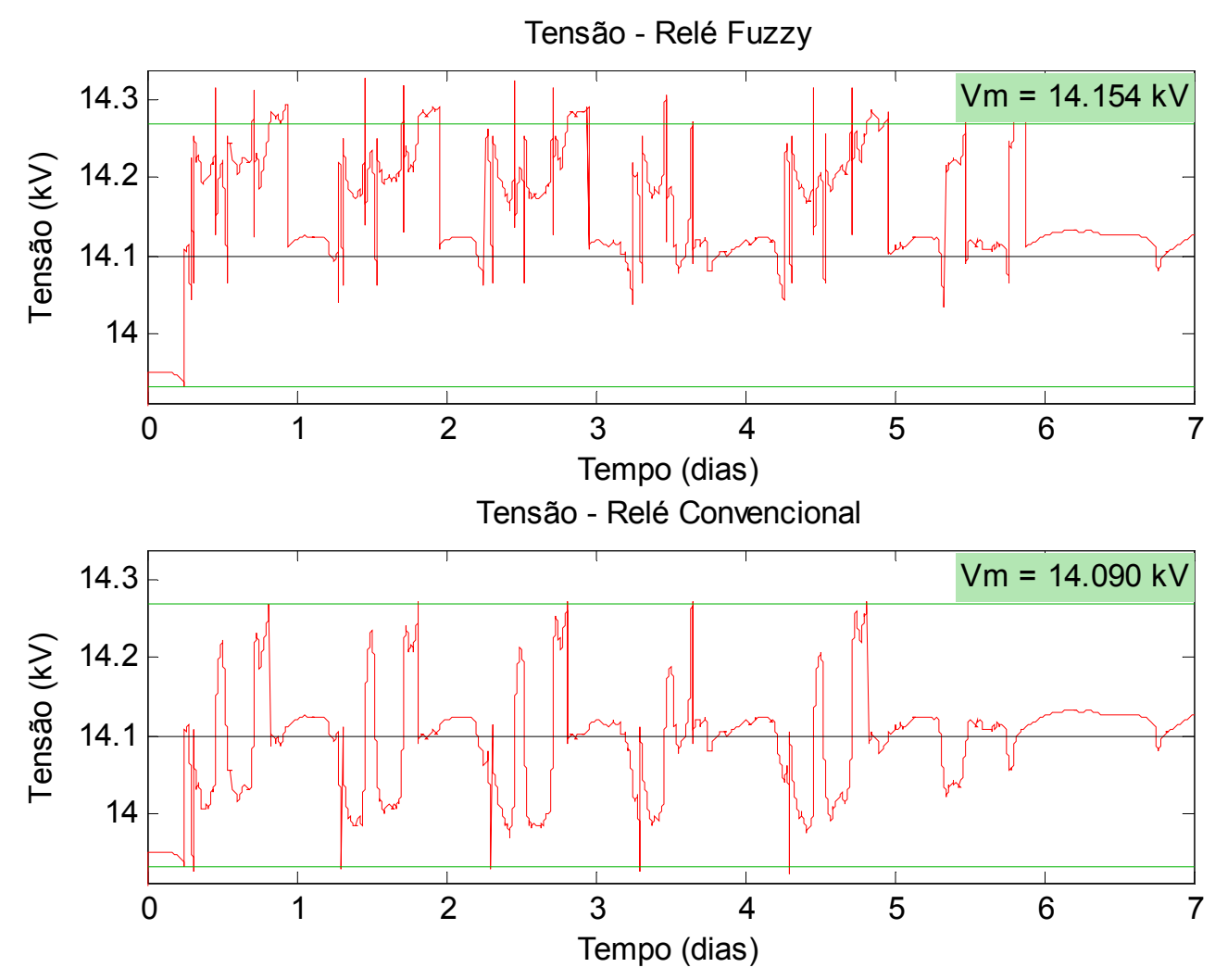

FIGURA 5.8 - Perfis de tensão para Votuporanga 1 (transformador 2).

Encontra-se registrado também na FIGURA 5.8 as tensões médias $(\mathrm{Vm})$ para a subestação Votuporanga 1 (transformador 2), tanto para o relé convencional como para o fuzzy.

Visualmente é possível se comprovar que o relé com módulo fuzzy manteve a tensão mais elevada, se comparado ao convencional. A tensão média dos 7 dias de simulação foi de $14.154 \mathrm{kV}$ para a estratégia fuzzy, contra $14.090 \mathrm{kV}$ da estratégia convencional, tendo então um ganho de $64 \mathrm{~V}$ de tensão média.

A filosofia da estratégia com módulo fuzzy não utiliza uma faixa fixa, mas sim dinâmica, isto porque a referência é dinâmica. Desta forma, uma verificação de tensão fora da faixa só pode ser realizada através do gráfico dinâmico da referência, conforme apresentado na FIGURA 5.9. 


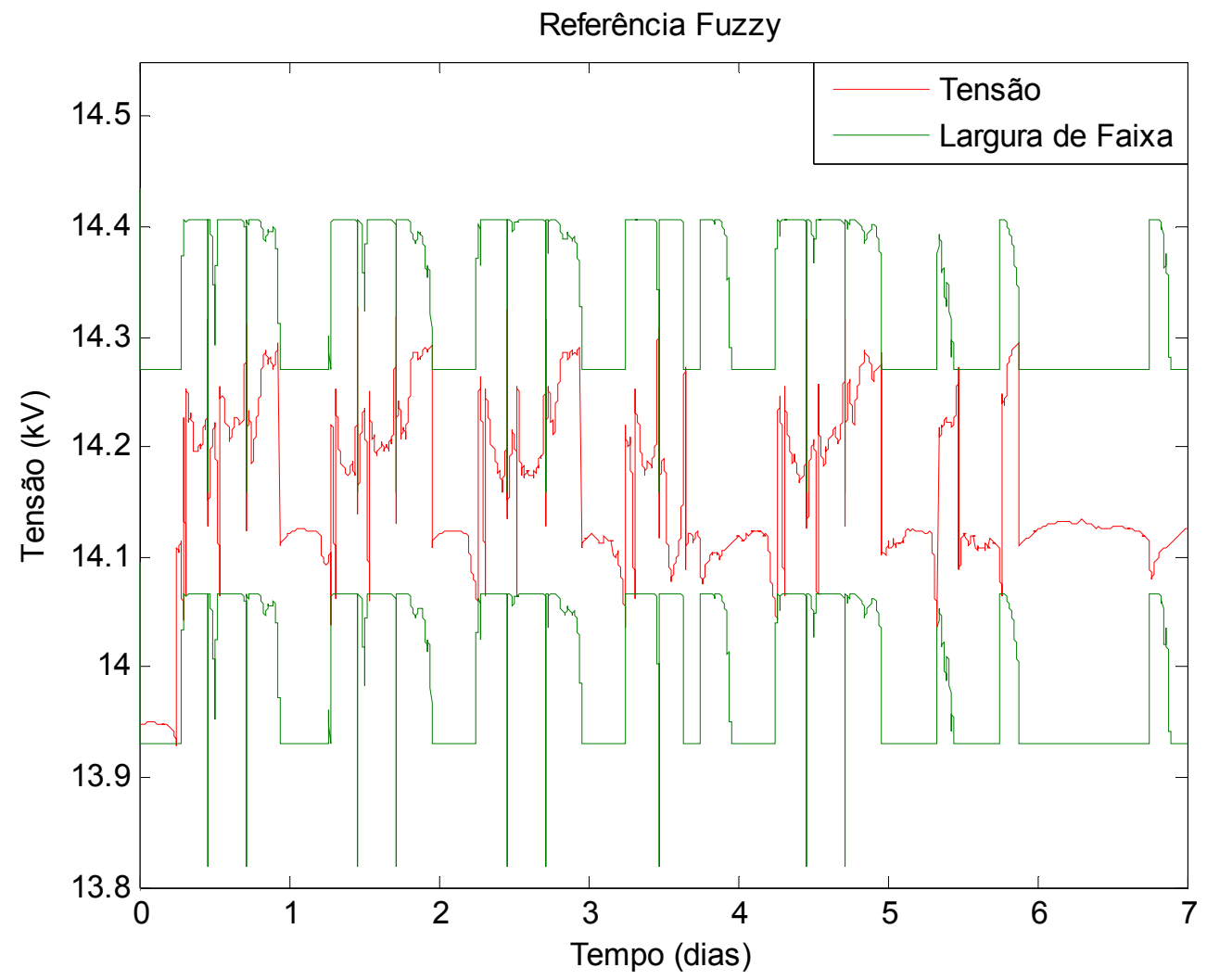

FIGURA 5.9 - Referência fuzzy para Votuporanga 1 (transformador 2).

Pode-se comprovar através da FIGURA 5.9 que a tensão não sai fora da faixa em nenhum momento. Isto porque com a referência fuzzy, para evitar comutações prematuras, a faixa dinâmica acompanha a evolução da carga pesada e da carga leve.

Na FIGURA 5.10 se encontra registrado o perfil de tensão para o relé fuzzy, juntamente com a curva de carga ativa de Votuporanga 1 (transformador 2). 


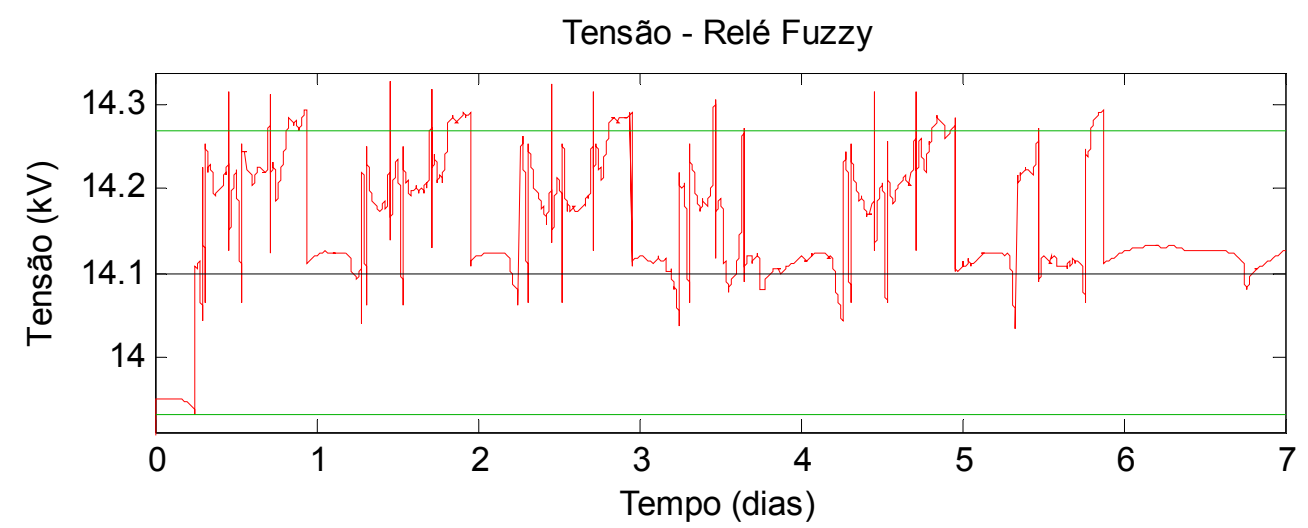

Potência Ativa - Relé Convencional

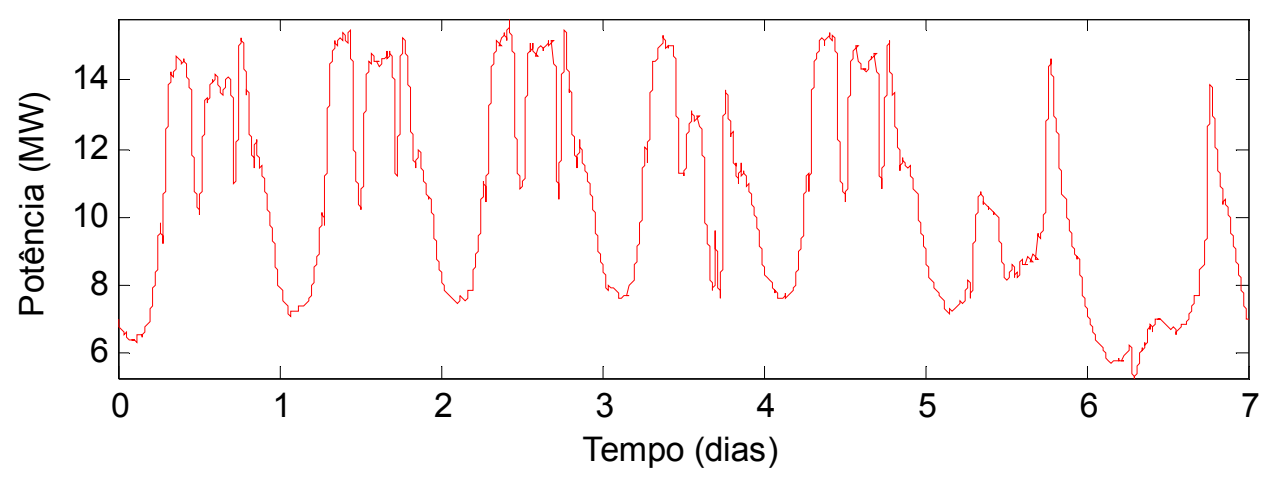

FIGURA 5.10 - Perfil de tensão em carga pesada para Votuporanga 1 (transformador 2).

Através da estratégia com módulo fuzzy, todos os trechos de carga pesada tiveram também a tensão acima da tensão de referência, como pode ser comprovado através da FIGURA 5.10.

O relé com módulo fuzzy ainda foi capaz de manter a tensão, na maior parte do tempo, na principal faixa de interesse de atuação: entre $14.1 \mathrm{kV}$ e $14.270 \mathrm{kV}$, cerca de $79 \%$, contra $58 \%$ da estratégia convencional.

Na FIGURA 5.11 encontra-se registrado o tempo de permanência nas faixas de interesse. 


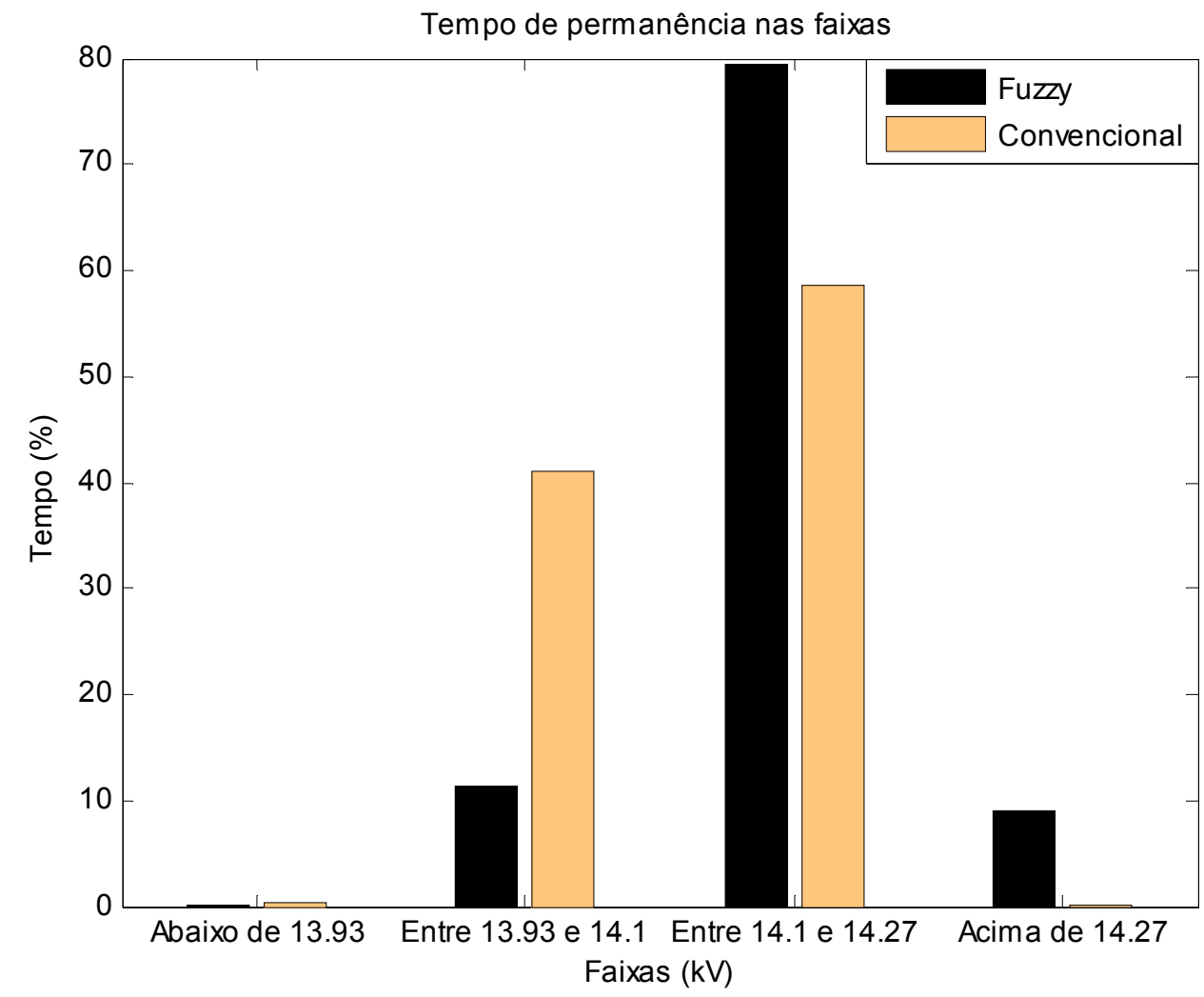

FIGURA 5.11 - Tempo de permanência nas faixas para Votuporanga 1 (transformador 2).

Analisando-se a tensão média em carga pesada o relé fuzzy manteve a tensão média mais elevada para todas as faixas de cargas ativas analisadas, principalmente para carregamentos superiores a $14.8 \mathrm{MW}$, onde a tensão média foi $168 \mathrm{~V}$ mais elevada que a convencional. Estas informações podem ser comprovadas na FIGURA 5.12. 


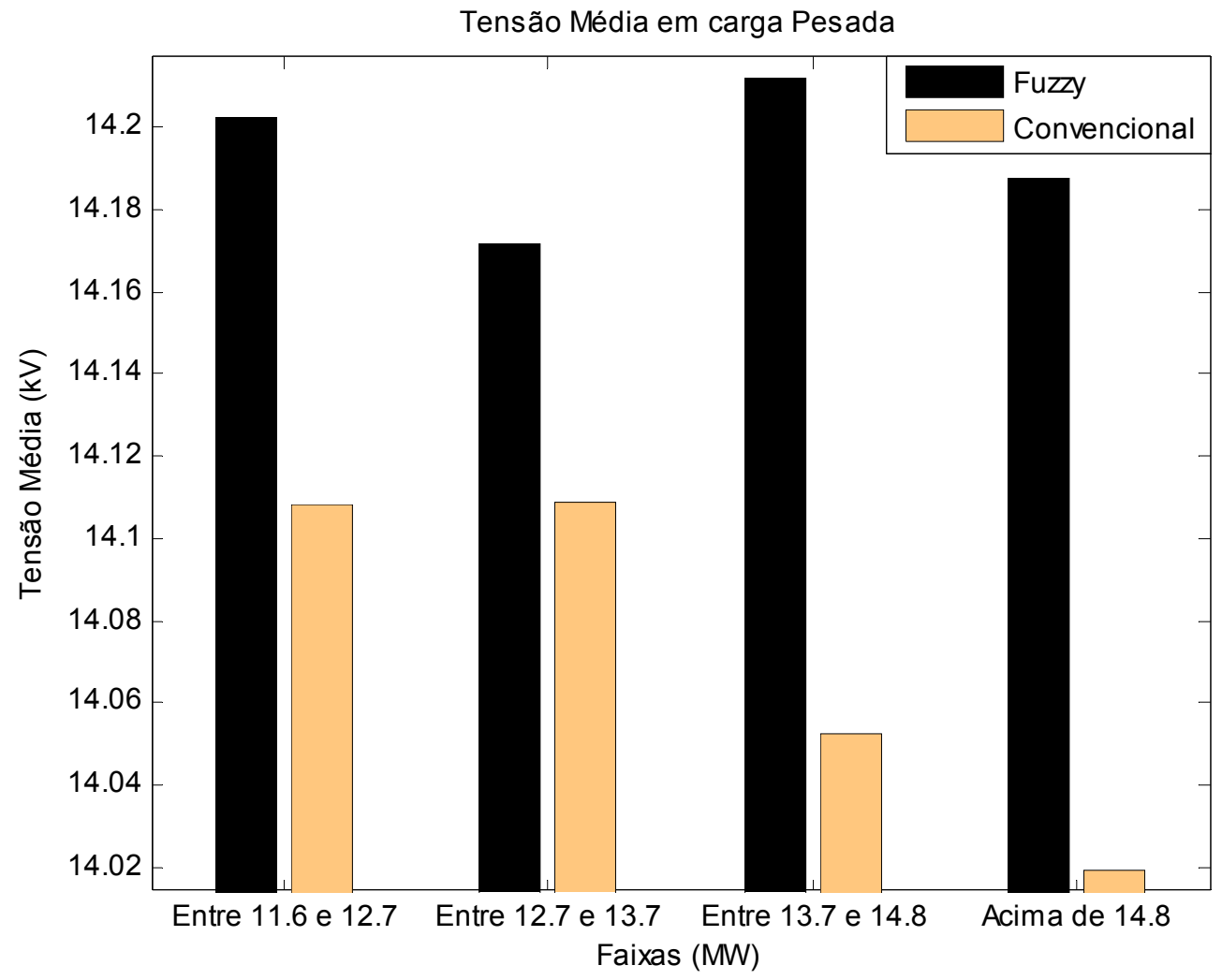

FIGURA 5.12 - Tensão média em carga pesada para Votuporanga 1 (transformador 2).

Na TABELA 5.3 encontram-se os principais resultados de simulação obtidos para Votuporanga 1 (transformador 2). Os resultados de comutações de tap foram convertidos para a base de tempo representada na TABELA 5.1, onde o tap comuta em média 183 vezes por semana.

TABELA 5.3 - Resumo dos resultados computacionais obtidos para Votuporanga 1 (transformador 2).

\begin{tabular}{|l|c|c|}
\hline \multicolumn{1}{|c|}{ Parâmetros de Regulação } & $\begin{array}{c}\text { Resultados } \\
\text { Fuzzy }\end{array}$ & $\begin{array}{c}\text { Resultados } \\
\text { Convencional }\end{array}$ \\
\hline Tensão Média (kV) & 14.154 & 14.090 \\
\hline Tempo em Tensão Crítica Superior (\%) & 0.000 & 0.000 \\
\hline Tempo em Tensão Crítica Inferior (\%) & 0.059 & 0.059 \\
\hline Tempo em Tensão Precária (\%) & 0.029 & 0.044 \\
\hline Número de Comutações de tap & 44 & 22 \\
\hline $\begin{array}{l}\text { Comutações de tap convertidas para a base } \\
\text { de 183 comutações por semana }\end{array}$ & 366 & 183 \\
\hline
\end{tabular}


Na TABELA 5.3 é possível se observar a diferença na tensão média da subestação e no número de comutações de tap. Os tempos em tensão precária e crítica são calculados com base na tensão de referência. Para fins de fiscalização estas medidas são feitas nos consumidores, portanto, analisar tais tempos na subestação apenas fornecem um parâmetro de comparação para desempenho das estratégias.

Para esta subestação a estratégia com módulo fuzzy ultrapassou o limite de 325 comutações por semana, o que muda a estimativa da manutenção de 6 anos para 5.31 anos. Neste caso é necessário um complemento no cálculo da potência média para que essa se ajuste melhor à subestação Votuporanga 1 transformador 2. Tal subestação possui um comportamento de carga que oscila muito quando em horário de ponta, resultando assim em maiores comutações em carga média, uma vez que a potência média não representa o melhor ajuste. Pode-se então utilizar uma função adicional para esta subestação a fim de ajustar a normalização das funções de pertinência do sistema fuzzy, de forma a usar um valor maior que a própria potência média quando em carga pesada.

\subsubsection{Subestação Ubatuba 2 (transformador 2)}

Como já foi abordado, Ubatuba 2 é uma subestação que possui um forte comportamento sazonal. Apesar do carregamento desta subestação ser menor que as demais simuladas, é possível se constatar a capacidade de generalização do sistema fuzzy desenvolvido. Na FIGURA 5.13 se encontra registrado o histórico de comutações de tap para a subestação Ubatuba 2 (transformador 2). 

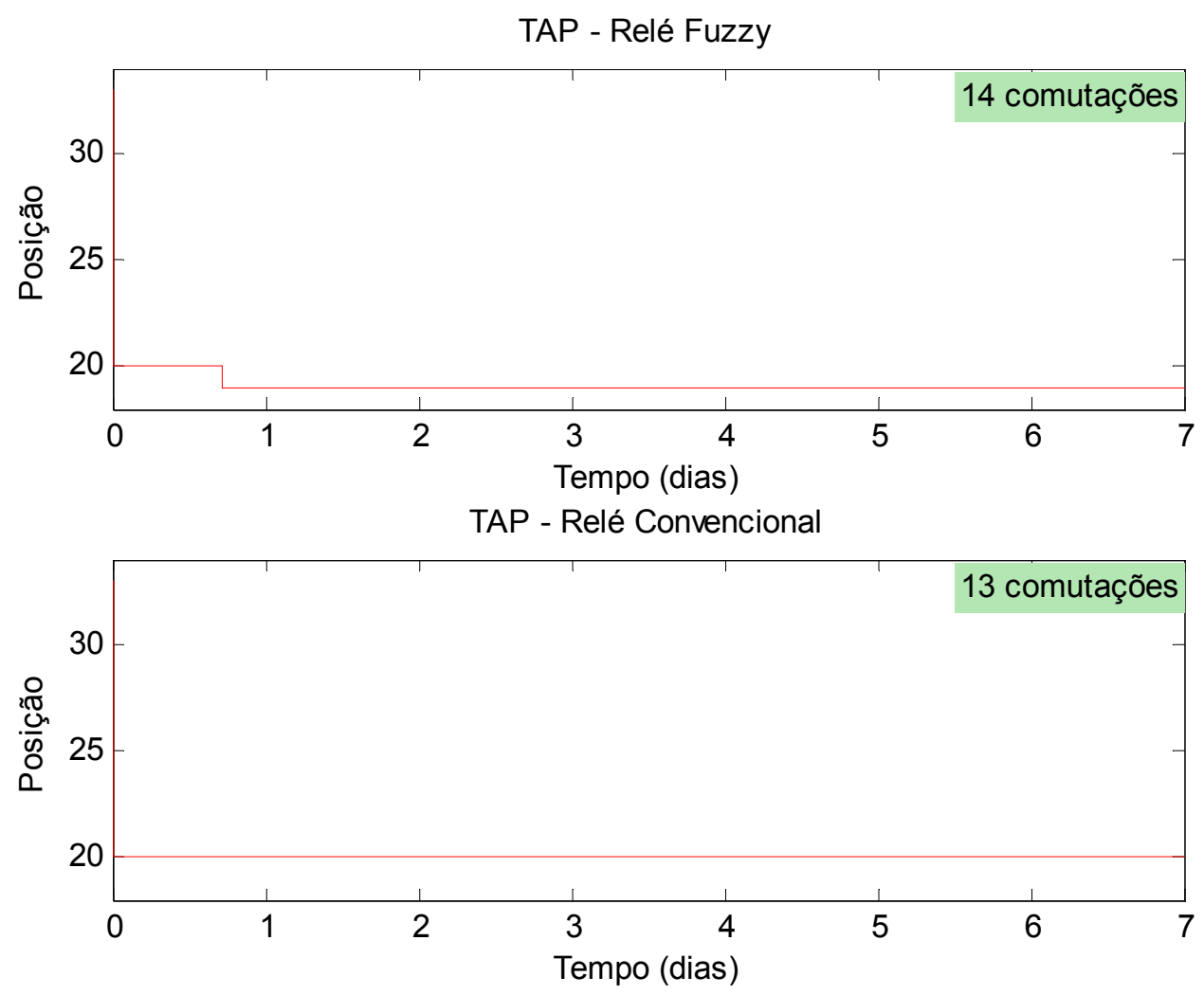

FIGURA 5.13 - Histórico de comutações de tap para Ubatuba 2 (transformador 2).

A partir da FIGURA 5.13, pode-se contemplar que tanto o relé com módulo fuzzy quanto o convencional apresentaram um comportamento com poucas comutações.

Apesar de ter comutado uma vez a mais que a estratégia convencional, o relé fuzzy apresentou excelentes ganhos de tensão, que podem ser comprovados através da FIGURA 5.14. 

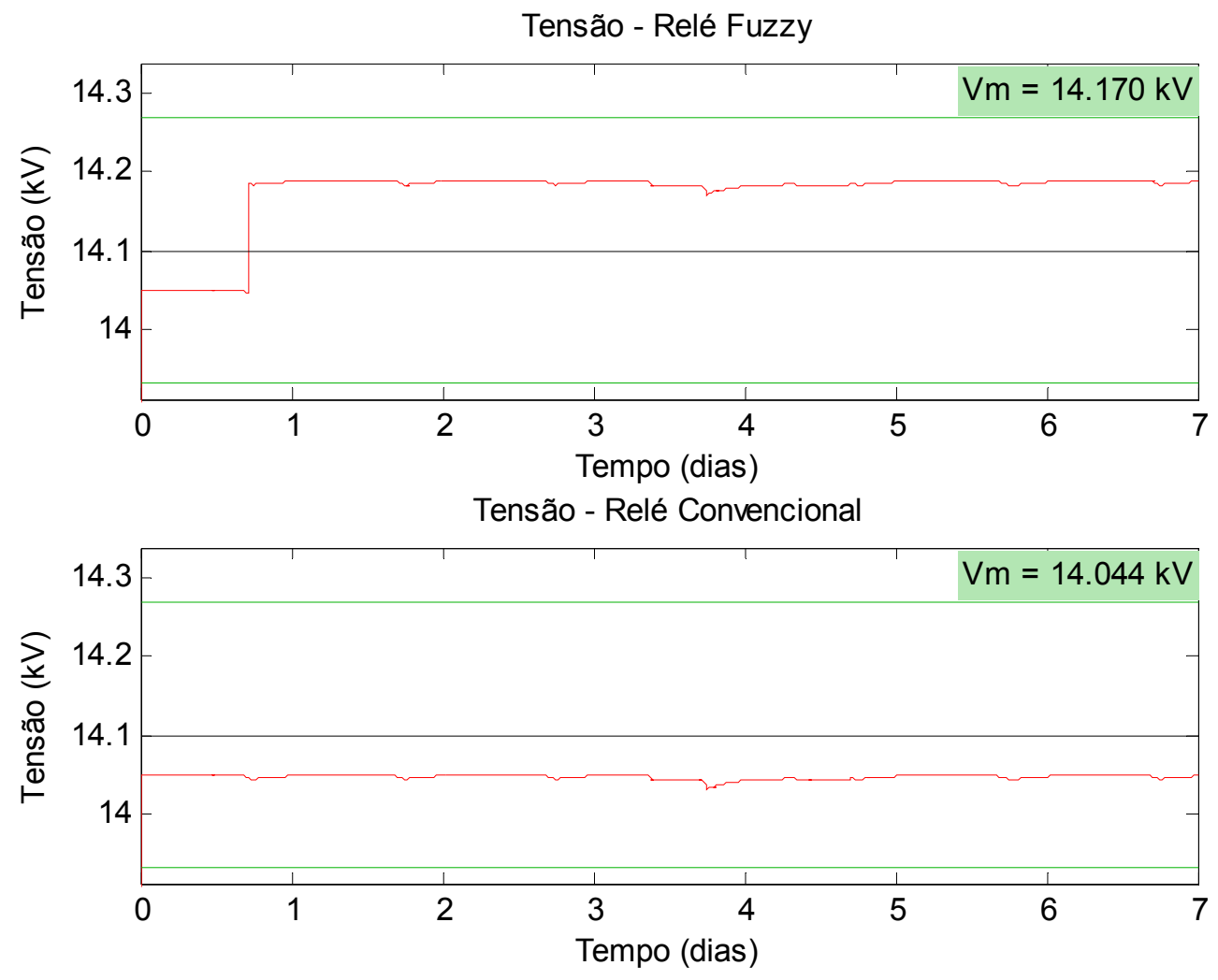

FIGURA 5.14 - Perfis de tensão para Ubatuba 2 (transformador 2).

Encontra-se registrado também na FIGURA 5.14 as tensões médias ( $\mathrm{Vm})$ para a subestação Ubatuba 2 (transformador 2), tanto para o relé convencional como para o fuzzy.

Visualmente é possível se comprovar que o relé com módulo fuzzy manteve a tensão mais elevada, se comparado ao convencional. A tensão média dos 7 dias de simulação foi de $14.170 \mathrm{kV}$ para a estratégia fuzzy, contra $14.044 \mathrm{kV}$ da estratégia convencional, tendo então um ganho de $126 \mathrm{~V}$ de tensão média. Para esta subestação pode-se afirmar que o aumento no número de comutações foi desprezível perto dos ganhos obtidos no perfil de tensão.

A filosofia da estratégia fuzzy com módulo fuzzy não utiliza uma faixa fixa, mas sim dinâmica, isto porque a referência é dinâmica. Desta forma, uma verificação 
de tensão fora da faixa só pode ser realizada através do gráfico dinâmico da referência, conforme apresentado na FIGURA 5.15.

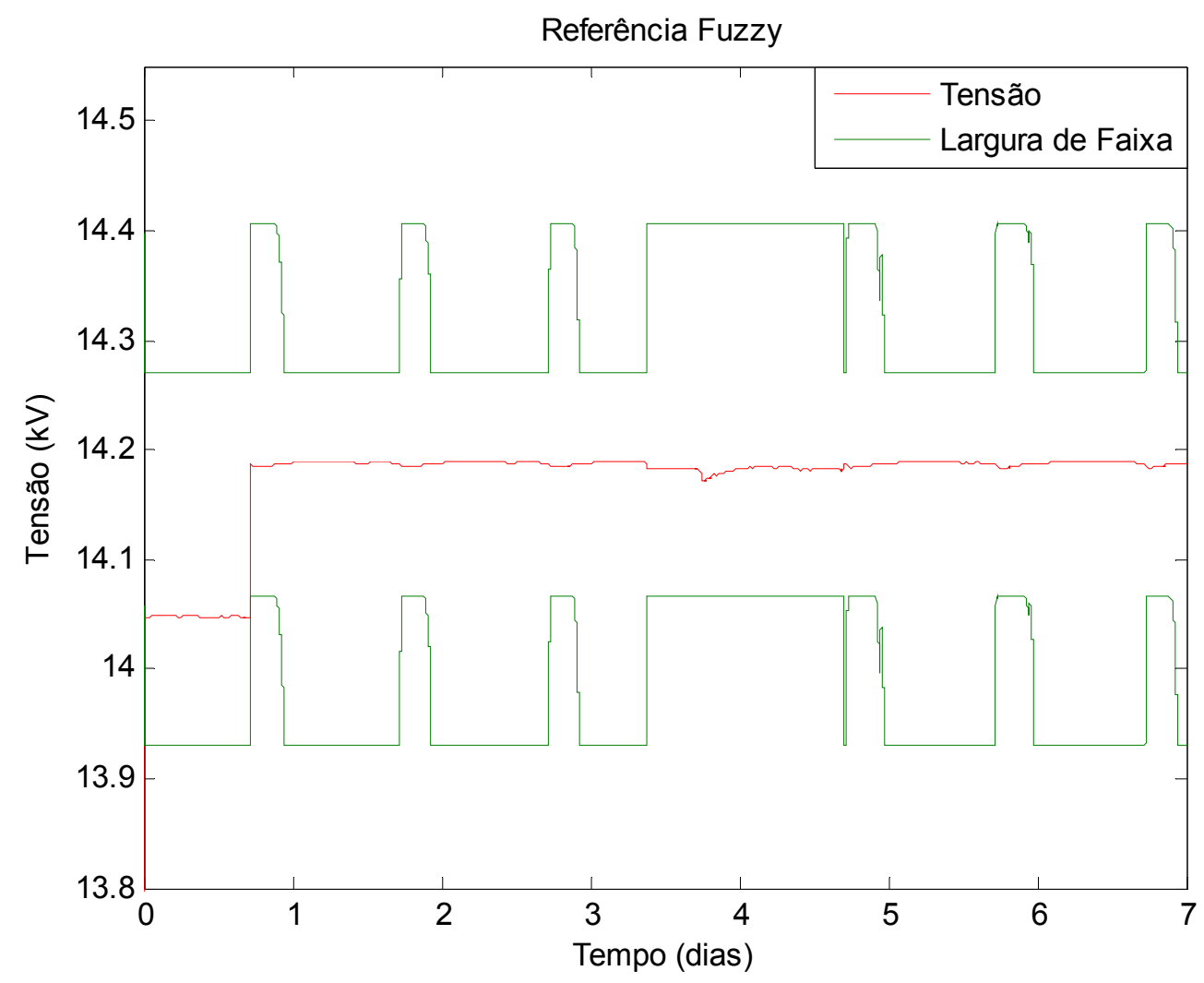

FIGURA 5.15 - Referência fuzzy para Ubatuba 2 (transformador 2).

Pode-se comprovar através da FIGURA 5.15 que a tensão não sai fora da faixa em nenhum momento. Isto porque com a referência fuzzy, para evitar comutações prematuras, a faixa dinâmica acompanha a evolução da carga pesada e da carga leve.

Na FIGURA 5.16 se encontra registrado o perfil de tensão para o relé fuzzy, juntamente com a curva de carga ativa de Ubatuba 2 (transformador 2). 

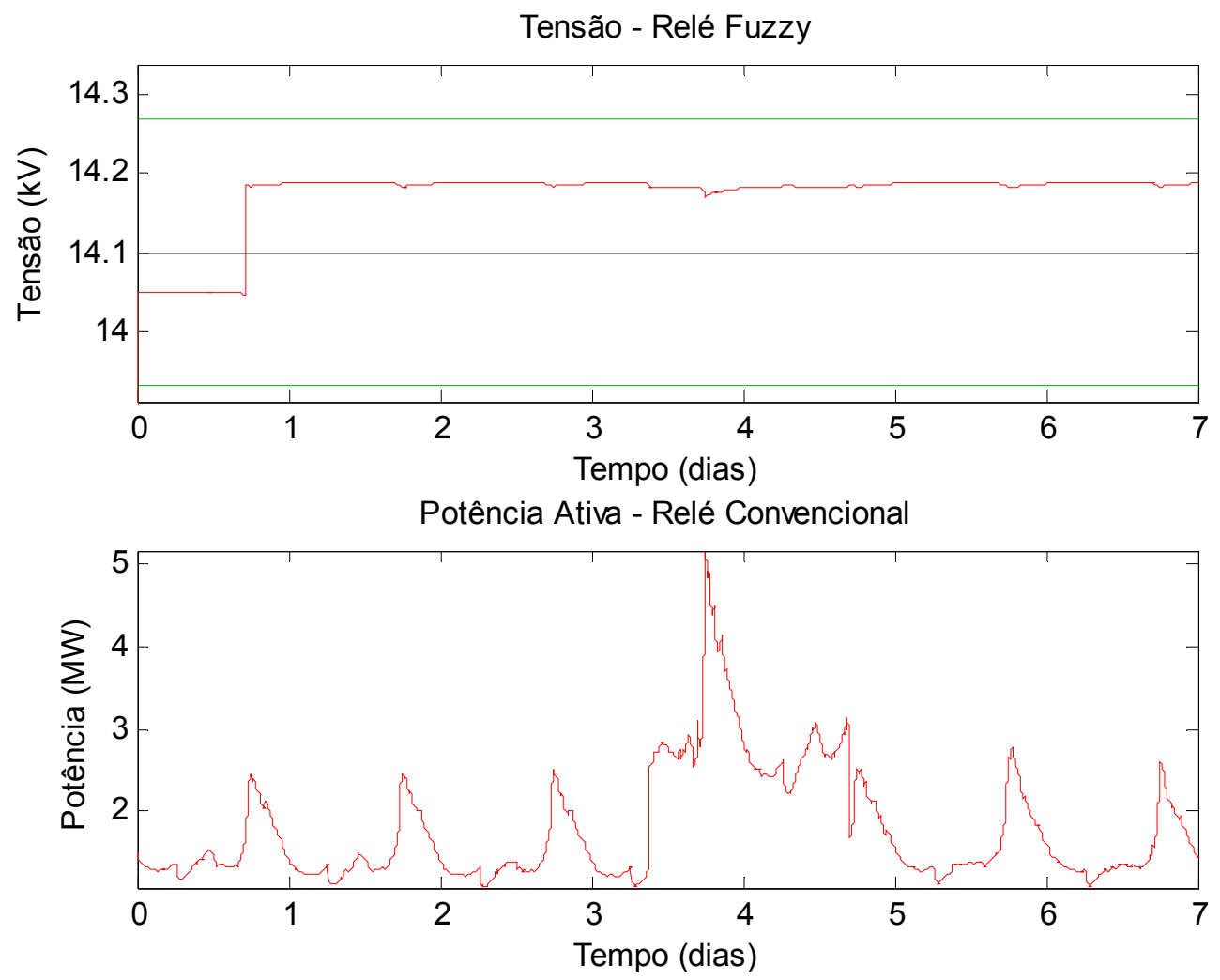

FIGURA 5.16 - Perfil de tensão em carga pesada para Ubatuba 2 (transformador 2).

Através da estratégia com módulo fuzzy, todos os trechos de carga pesada tiveram a tensão acima da tensão de referência, como pode ser comprovado através da FIGURA 5.16. A potência ativa média, utilizada para normalização, para esta subestação foi elevada devido a presença de uma grande demanda próximo do $4^{\circ}$ dia de simulação, o que explica o fato da tensão ser mantida acima da referência na maior parte do tempo.

O relé com módulo fuzzy também foi capaz de manter a tensão, na maior parte do tempo, na principal faixa de interesse de atuação: entre 14.1 kV e 14.270 $\mathrm{kV}$, cerca de $89 \%$, contra $0 \%$ da estratégia convencional.

Na FIGURA 5.17 encontra-se registrado o tempo de permanência nas faixas de interesse. 


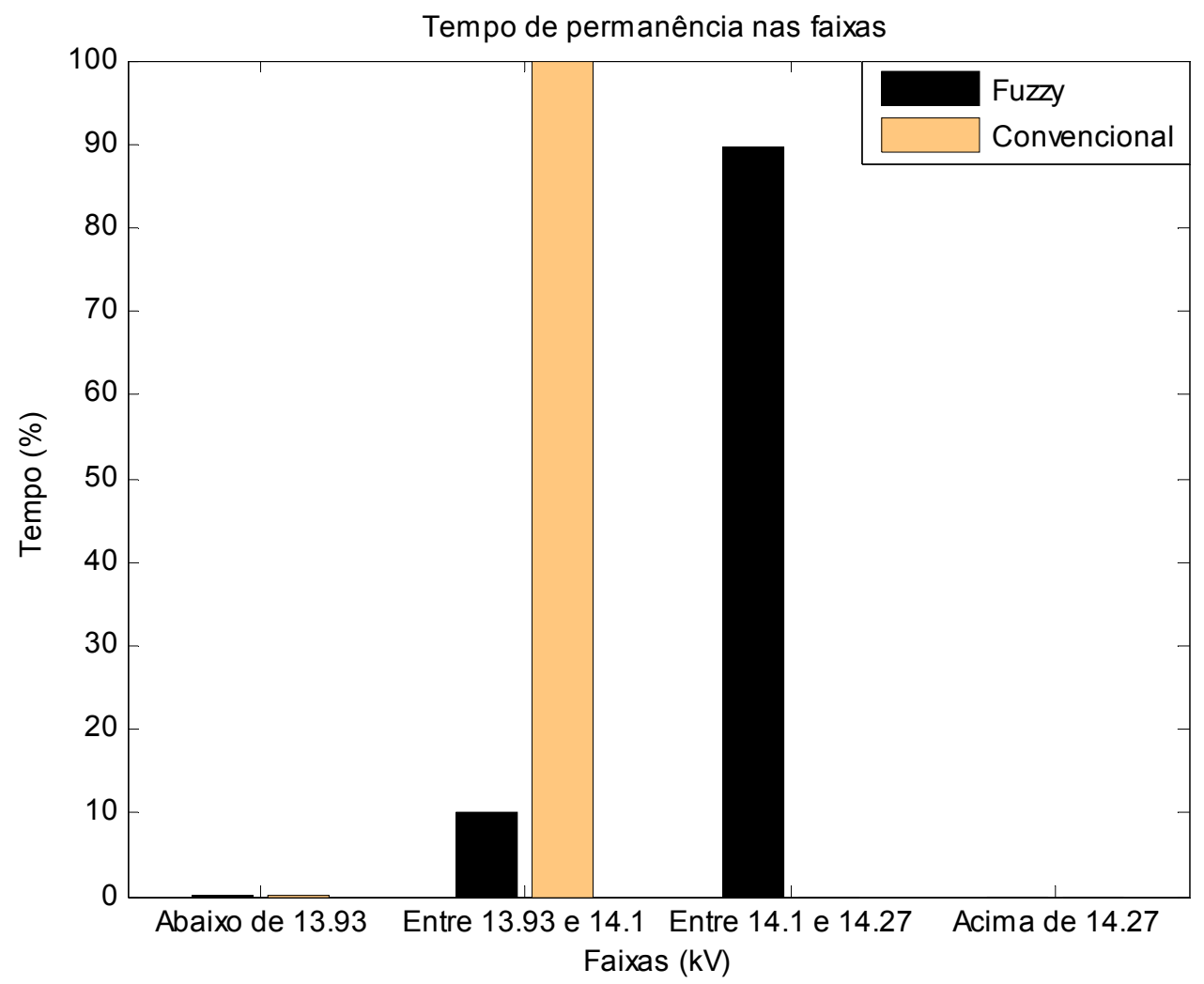

FIGURA 5.17 - Tempo de permanência nas faixas para Ubatuba 2 (transformador 2).

Analisando-se a tensão média em carga pesada o relé fuzzy manteve a tensão média mais elevada para todas as faixas de cargas ativas analisadas, principalmente para carregamentos superiores a $4.37 \mathrm{MW}$, onde a tensão média foi $140 \mathrm{~V}$ mais elevada que a convencional. Estas informações podem ser comprovadas na FIGURA 5.18. 


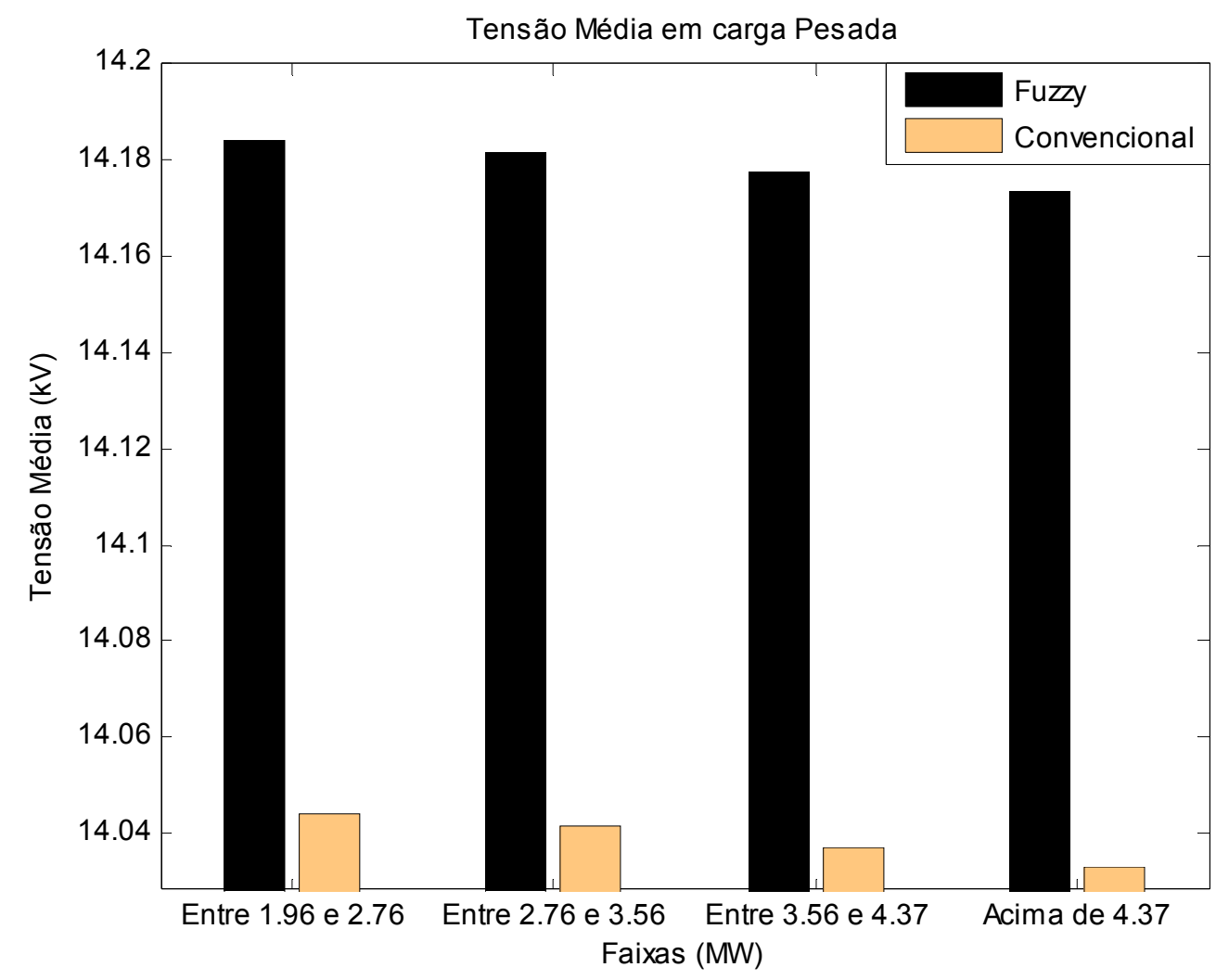

FIGURA 5.18 - Tensão média em carga pesada para Ubatuba 2 (transformador 2).

Na TABELA 5.4 encontram-se os principais resultados de simulação obtidos para Ubatuba 2 (transformador 2). Os resultados de comutações de tap foram convertidos para a base de tempo representada na TABELA 5.1, onde o tap comuta em média 70 vezes por semana.

TABELA 5.4 - Resumo dos resultados computacionais obtidos para Ubatuba 2 (transformador 2).

\begin{tabular}{|l|c|c|}
\hline \multicolumn{1}{|c|}{ Parâmetros de Regulação } & $\begin{array}{c}\text { Resultados } \\
\text { Fuzzy }\end{array}$ & $\begin{array}{c}\text { Resultados } \\
\text { Convencional }\end{array}$ \\
\hline Tensão Média (kV) & 14.170 & 14.044 \\
\hline Tempo em Tensão Crítica Superior (\%) & 0.000 & 0.000 \\
\hline Tempo em Tensão Crítica Inferior (\%) & 0.044 & 0.044 \\
\hline Tempo em Tensão Precária (\%) & 0.044 & 0.044 \\
\hline Número de Comutações de tap & 14 & 13 \\
\hline $\begin{array}{l}\text { Comutações de tap convertidas para a base } \\
\text { de 70 comutações por semana }\end{array}$ & 76 & 70 \\
\hline
\end{tabular}


Na TABELA 5.4 é possível se observar a diferença na tensão média da subestação. O número de comutações foi praticamente o mesmo para as duas estratégias, no entanto a única comutação realizada a mais pelo módulo fuzzy foi suficiente para modificar completamente o perfil de tensão da subestação.

Os tempos em tensão precária e crítica são calculados com base na tensão de referência. Para fins de fiscalização estas medidas são feitas nos consumidores, portanto, analisar tais tempos na subestação apenas fornecem um parâmetro de comparação para desempenho das estratégias.

Para esta subestação o limite de 325 comutações por semana ficou muito distante de ser atingido, o que faz a manutenção ser realizada pelo tempo mínimo de 6 anos e não pelo número de comutações.

\subsection{Análise dos requisitos computacionais do sistema fuzzy desenvolvido}

Os custos computacionais inerentes à implementação do relé com módulo fuzzy pode chegar a um nível bem aceitável, pois uma vez modelado o sistema fuzzy, basta se empregar a superfície fuzzy de relacionamento entre as entradas e a saída. Isto é possível, pois a estratégia inteligente possui apenas duas entradas e uma saída, assim o relacionamento das entradas em relação à saída se resume a uma matriz que contenha armazenada a superfície fuzzy, não havendo a necessidade de implementação em hardware de todo sistema de inferência fuzzy. 
A saída desejada é obtida fazendo-se uma indexação nesta matriz, onde as variáveis de entrada seriam as coordenadas de indexação da mesma matriz.

O espaço em memória necessário para a implementação da superfície fuzzy depende da resolução de pontos que se deseja empregar. Quanto maior a resolução, melhor será a qualidade da resposta, porém mais elevada será a quantidade necessária de memória para armazenar a superfície fuzzy.

A seguir se encontra descrito cada item necessário para a implementação da estratégia fuzzy.

1. Variáveis de Entrada: Potência Ativa e Desvio da Tensão (Variáveis Reais);

2. Variável de Saída: Estímulo à Tensão de Referência (Variável Real);

3. Parâmetros de Ajuste: Temporização (tempo morto), Tensão de Referência, Desvio permitido e Potência Média;

4. Operações Matemáticas: Elementares (Adição, Subtração, Multiplicação e Divisão);

5. Matrizes: Tomando-se 100 pontos de discretização seria então necessária uma Matriz 100×100 (Números Reais). Esta matriz contém a superfície fuzzy e seu espaço em memória depende da quantidade de pontos de discretização;

6. Recursos Extras: Caso a potência ativa média não seja parametrizada, deve-se incluir no relé funcionalidades que permitam extrair a demanda média da subestação. 


\section{Conclusões}

Ultimamente, tem-se verificado junto ao cenário atual do setor elétrico brasileiro uma constante busca pela melhoria dos serviços prestados pelas companhias de distribuição de energia elétrica aos seus consumidores.

De fato, essa crescente busca implica sobretudo no acréscimo de qualidade ao fornecimento de energia elétrica aos clientes da concessionária. De maneira ampla, pode-se caracterizar todo este empenho tendo como objetivo geral a melhoria da robustez dos sistemas de distribuição de energia elétrica.

Este trabalho apresentou inúmeros desafios, principalmente em relação às normalizações necessárias para se deixar o módulo inteligente genérico. A normalização por meio da potência ativa média se mostrou um excelente parâmetro de regulação, salvo situações onde a potência ativa oscila muito quando em carga pesada. Nestas situações necessita-se utilizar valores maiores que a potência média visando garantir que as funções de pertinência sejam normalizadas corretamente.

Os objetivos principais de se realizar um controle na subestação e realizar comutações de tap mais eficientes, juntamente com uma elevação na tensão média, foram contemplados com as simulações efetuadas no capítulo anterior.

Deve-se destacar que em alguns casos o número de comutações dobrou em relação ao método convencional, fato este devido a não mais existência da zona morta de atuação do relé. O AVR com módulo fuzzy monitora as variáveis elétricas 
da rede constantemente e sugere modificações na tensão de referência visando melhorar o perfil de tensão durante todo o tempo, buscando-se ainda economizar comutações em carga leve e elevar a tensão média em carga pesada.

Através dos resultados obtidos, comprova-se que para elevar a tensão média são necessárias mais comutações, principalmente em cargas pesadas; dessa forma, a economia de comutações ocorre quando o sistema se encontra em carga leve.

A faixa de atuação simulada de $340 \mathrm{~V}$ e a referência de $14.1 \mathrm{kV}$ são os parâmetros de tensão mais empregados pela concessionária de energia responsável pelas subestações analisadas, sendo os mesmos seguros para todos os consumidores atendidos pela subestação.

Por meio das curvas de demanda reais utilizadas para simulação, o sistema fuzzy desenvolvido se mostrou bem eficiente em manter a tensão média mais elevada, o que para um sistema de distribuição predominantemente modelado à impedância constante significa uma maior receita para a concessionária de distribuição.

Finalmente, é de grande valia destacar o desempenho do módulo inteligente desenvolvido frente aos objetivos delineados no começo deste trabalho. A validação da estratégia inteligente através de dados reais de subestações de distribuição apresentou resultados excelentes e muito promissores para uma futura aplicação prática de um relé fuzzy com funcionalidades inteligentes.

Como trabalhos futuros, pode-se destacar a investigação do aperfeiçoamento da estratégia proposta considerando as características individuais de cada um dos alimentadores saindo das subestações. 


\section{Referências Bibliográficas}

[1] Resolução No 505/2001 - Estabelece de forma atualizada e consolidada, as disposições relativas à conformidade dos níveis de tensão de energia elétrica em regime permanente. ANEEL - Agência Nacional de Energia Elétrica. Disponível em: http://www.aneel.com.br. Acessado em: 26 de julho de 2006.

[2] BRASIL. Lei No 8987, de 13 de fevereiro de 1995. Dispõe sobre o regime de concessão e permissão da prestação de serviços públicos previsto no art. 175 da Constituição Federal, e dá outras providências. Diário Oficial da União, Brasília, 13 de fevereiro de 1995.

[3] BRASIL. Lei $N^{\circ}$ 9074, de 07 de julho de 1995. Estabelece normas para outorga e prorrogações das concessões e permissões de serviços públicos e dá outras providências. Diário Oficial da União, Brasília, 7 de julho de 1995.

[4] BRASIL. Lei $N^{\circ}$ 9427, de 26 de dezembro de 1996. Institui a Agência Nacional de Energia Elétrica - ANEEL, disciplina o regime das concessões de serviços públicos de energia elétrica e dá outras providências. Diário Oficial da União, Brasília, 26 de dezembro de 1996. 
[5] DUgAN, R. C., MCgRanaghan, M. F., SANTOSO, S., BeATY H. W. Electrical Power Systems Quality. Second Edition, New York: McGraw Hill, 2003. 528 p.

[6] CHOI, J. H., KIM, J. C. The online voltage control of ULTC transformer for distribution voltage regulation. International Journal of Electrical Power \& Energy Systems, v. 23, p. 91-98, fev. 2001.

[7] C.S. ENGINEERS. Electrical Transmission and Distribution Reference Book. Fourth Edition, East Pittsburgh: Westinghouse Electric, 1964. 832 p.

[8] CHEN-CHING, L., PIERCE, D. A., SONG, H. Intelligent system applications to power systems. IEEE Computer Applications in Power, v. 10, p. 21-22, 24, out. 1997.

[9] SHORT, T. A. Electric Power Distribution Handbook. New York: CRC Press, 2003. $784 \mathrm{p}$.

[10] CEMIG. Instrução Para Ajuste de Reguladores de Tensão de 13,8 kV de Subestações, 1986.

[11] SUNDHARARAJAN, S., PAHWA, A. Optimal selection of capacitors for radial distribution systems using a genetic algorithm. IEEE Transactions on Power Systems, v. 9, p. 1499-1507, ago. 1994. 
[12] SANTOSO, N. I., TAN, O. T. Neural-net based real-time control of capacitors installed on distribution systems. IEEE Transactions on Power Delivery, v. 5, p. 266-272, jan. 1990.

[13] PANSINI, J . A. Guide to Electrical Power Distribution Systems. Sixth Edition, New York: CRC Press, 2000. 276 p.

[14] SIMAS FILHO, E., F. Monitoramento de Reguladores de Tensão Utilizando Análise de Vibração Através de Sistemas Inteligentes. 2004. 99 f. Dissertação (Mestrado em Engenharia Elétrica) - Curso de Pós-Graduação em Engenharia Elétrica, Universidade Federal da Bahia, Bahia, 2004.

[15] SEN, P. K. LARSON, S. L. Fundamental concepts of regulating distribution system voltages. In: Rural Electric Power Conference, 1994. Colorado Springs, USA, p. C1/1-C110, 1994.

[16] LIANG, R. H., WANG, Y. S. fuzzy-based reactive power and voltage control in a distribution system. IEEE Transactions on Power Delivery, v. 18, n. 2, p. 610-618, abr. 2003.

[17] TREETECH. Manual Técnico, Relé regulador de tensão - AVR, 2005.

[18] BECKWITH ELECTRIC. M-2667 Autodaptive Tapchanger Control Instruction Book. Disponível em: www.beckwithelectric.com . Acessado em 28/08/2006. 
[19] HU, Z., WANG, X., CHEN, H., TAYLOR, G. A. Volt/VAr control in distribution systems using a time-interval based approach. IEE Proceedings on Generation, Transmission and Distribution, v. 150, n. 5, p. 548-554, set. 2003.

[20] LIU, Y. ZHANG, P. QIU, X. Optimal volt/var control in distribution systems. International Journal of Electrical Power \& Energy Systems, v. 24, n. 4, p. 271-276, 2002.

[21] HSU, Y. Y., LU, F. C. A combined artificial neural network-fuzzy dynamic programming approach to reactive power/voltage control in a distribution substation. IEEE Transactions on Power Systems, v. 13, № 4, p. 1265-1271, nov. 1998.

[22] DIXON, M. Innovative Volt/VAr management provides payback. In: Transmission and Distribution Conference and Exposition, 2001 IEEE/PES. Atlanta, USA, v. 1, p. 461-468, 2001.

[23] ZADEH, L. A. Fuzzy sets. Information and Control, v. 8, p. 29-44, 1965.

[24] LEE, C. C. Fuzzy logic in control systems: fuzzy logic controllers - Part I and II. IEEE Transactions on Systems, Man and Cybernetics, v. 20, p. 404-435, 1990. 
[25] ZADEH, L. A. Outline of new approach to the analysis of complex systems and decision. IEEE Transactions on Systems, Man and Cybernetics, v. 3, p. 28-44, 1973. 